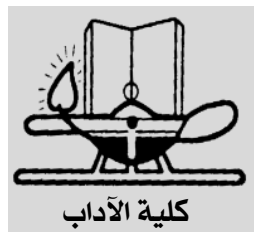

حوليات آداب عين شمس (عدد خاص Y IV ) http://www.aafu.journals.ekb.eg

(دورية علمية محكمةة)
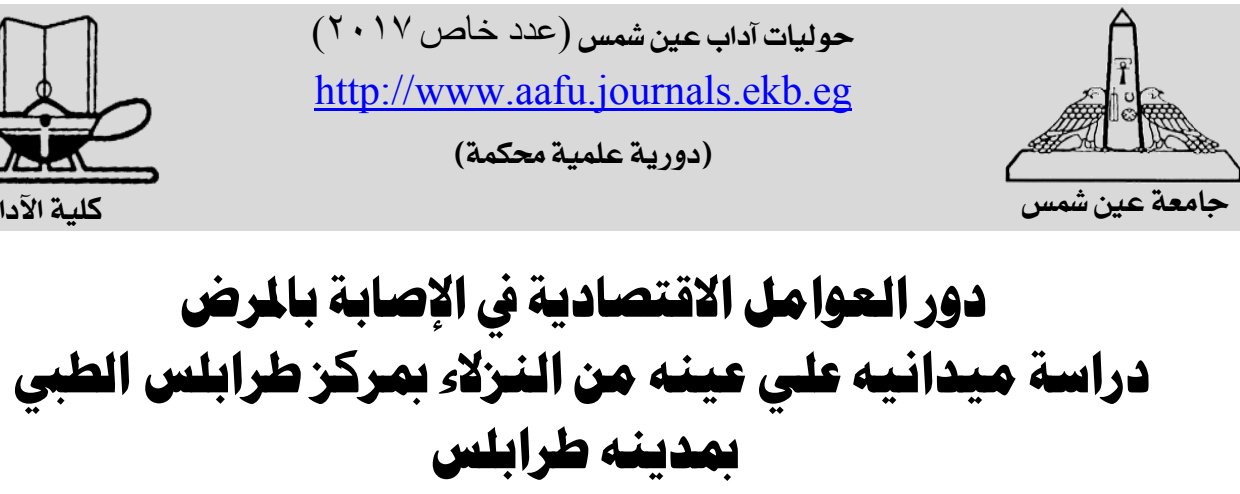

* إبتسام ميلاد خير حديدان

علم الإجتماع- جامعة عين شمس

يتمثل موضوع مشكلة الدراسة في الكثف عن دور العو امل الاقتصادية المتمثلة في

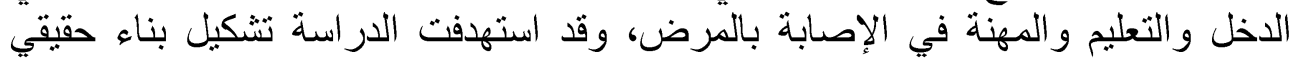

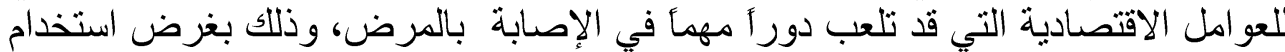

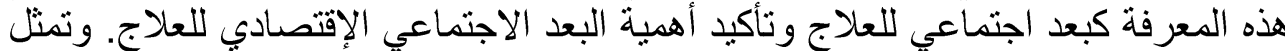

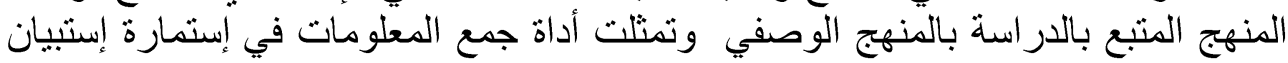
لقياس مؤشرات العوامل الاقتصادية. من خلاتل التتخدام العينة الطبقية والعينة القصدية، وقد خلصت الدر اسة إلى النتائج التالية : ـ هنـاك أثر معنوي دال إحصـائيًا للعو امل الاقتصـادية في الإصـابة بـالمرض عند مستوى

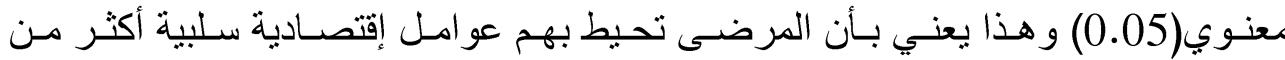

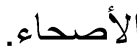
أ. هناك أثر معنوي دال للدخل في الإصابة بالمرض عند مستوى معنوي (0.05 ). ب. هناك أثر معنوي دال للتعليم في الإصـابة بالمرض عند مستوى معنوي (0.05 ). ج. هناك أثر معنوي دال للمهنة في الإصابة بالمرض عند مستوى معنوي (0.05 ).

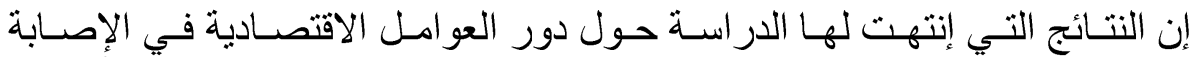

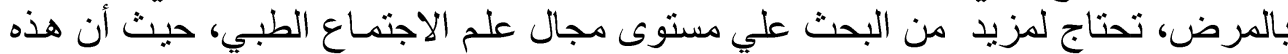

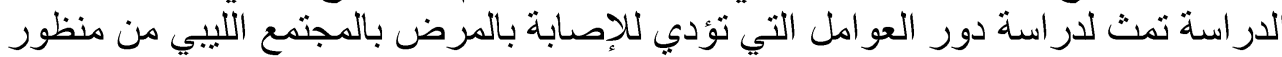

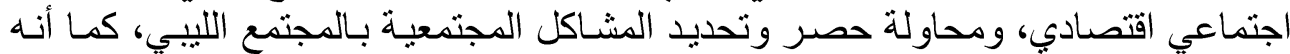

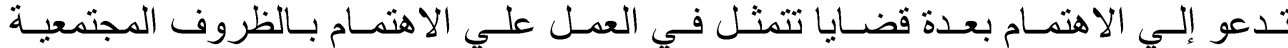

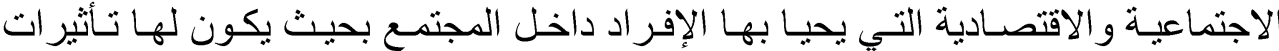

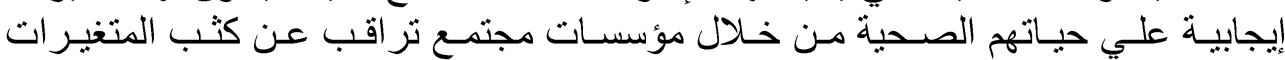

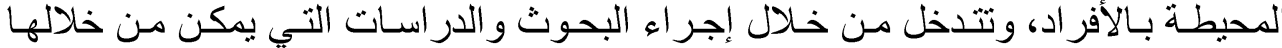

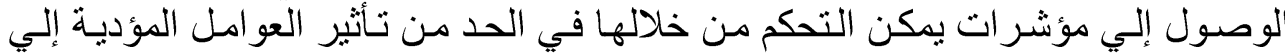




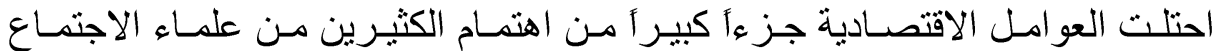

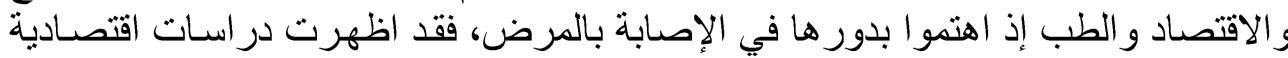

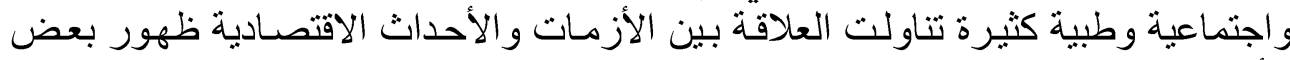

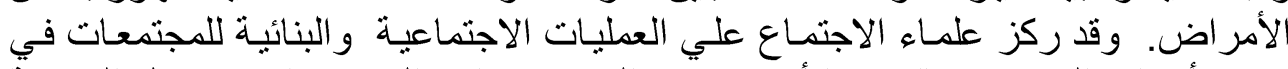

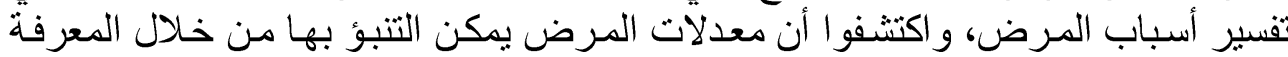

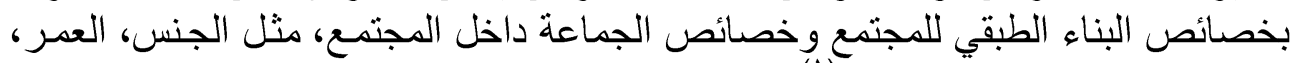

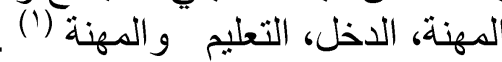

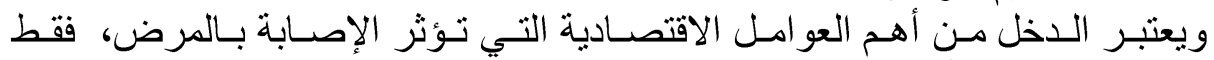

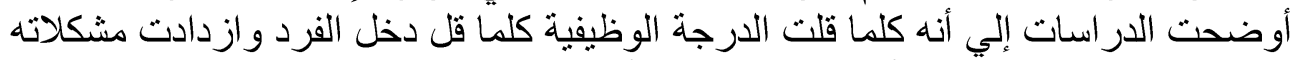

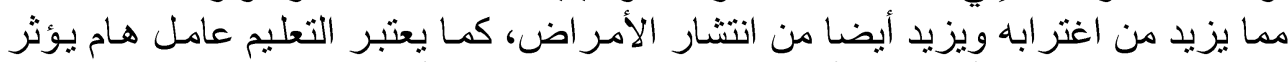

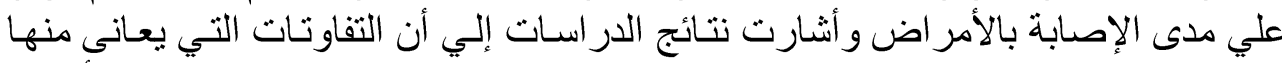

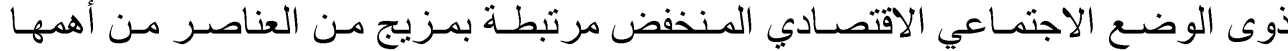

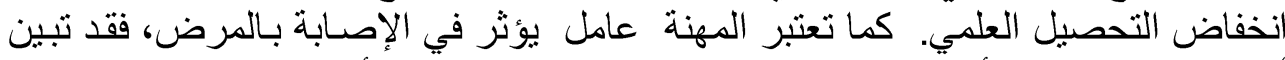

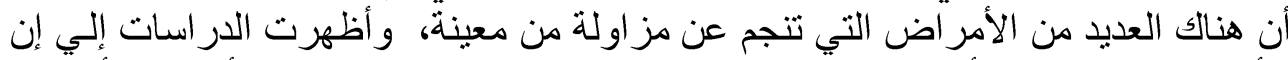

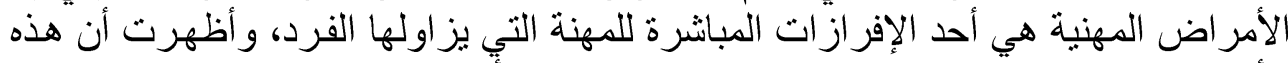

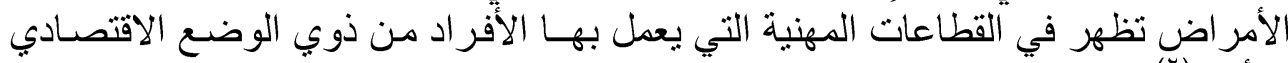

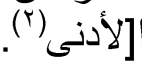

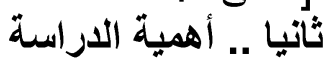

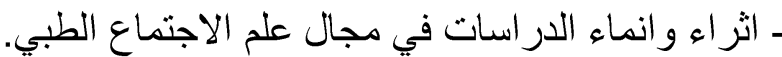

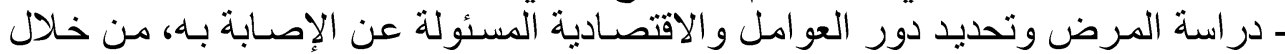

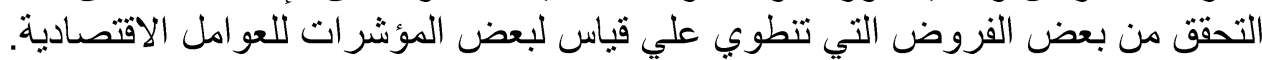

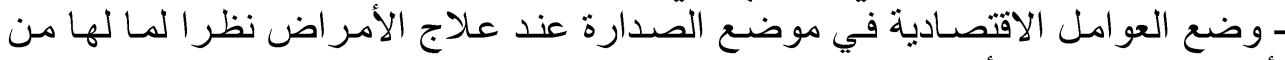

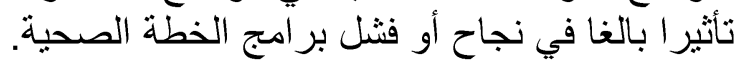

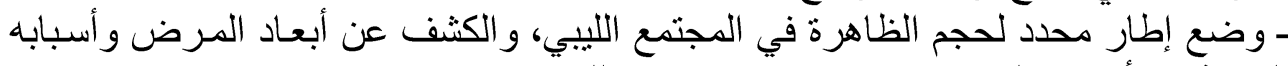
الكامنة في أعماق البناء الاجتماعي و الالقتصادي للمجنمع. للفيك.

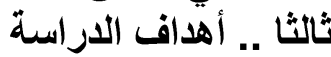

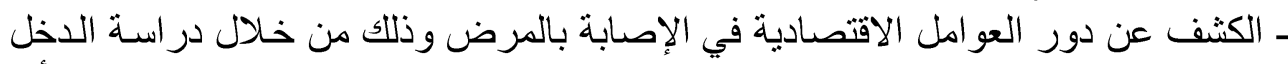

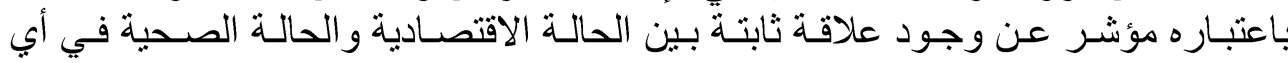

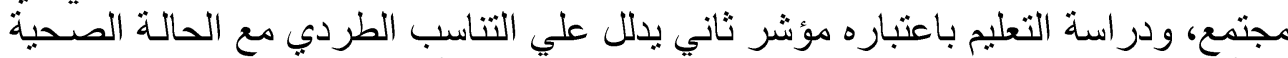

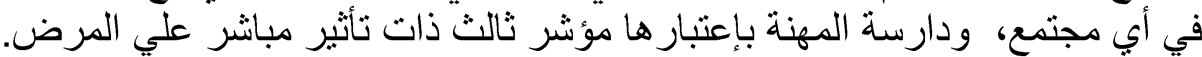

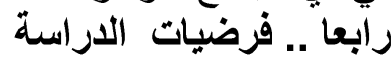

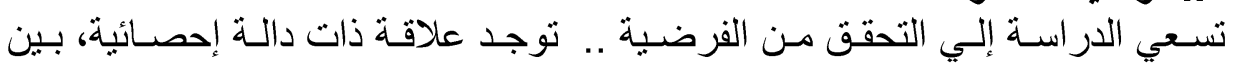

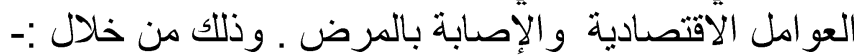
أ. توجد علاقة ذات دالة إحصائية ، بين الإخل الإنل و الإصابة بالمرض.

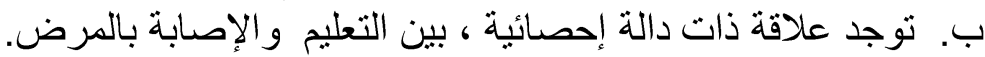

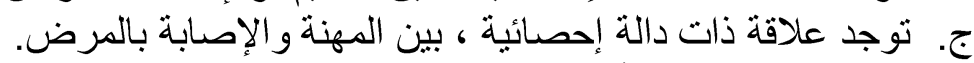




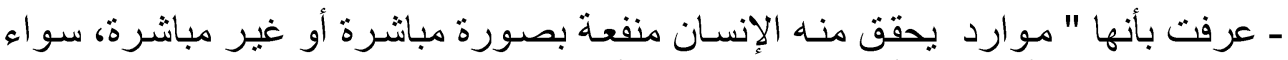

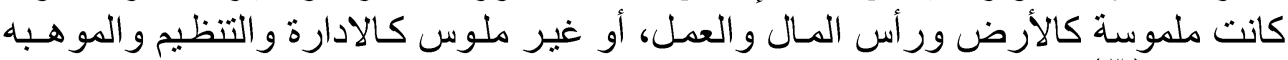

ـ عرفه عبد السلام و الدويبي بأنه "عبارة عن العائد الدوري الذي يحصل عليـة الفرد في نهاية كل فترة زمنية محددة "الم ؛ ؛ ).

ـ تعريف إجرائي للاخل " قدر من المال يتحصل عليه الفرد لسد احتياجاته المعيشية "

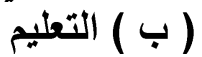
- عرفه " اثتايندوف "بأنه" كل نشاط مخطط ومنظم و هـادف ومنهجي للتأثير في حدوث

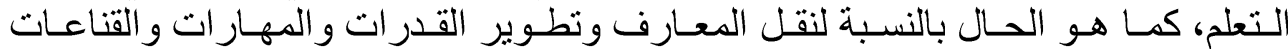

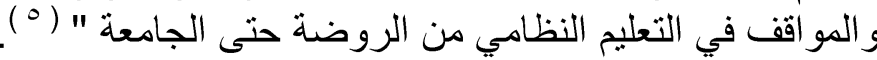

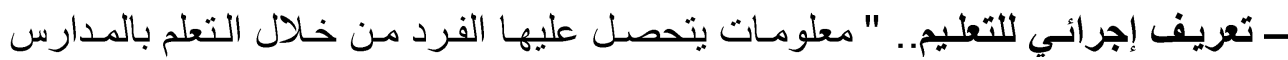

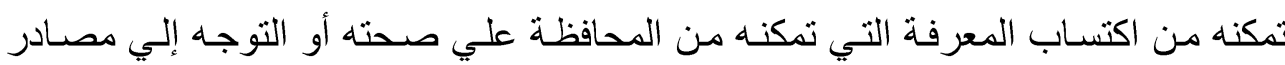

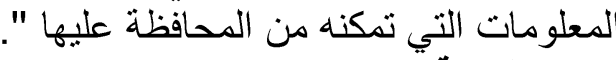

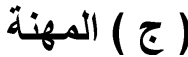

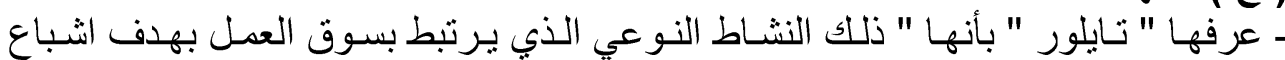

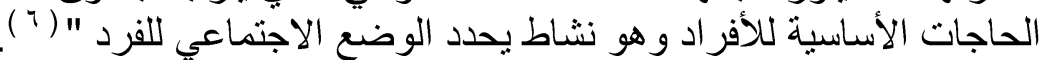

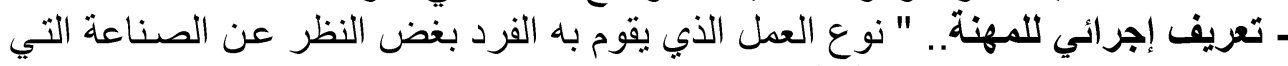

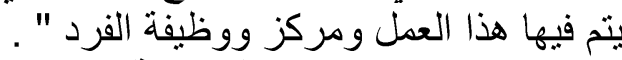

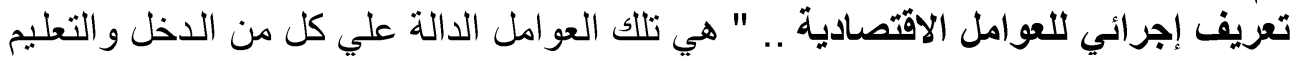

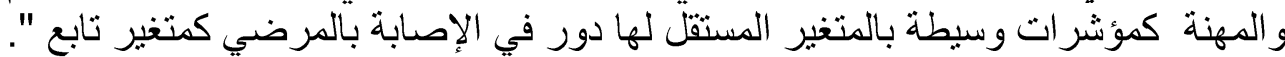

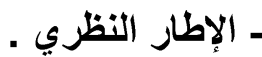
أولا .. المداخل النظرية الاجتماعية التي المرض كظاهرة إجتماعية

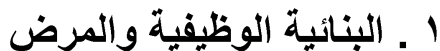

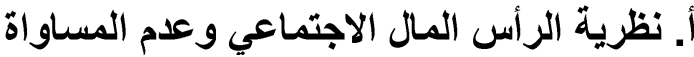

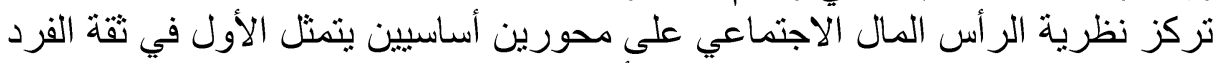

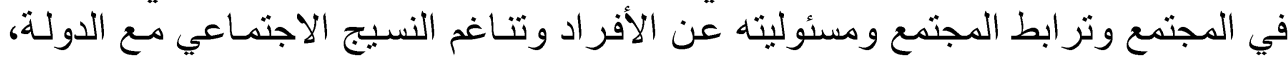

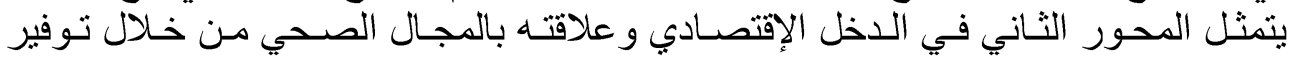

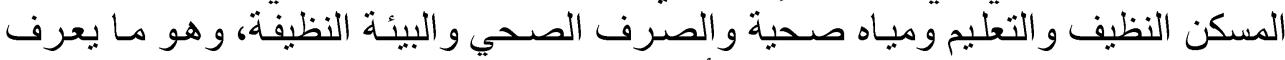

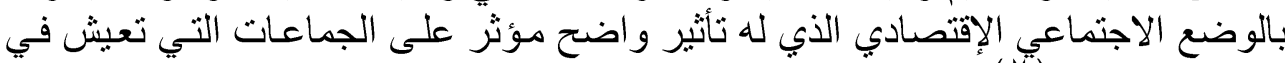

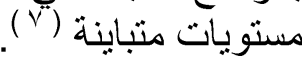

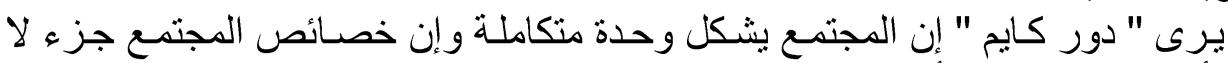

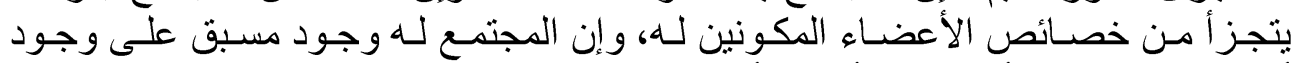

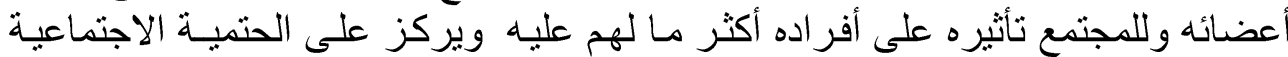

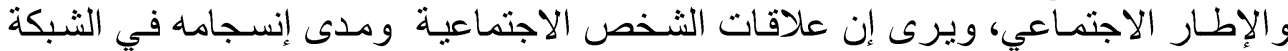

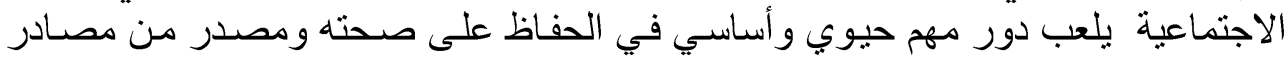

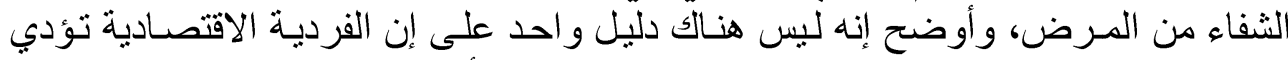

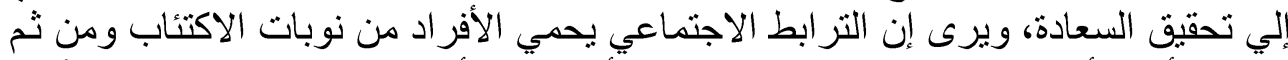

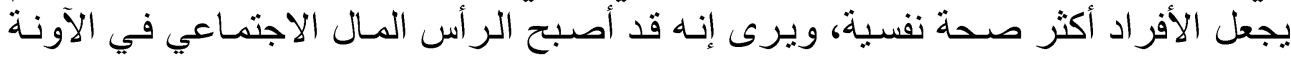


الأخيرة مهم في تقبير الإختلاف و الفروق بين الصحة و المرض في الطبقات الاجتماعيـة المختلفة (1)

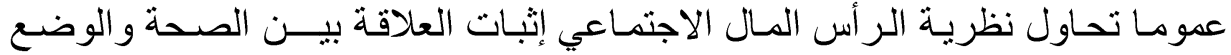

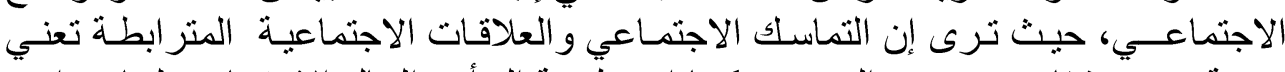

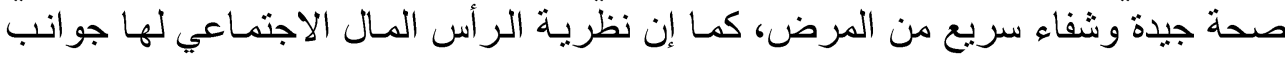

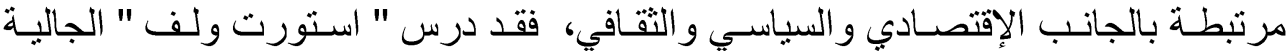

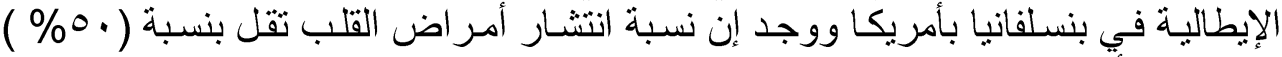

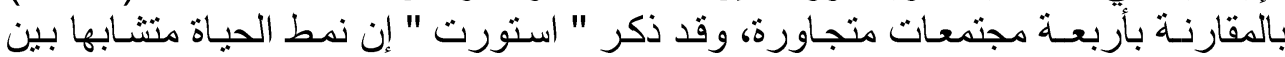

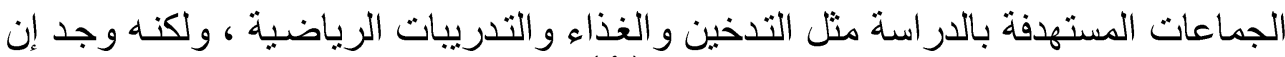

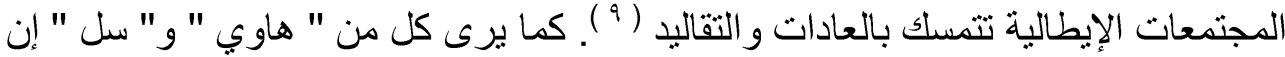

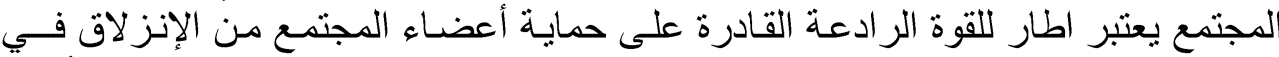

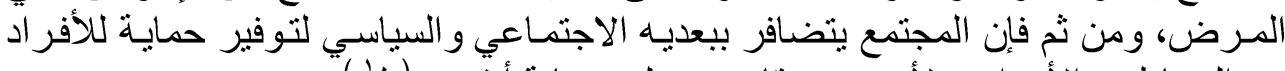

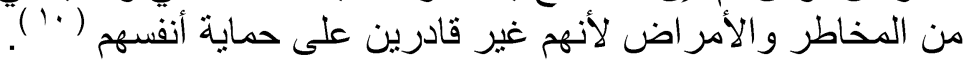

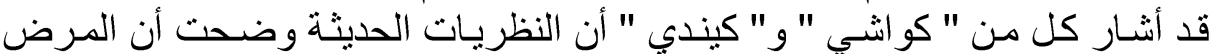

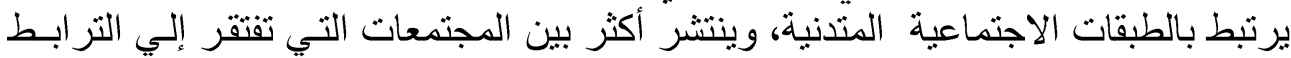

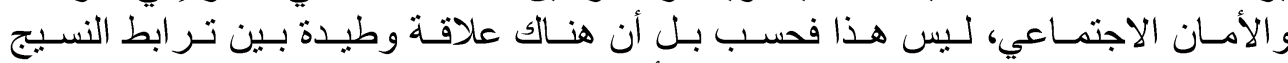

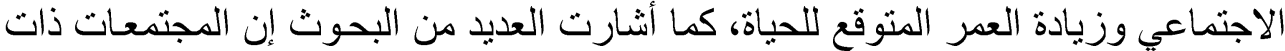

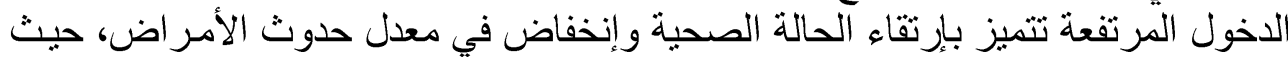

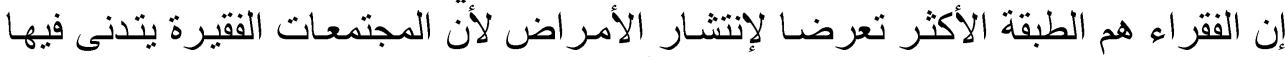

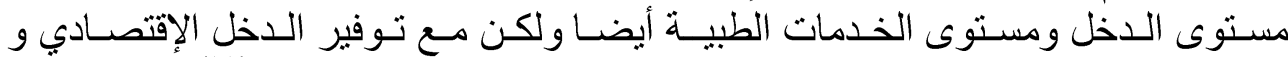

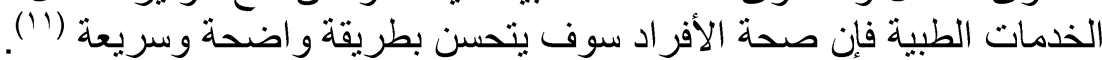

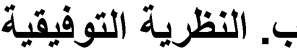

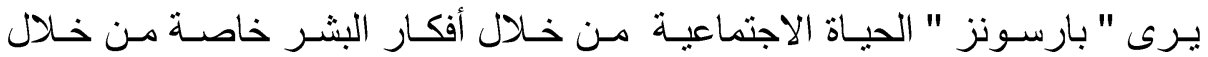

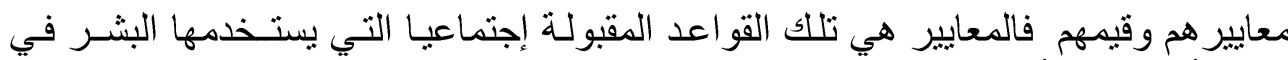

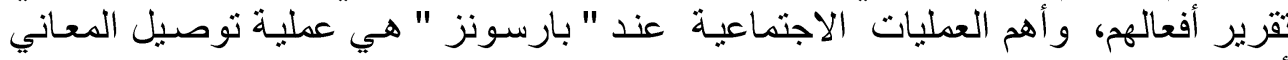

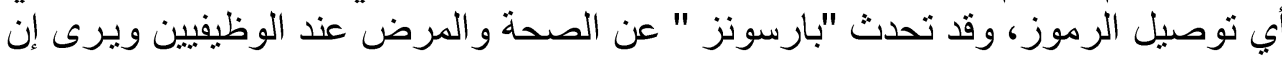

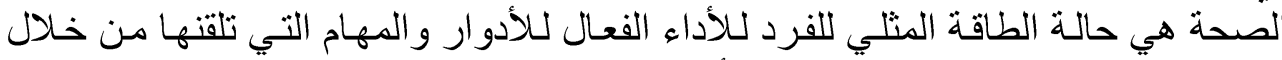

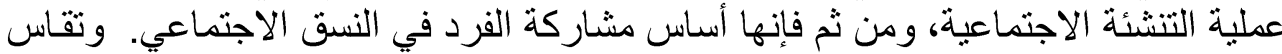

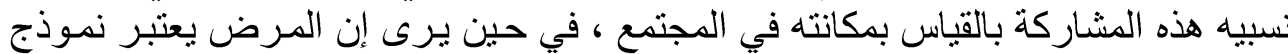

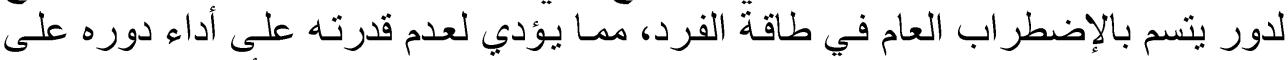

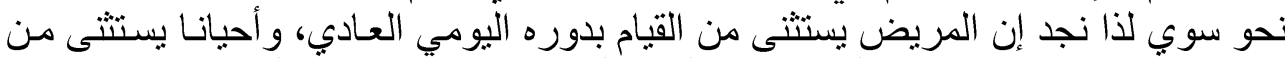

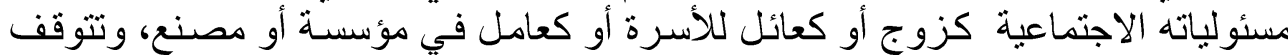

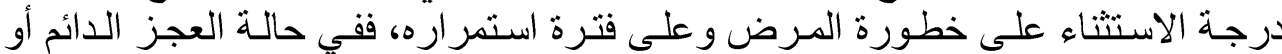

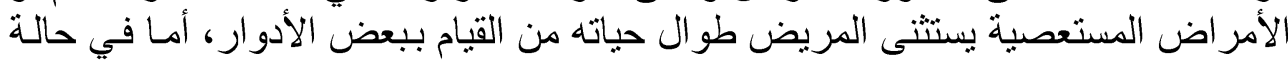

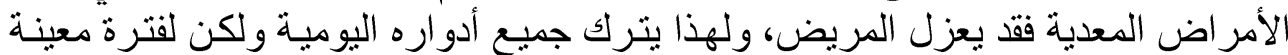

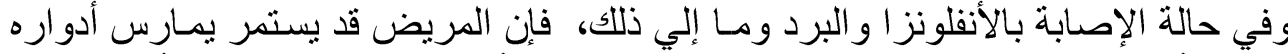

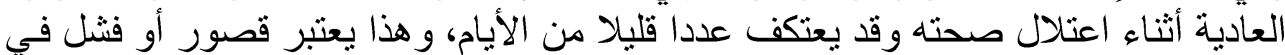

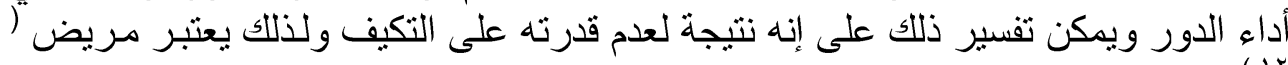

كما يرى " بارسونز " إن المرض هو حاله من الاضطر اب في الوظيفة الطبيعية

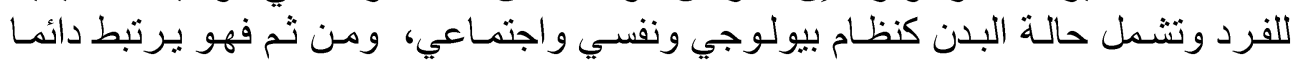




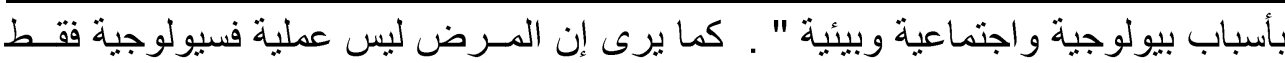

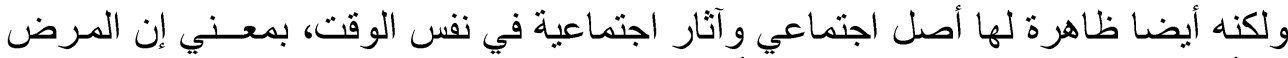

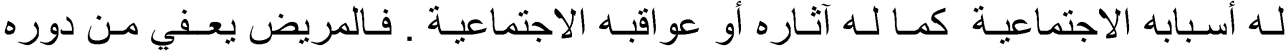

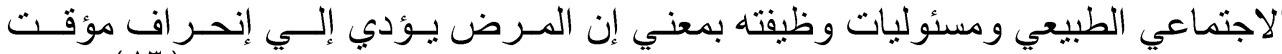

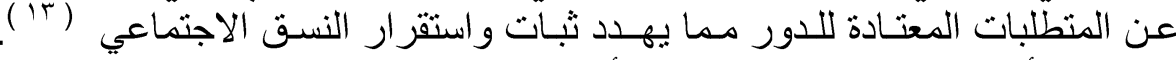

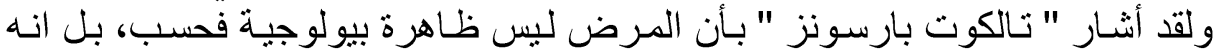

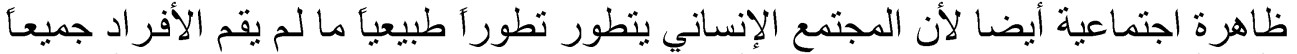

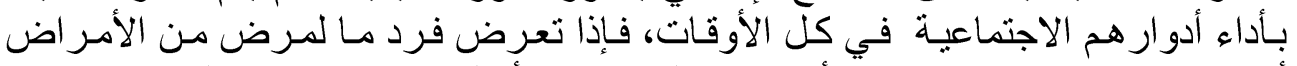

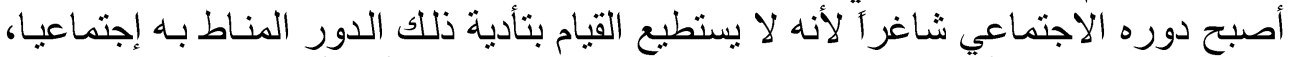

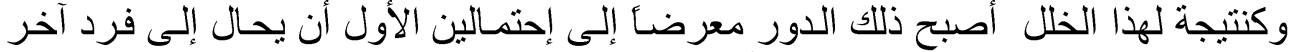

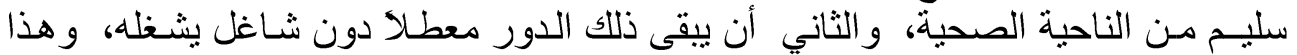

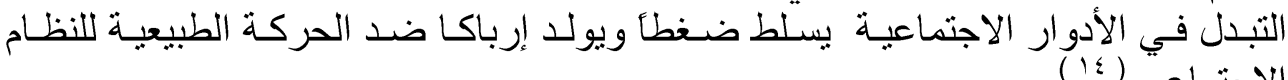

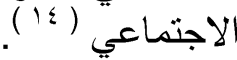

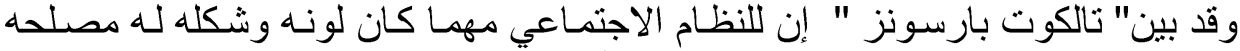

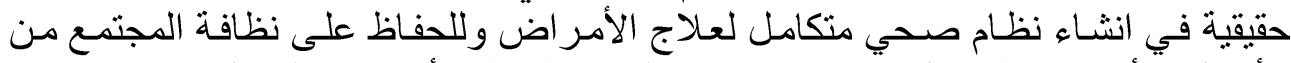

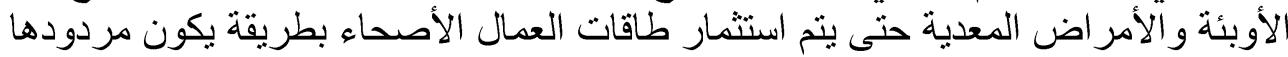

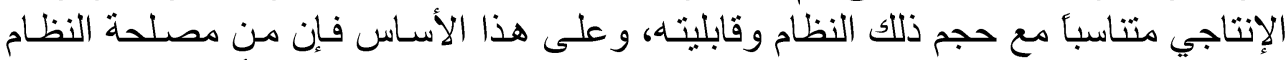

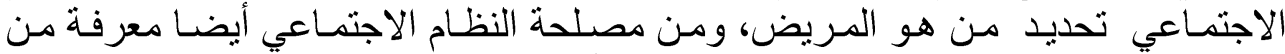

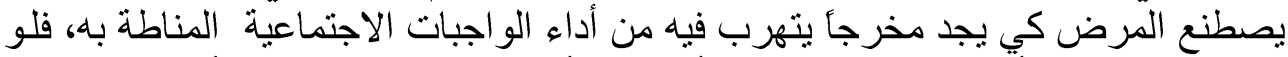

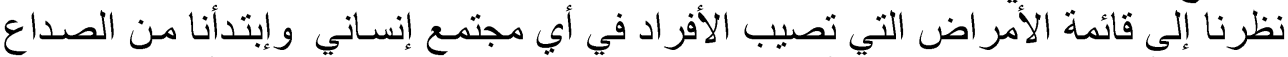

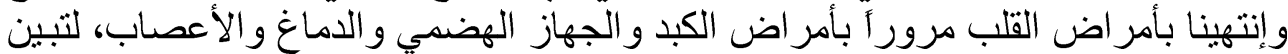

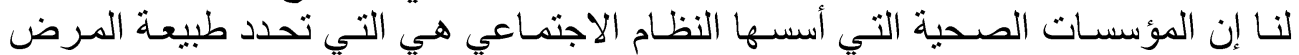

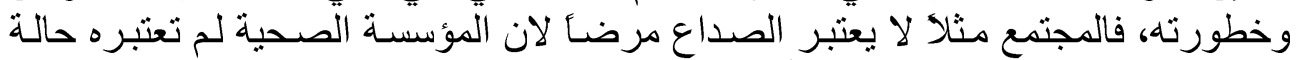

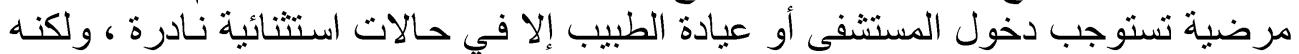

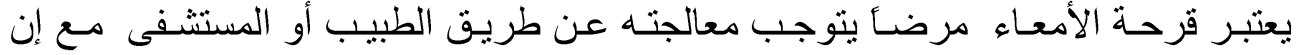

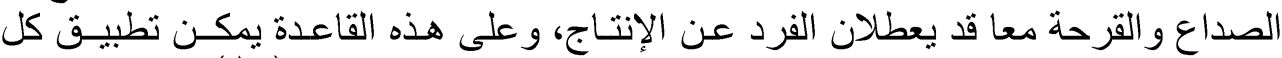

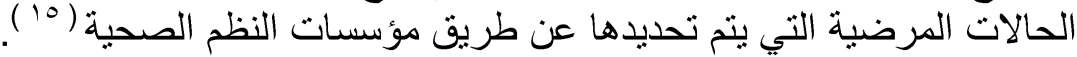

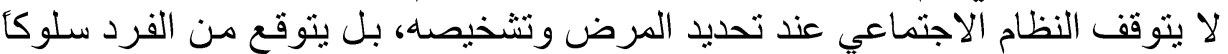

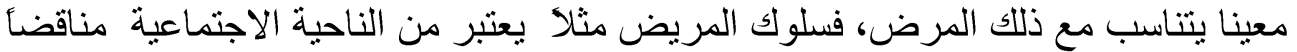

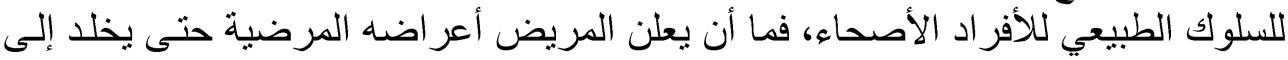

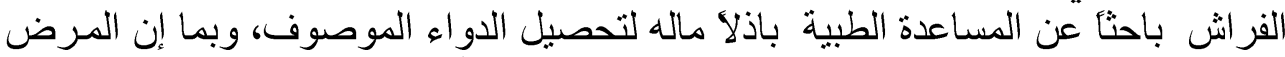

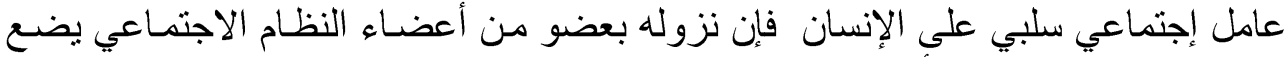

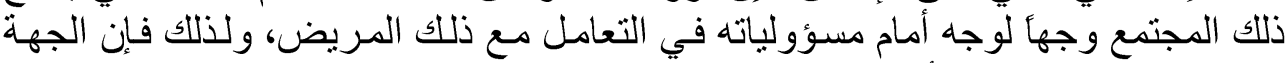

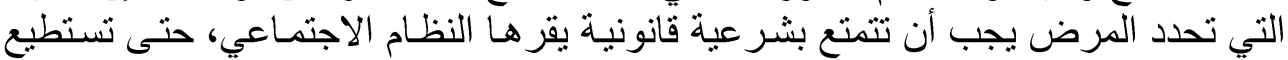

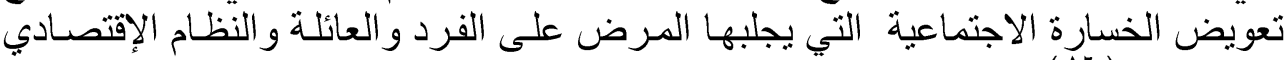

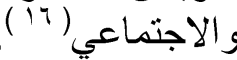

بشكل عـام تعتبر البنائية الوظيفية المرض لون من ألوان الإنحر اف الاجتمـاعي لأن

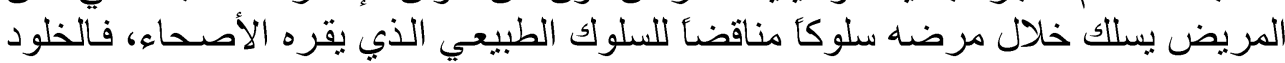

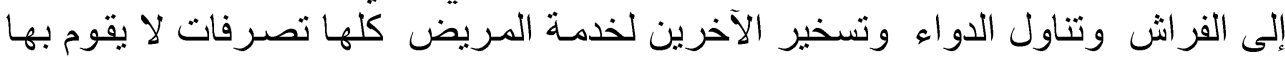

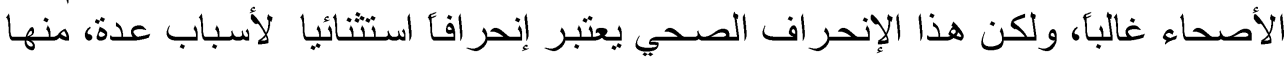


أو لا أن هذا السلوك يستغرق فترة قصبرة محدودة ، وثانيًا إنه يعبر عن قوة لا ار ادية داخل

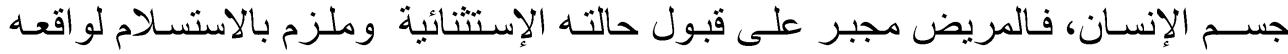

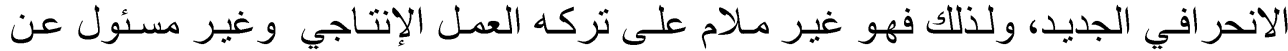

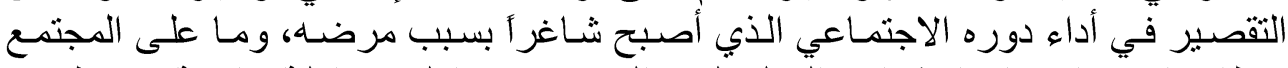

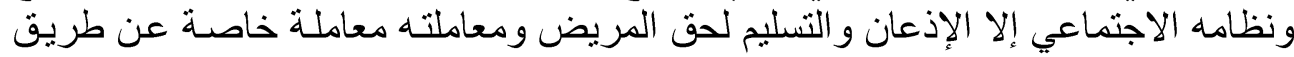

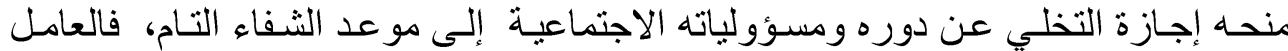

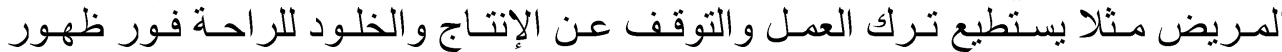

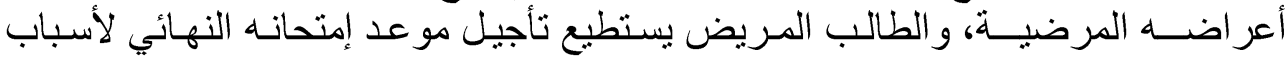

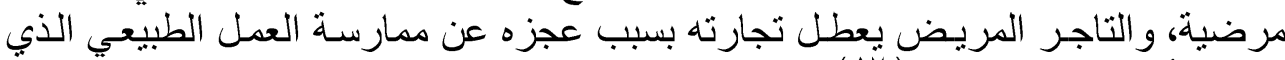

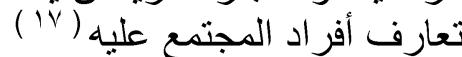

لاشك إن المريض الصادق ينبخي أن بطلب علاجأ سريعأ لحالته المرضية الاستثنائية

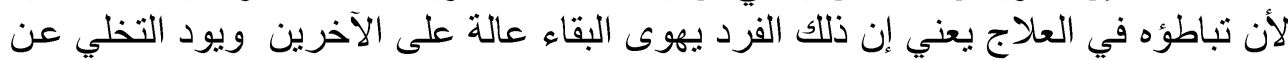

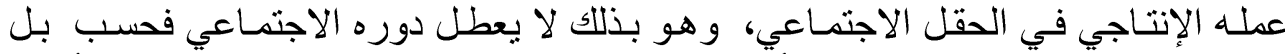

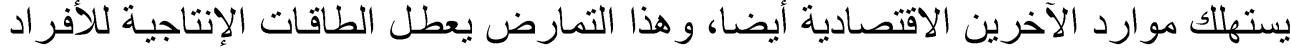

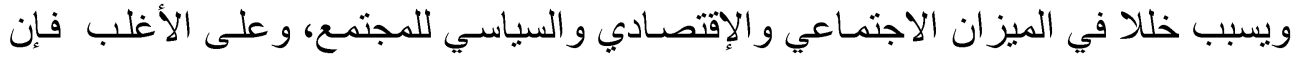

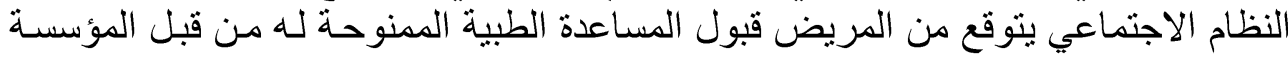

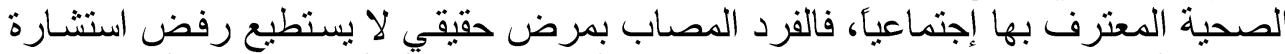

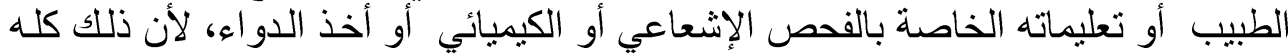

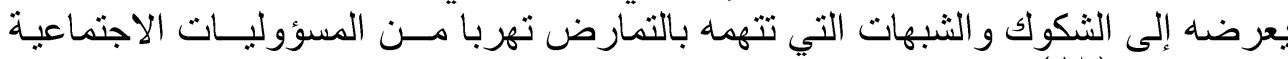

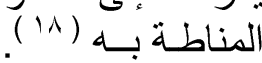

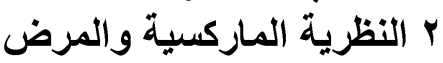

يربط المدخل المادي التاريخي بين المرض وضئ وطبيعة المجتمع والأيديولوجيا

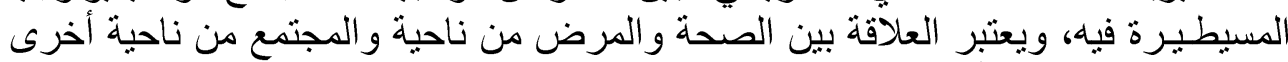

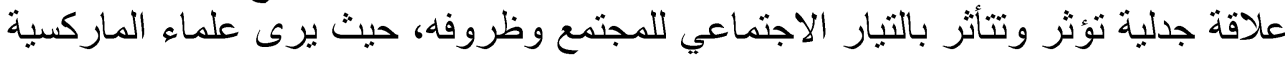

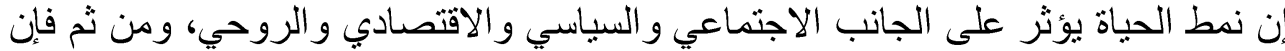
الطبقات الاجتماعية في المجتمع الرأسمالي تؤثر على النى النسق الطبي، فمن يملك وسائل

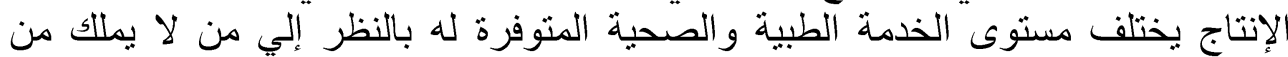

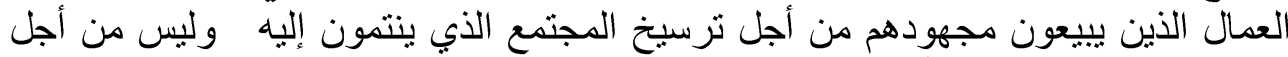

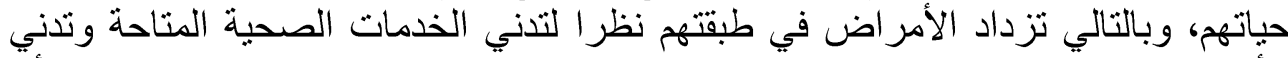

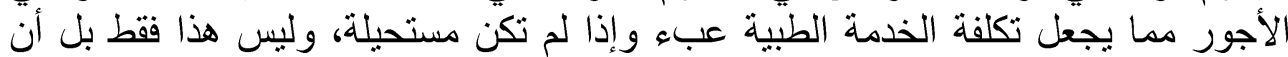

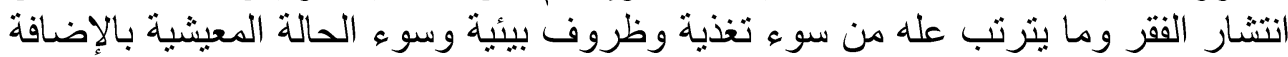

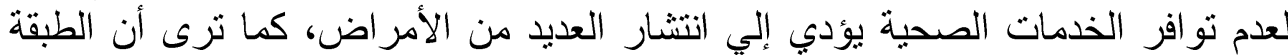

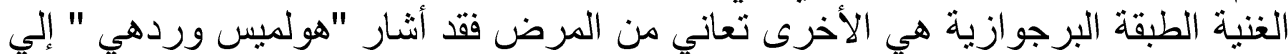

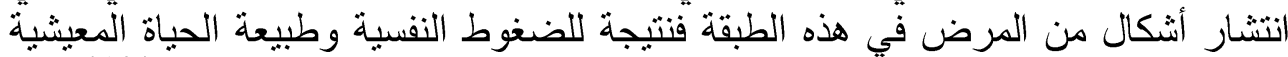

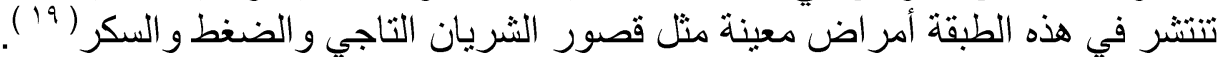

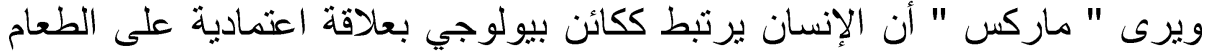

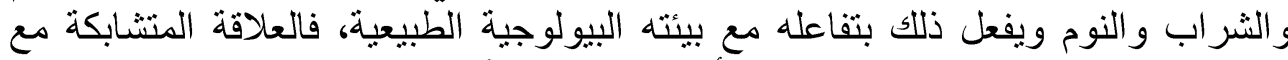

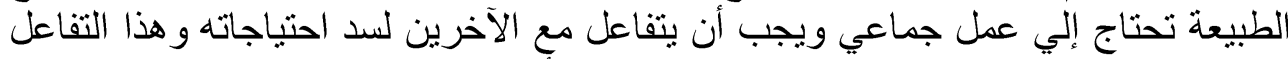

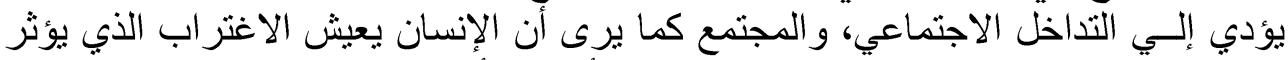

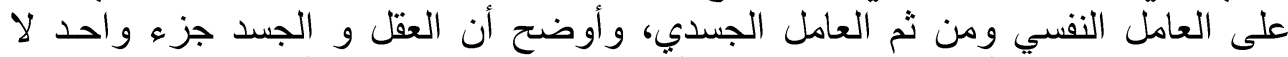

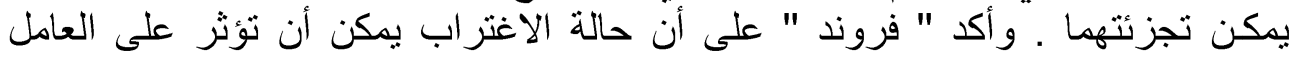




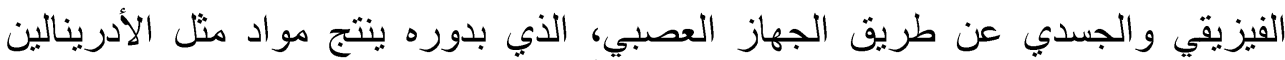

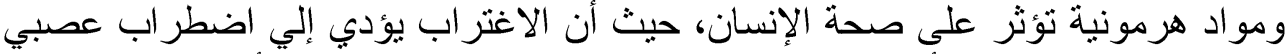

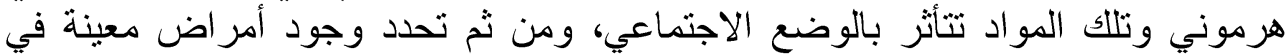

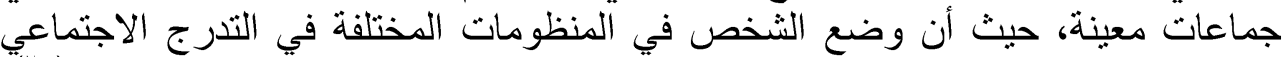

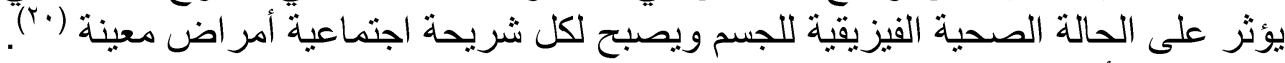

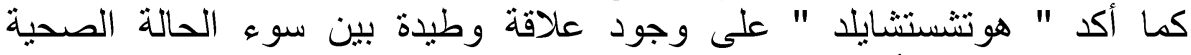

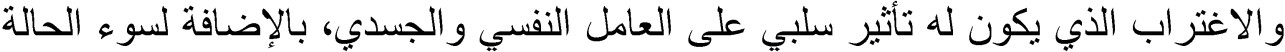

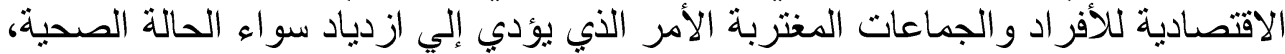

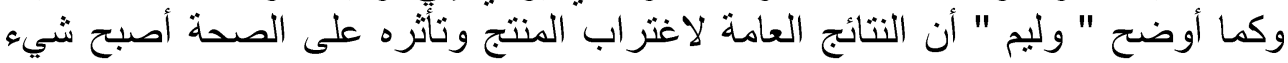

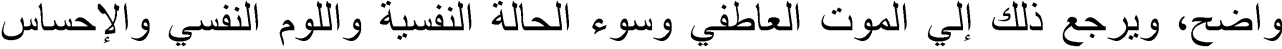

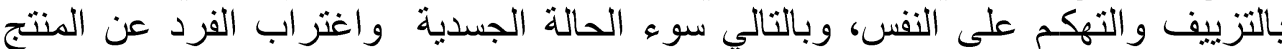

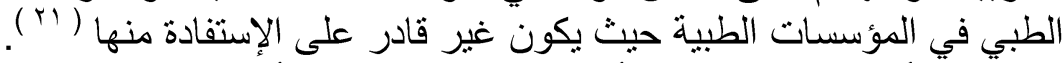

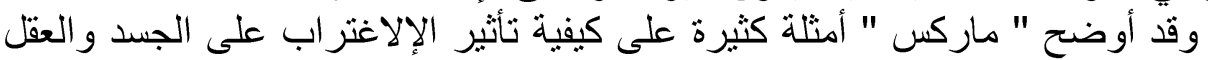

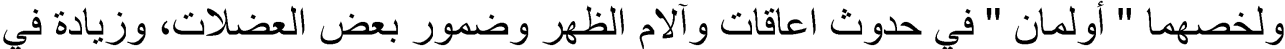

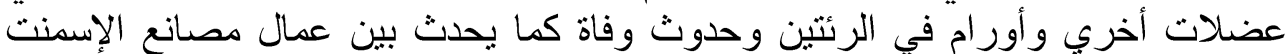

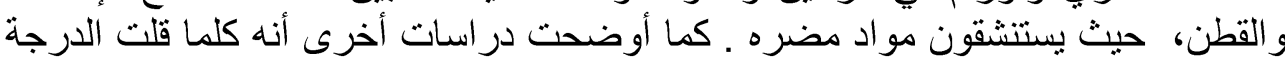
الوظيفية كلما قل دخل الفرد وإزدادت مشكلاته مما يزيد من اغتر ابه ويزيد أيضا من انتشار النهار

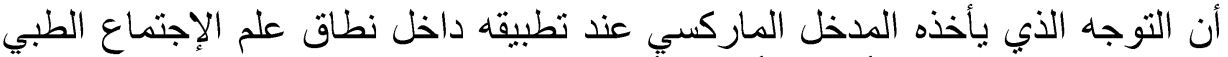

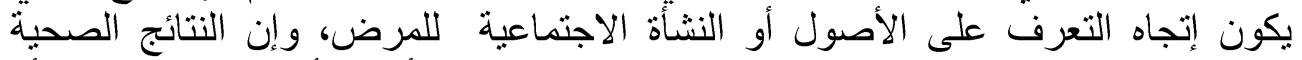

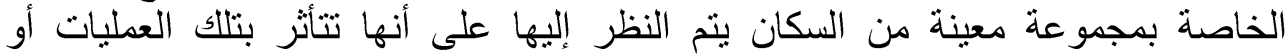

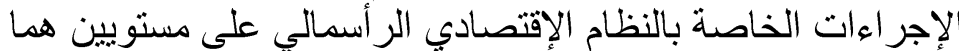

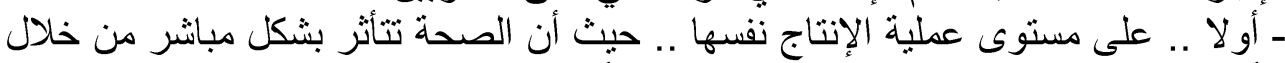

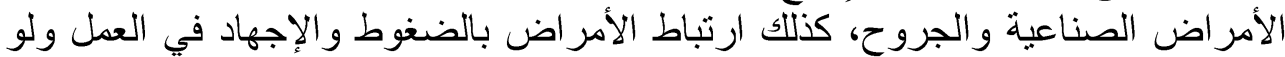

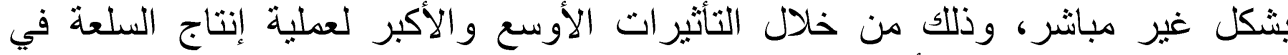

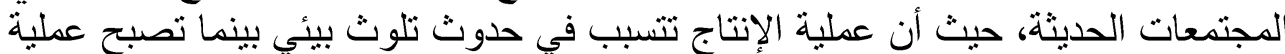

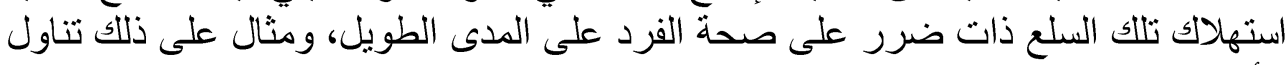
الأطعمة المصنعة و الإضافات الكيميائية و هكذا.

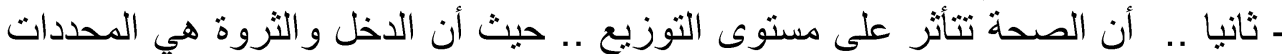

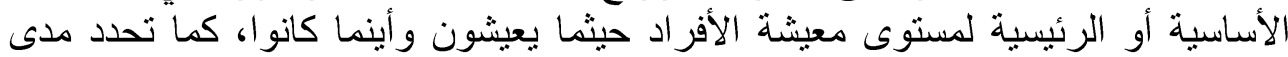

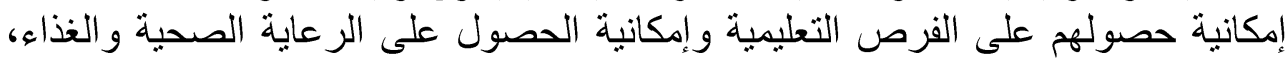

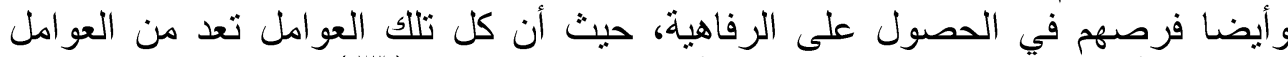

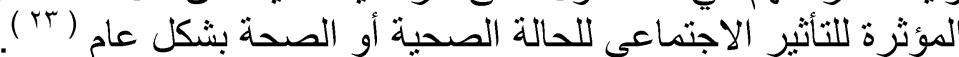

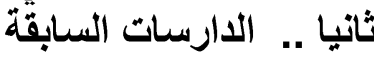

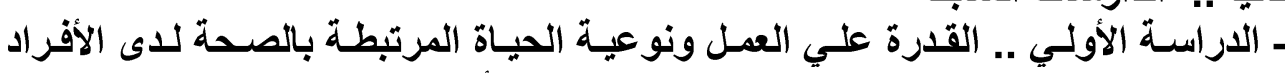

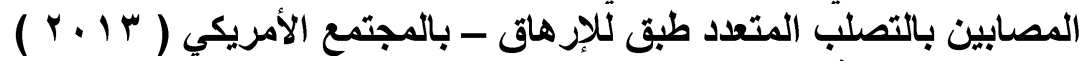

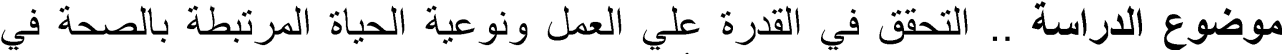

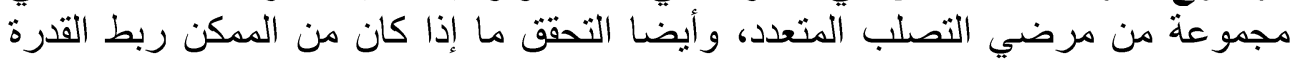

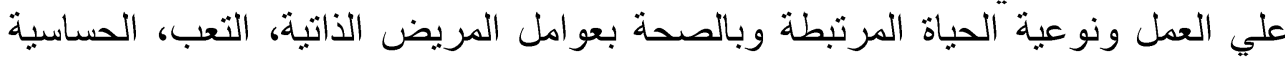
للحرارة، الخلل المعرفي، الإضطر اب العاطفي، درجة الإعاقة. 


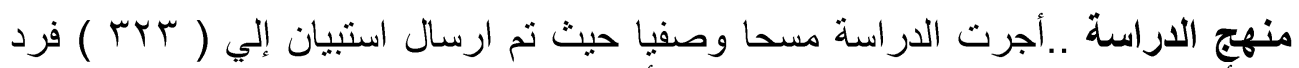

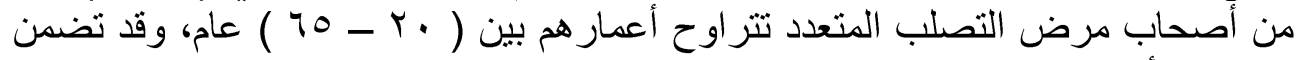

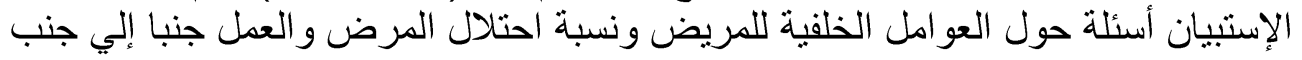

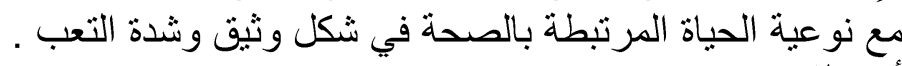
أهم النتائج ـ ثم العثور علي أن مستويات التعب والخلل الإدر اكي و الاضطر اب العاطفي تكون العوامل

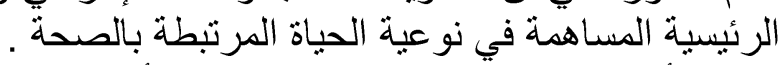

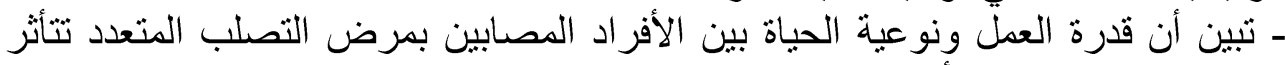

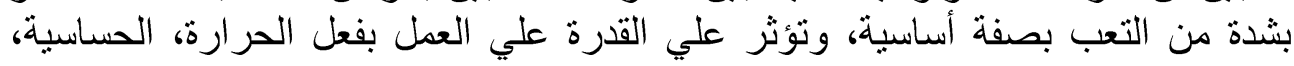
الصعوبات المعرفية،

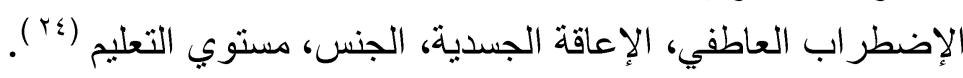

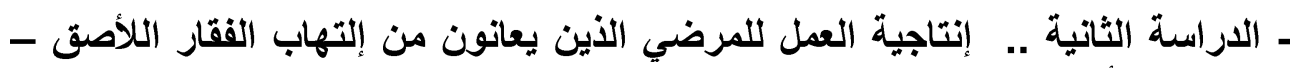

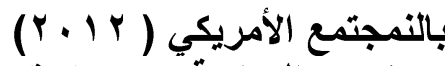

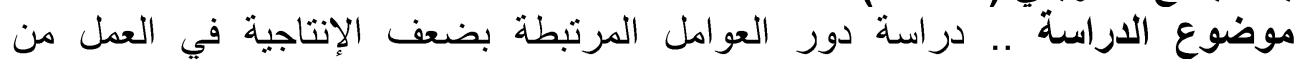

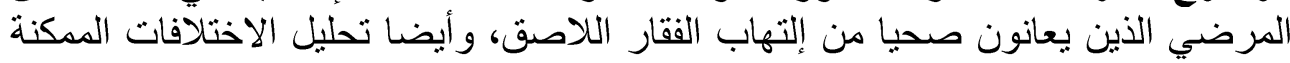
في السن والنوع.

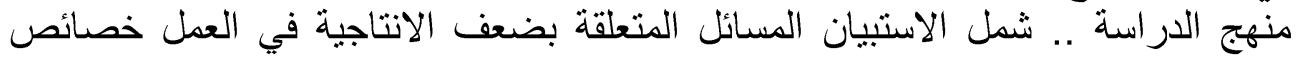

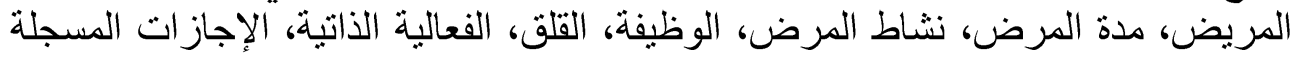

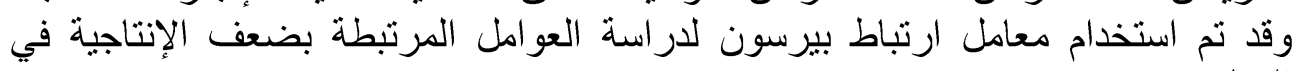
العمل

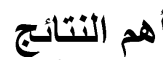

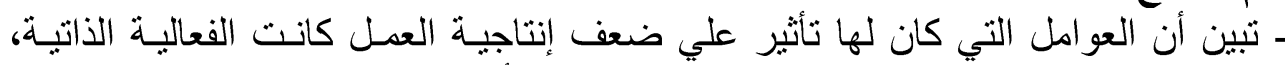

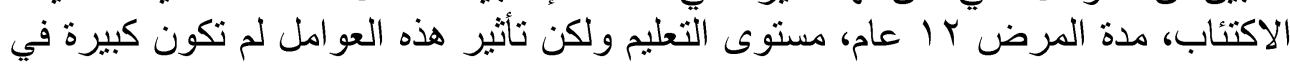

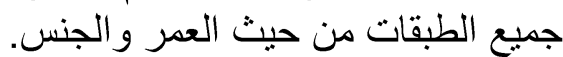

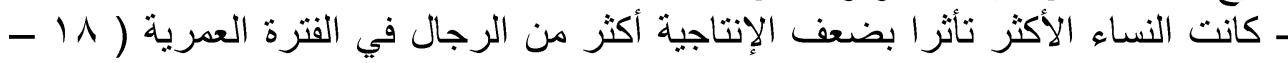
(ro) ( or

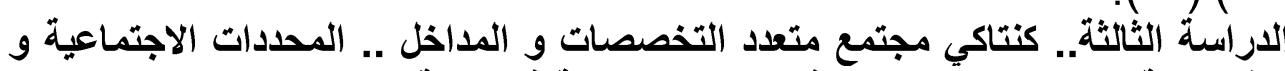

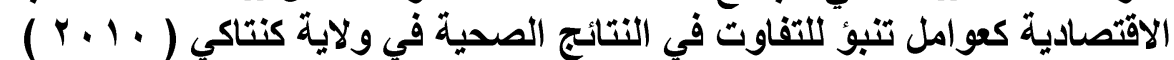

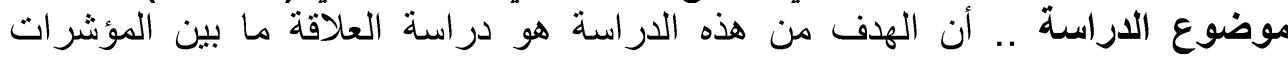

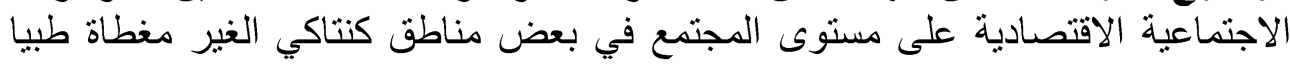

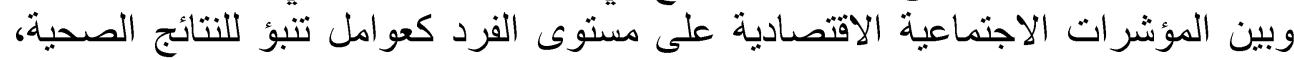

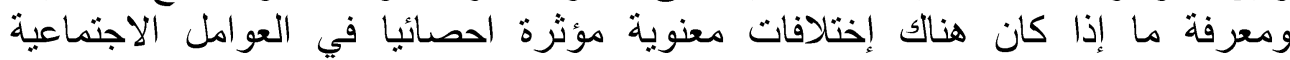

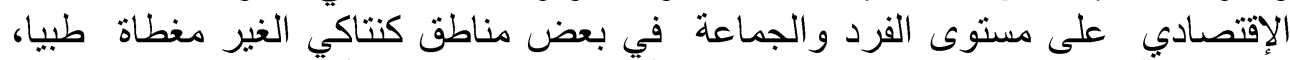

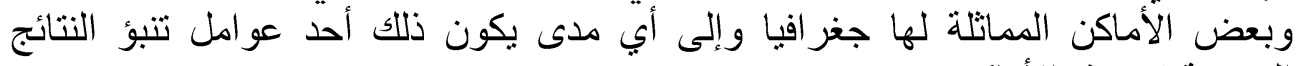

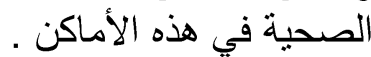

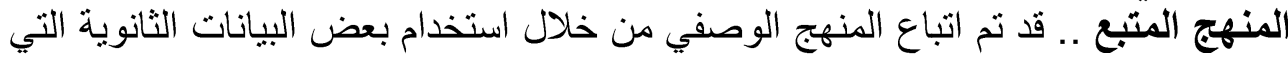

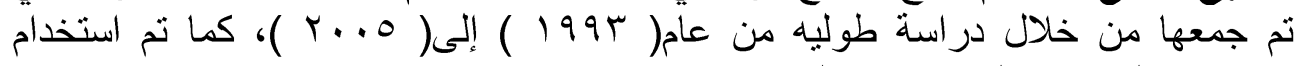

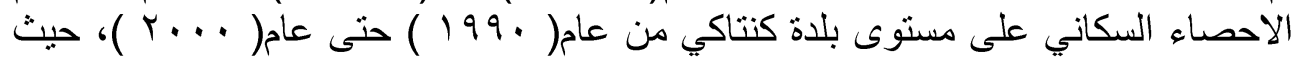

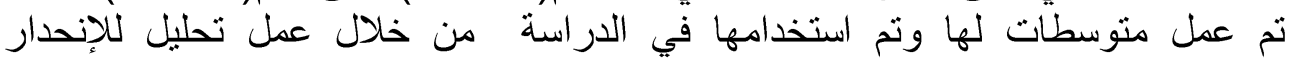




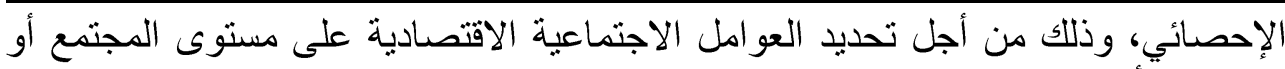

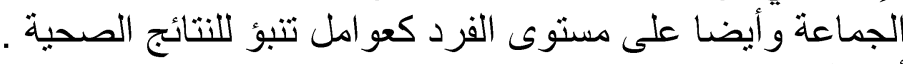

أهم التنائج

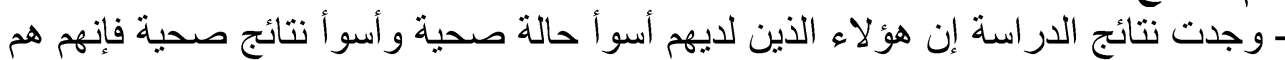

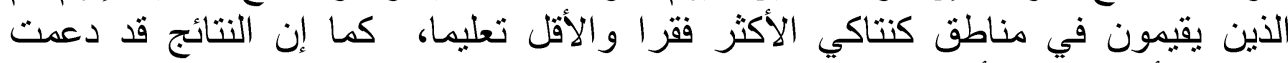

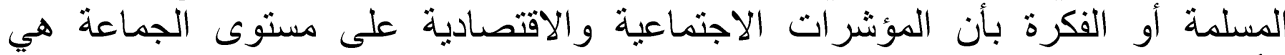

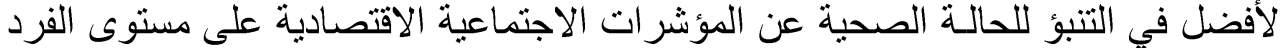

لاراسة الرابعة .. تأثثير الحالة الاجتماعية الاقتصادية علي الآثار الصحية السلبية للفقدان

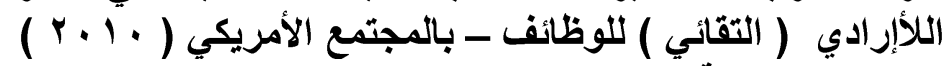

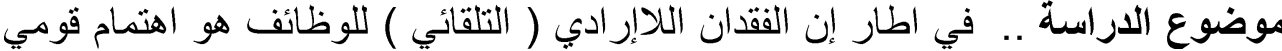

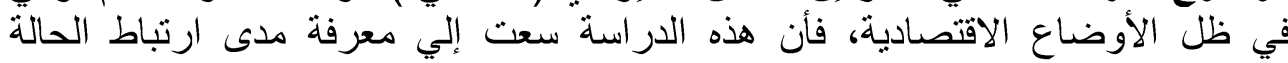

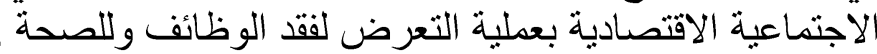

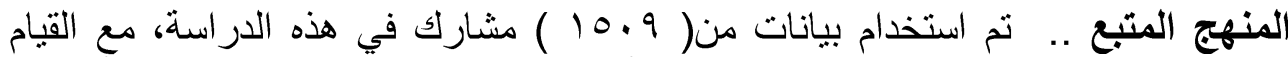

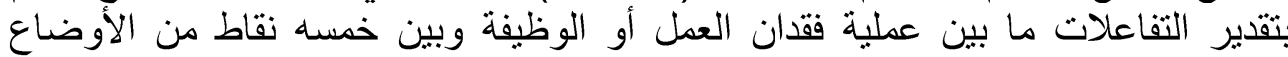

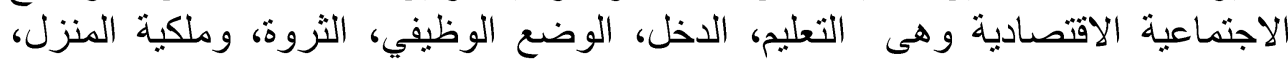

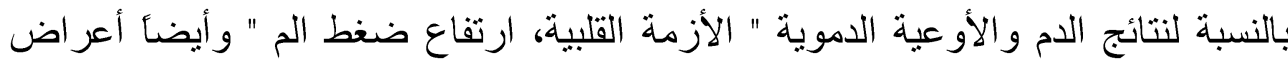

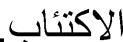

أهم النتائج

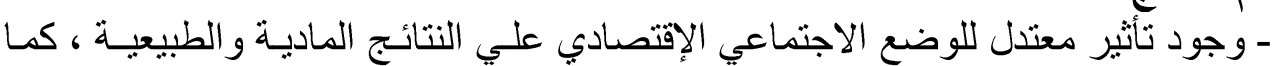

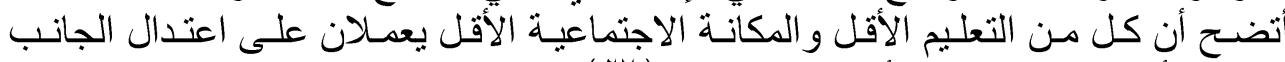

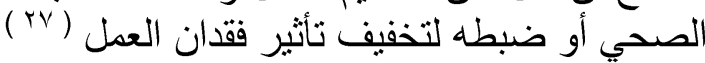

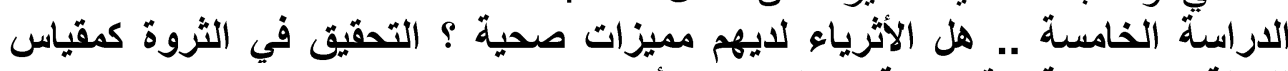

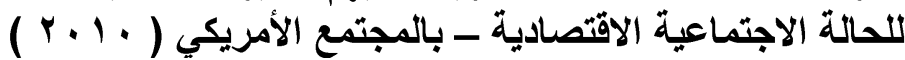

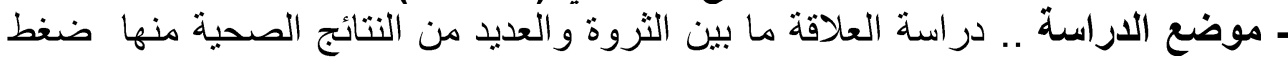

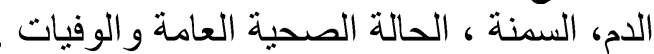

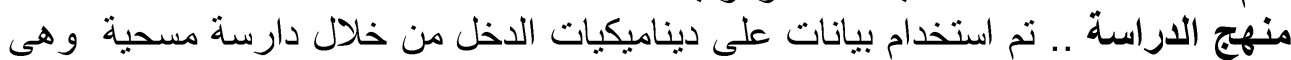

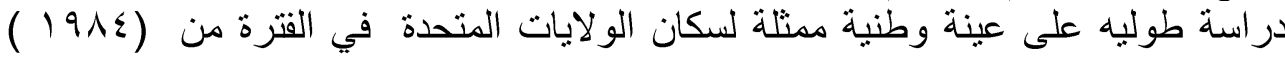

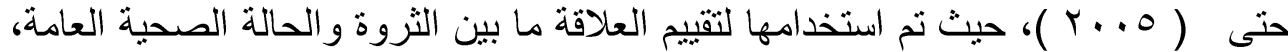

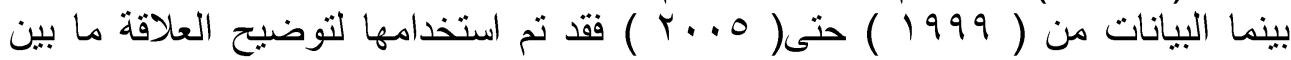
الثروة وضغط الدم، السمنة. أهم النتائج

ـ هناك علاقة عكسية قوية ما بين الثروة بين الحالة الصحية المتدنية وبين الوفاة، وإن

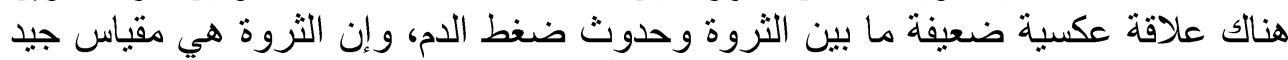
لقباس الوضع الاجتماعي الإقتصادي و لابد من أخذها في الاعتبار في الدراس استات المستقبلية

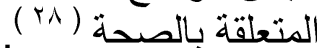

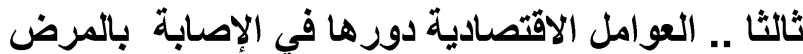

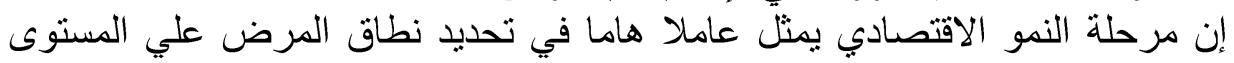

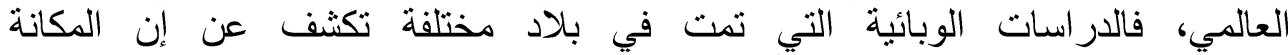
السوسيو اقتصادية ترنبط بوضوح بأنواع معينة من المرض. فالدية فلدارسات الإنجليزية علي 


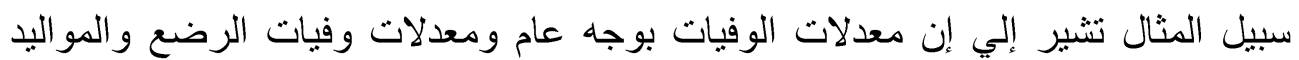

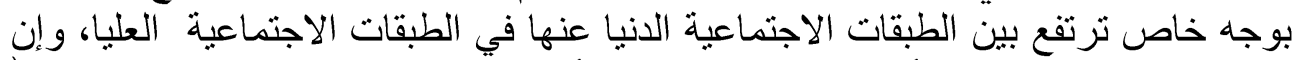

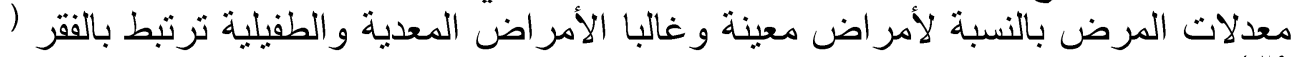

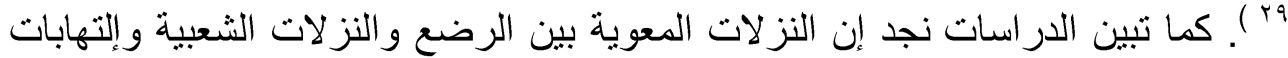

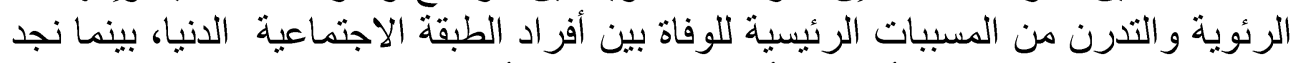

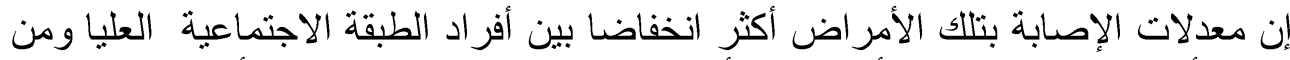

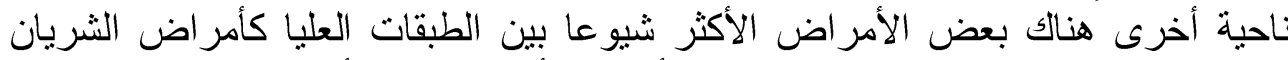

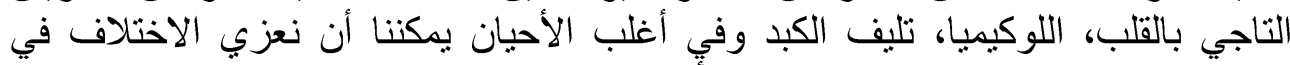

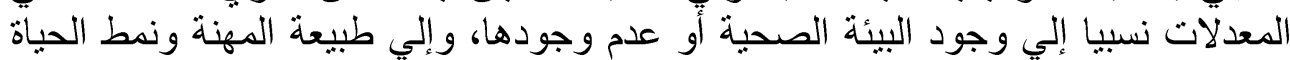

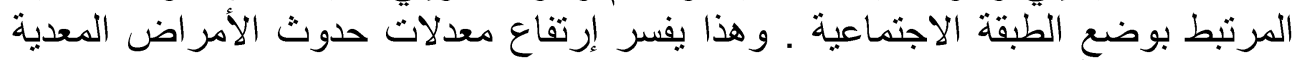

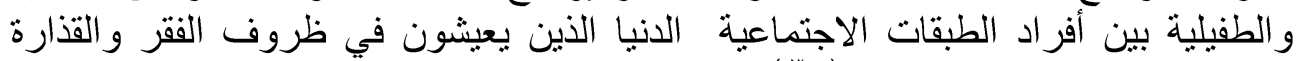

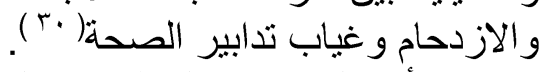
ومن أهم المتغير ات المؤثرة المنير في العو امل الاقتصادية :

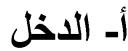

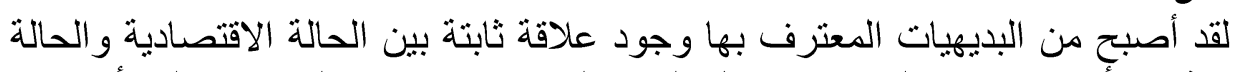

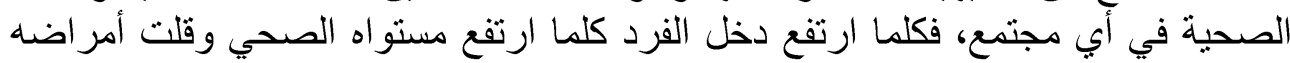

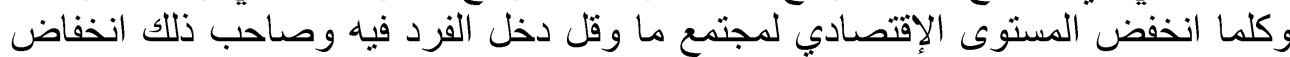

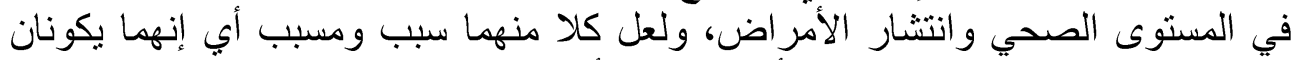

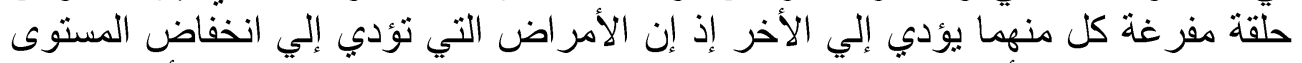

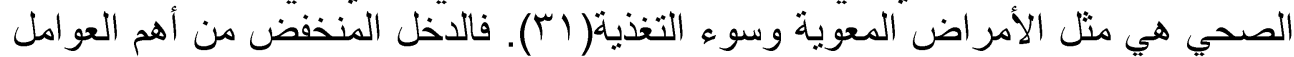

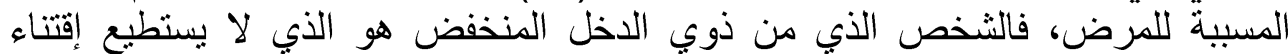

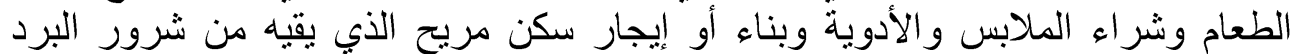

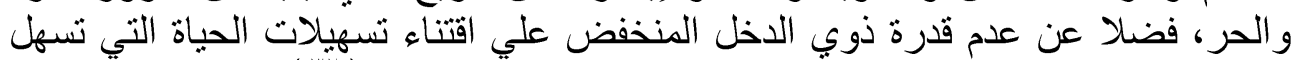

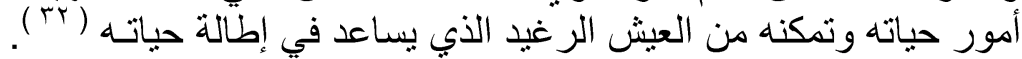

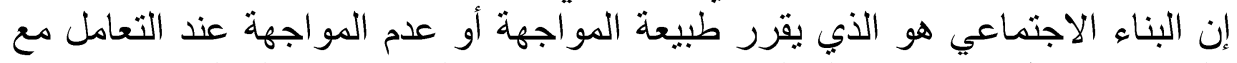

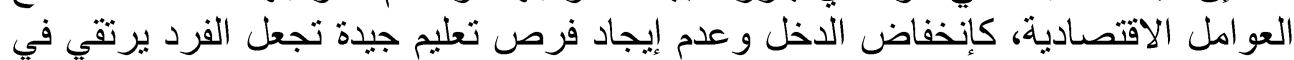

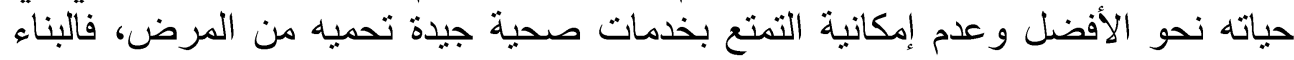

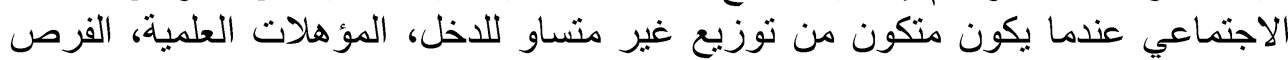

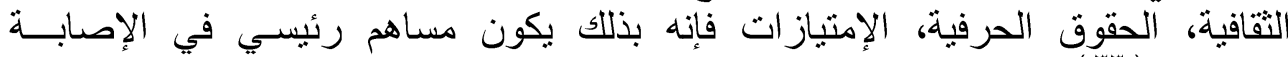

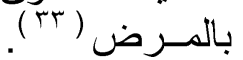

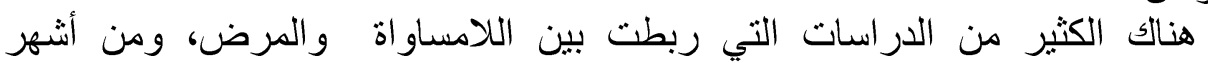

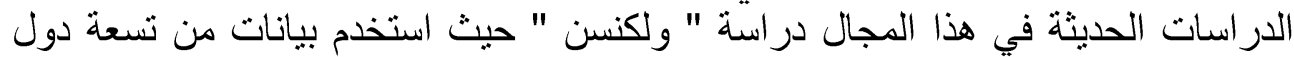

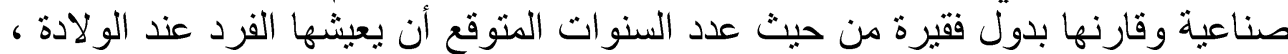

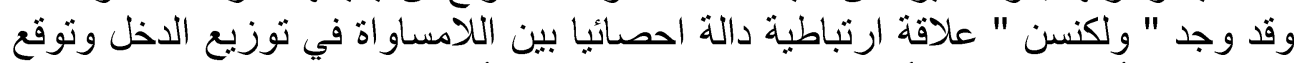

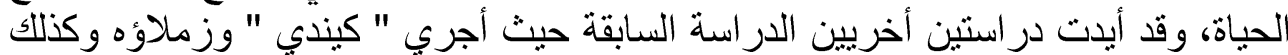

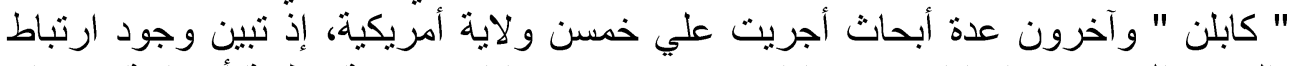

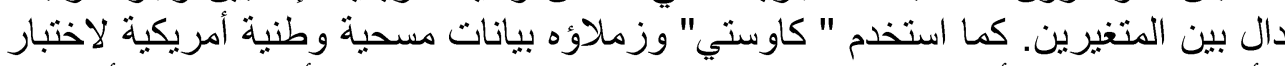

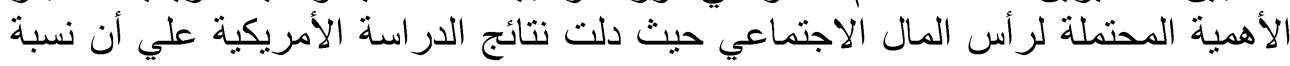

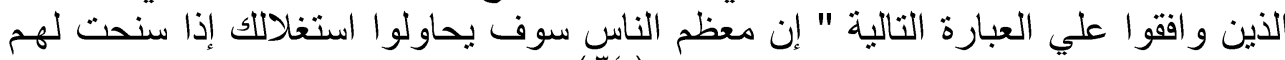

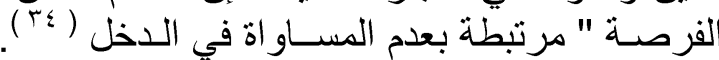




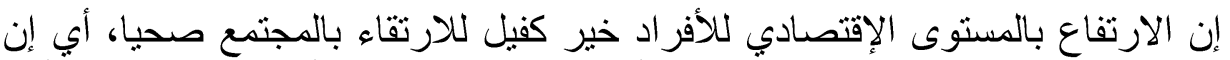

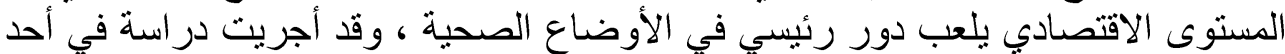

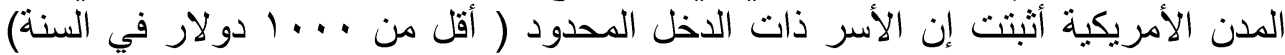

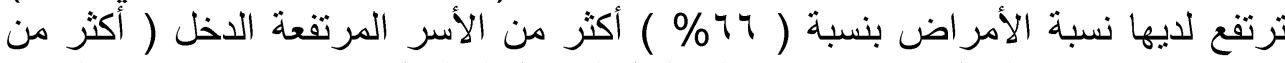

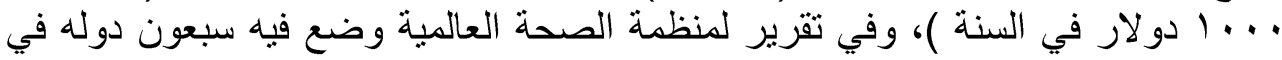

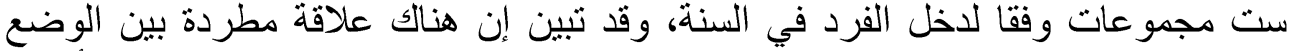

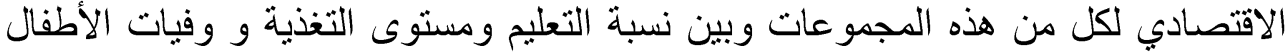

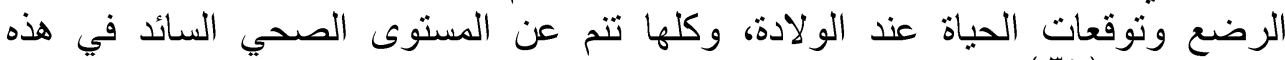

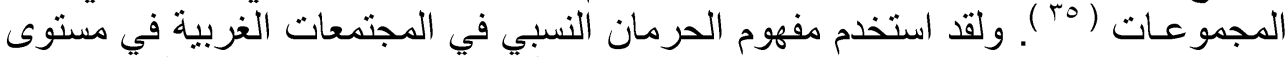

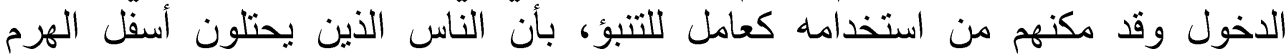

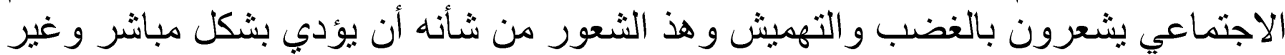

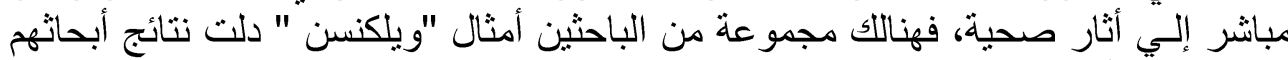

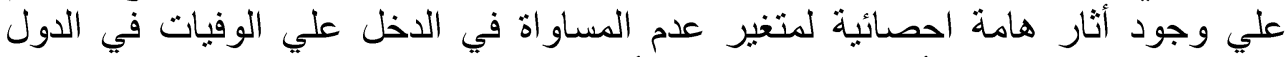

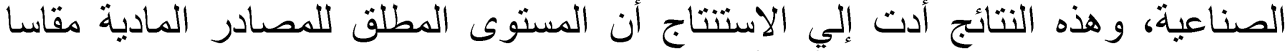

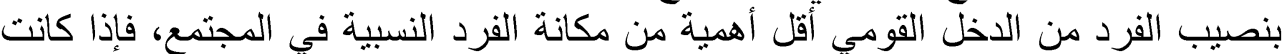

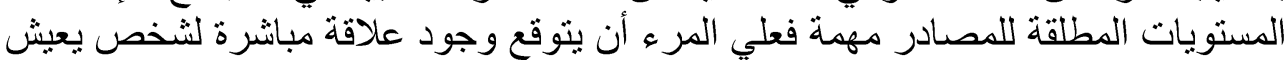

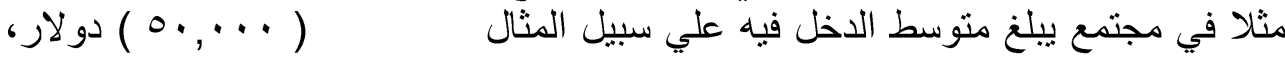

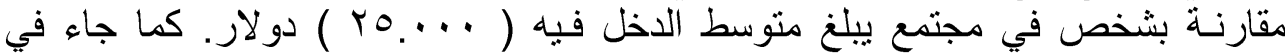

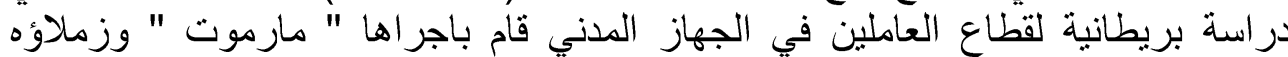

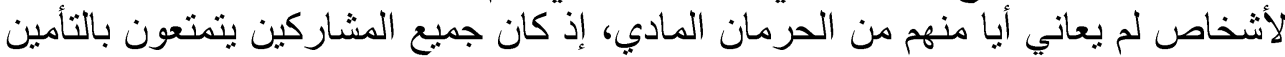

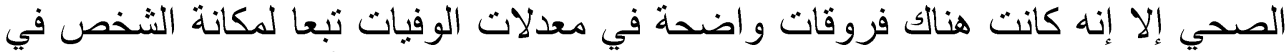

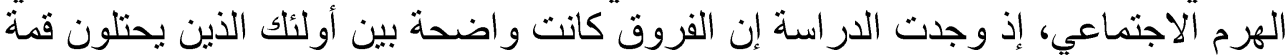

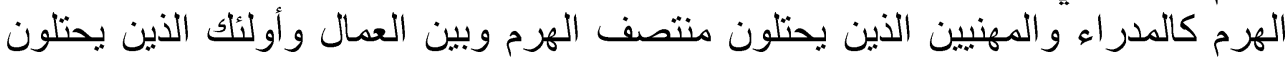

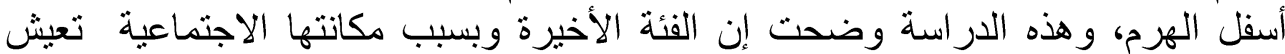

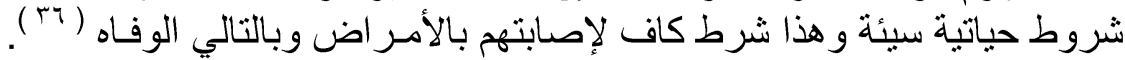

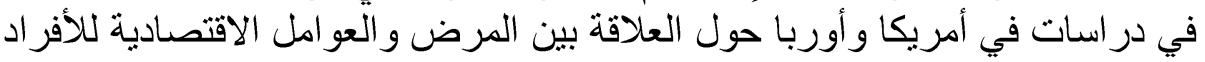

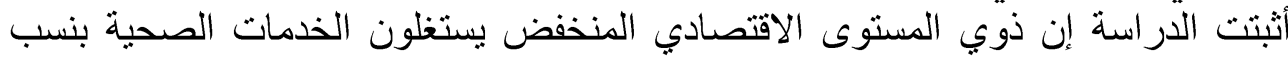

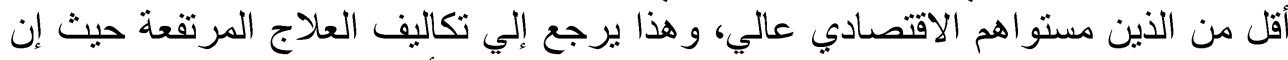

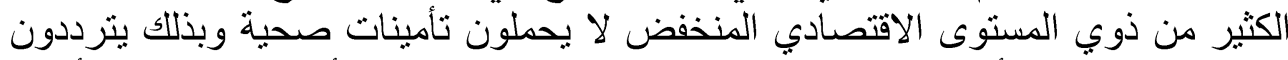

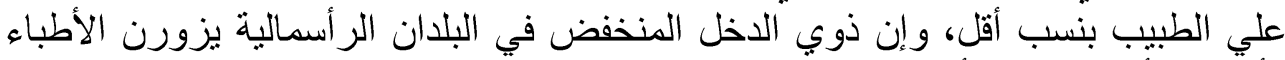

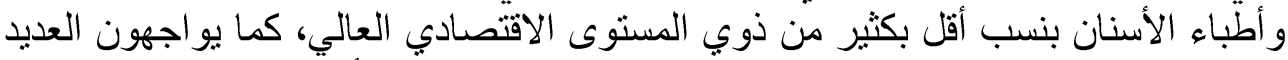

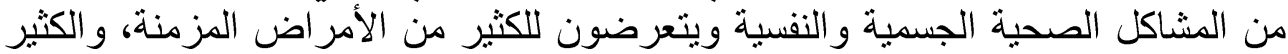
من الاعاقات الجسمية ويتحصلون علي خدمات طبية أقل مما تستحقه أعر اضهم المرنة الرضية

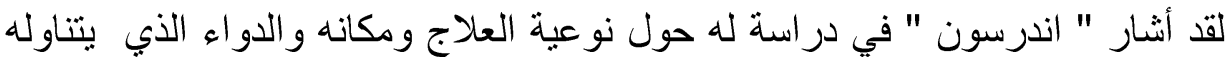

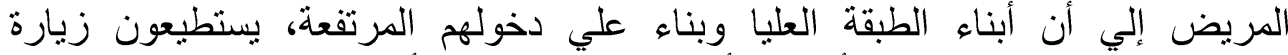
المستشفيات الخاصة وشر اء الأدوية الأجنبية ـ في حين إن أبناء الطبقة الدنيا بشكل عام

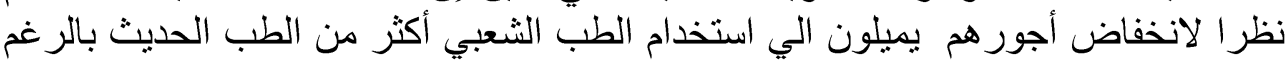

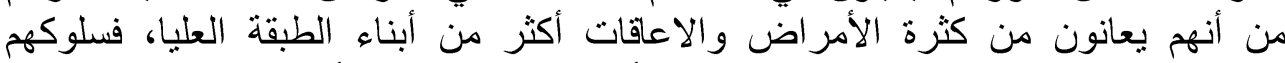

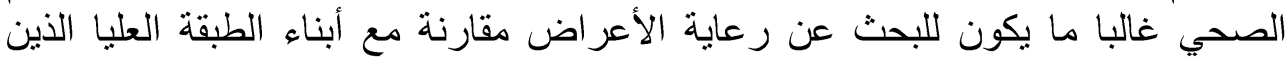




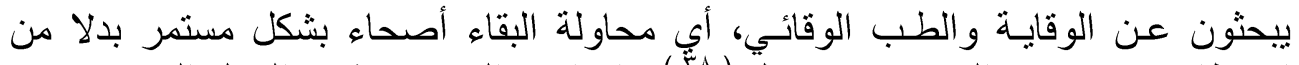

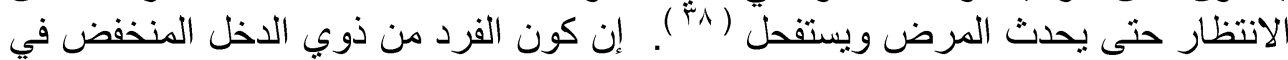

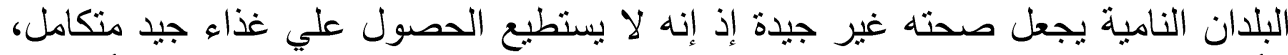

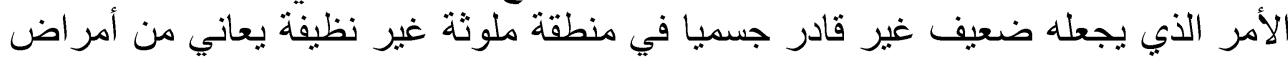

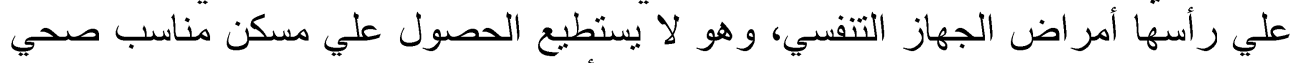

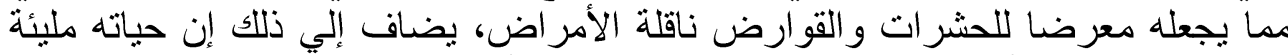

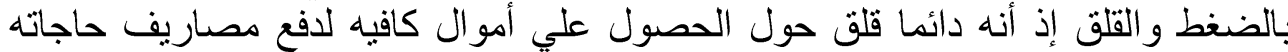

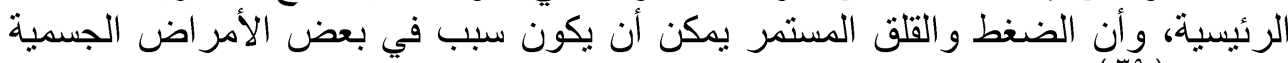

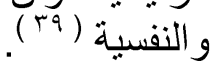

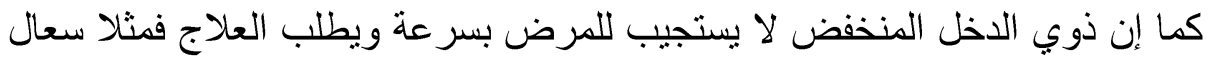

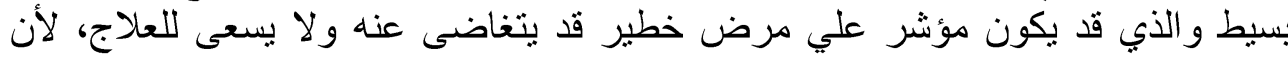

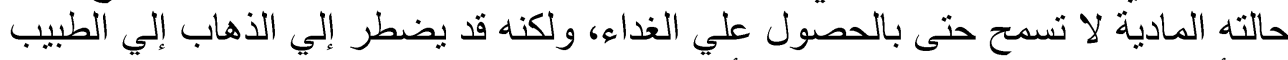

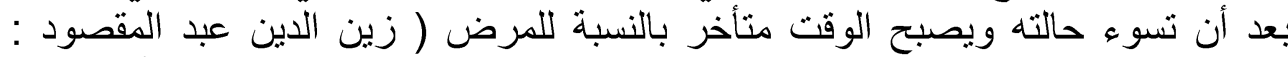

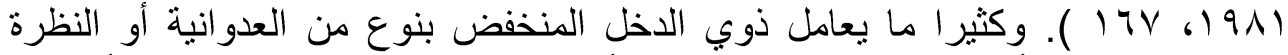

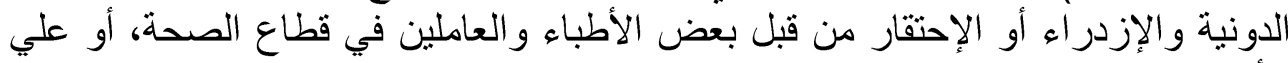

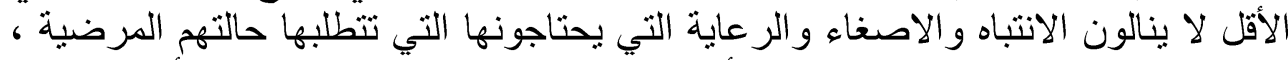

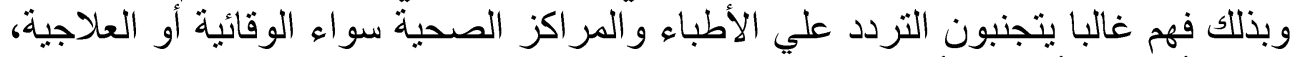

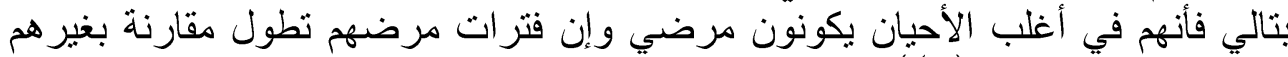

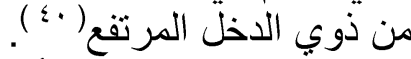

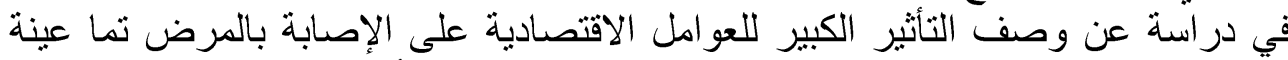

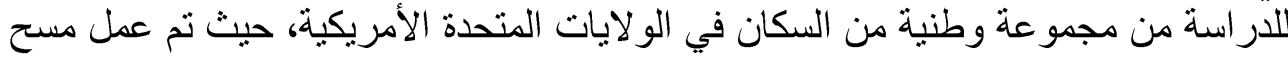

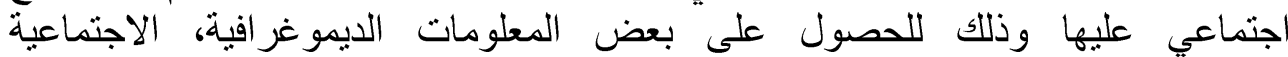

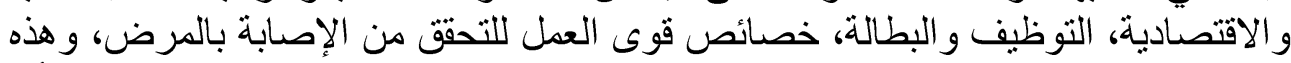

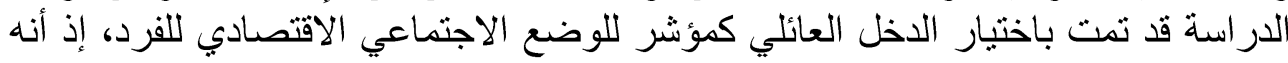

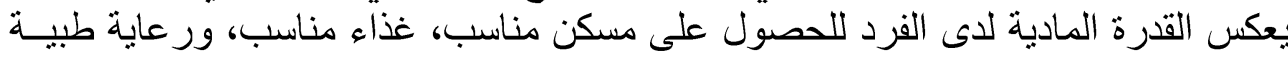

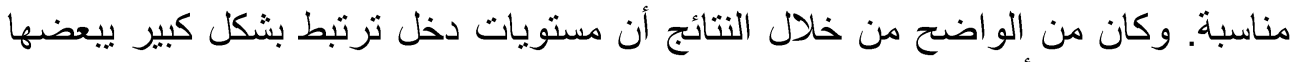

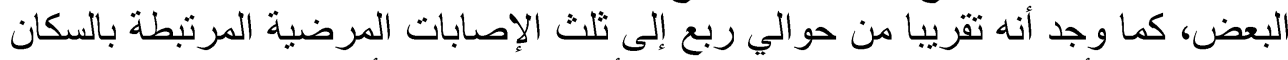

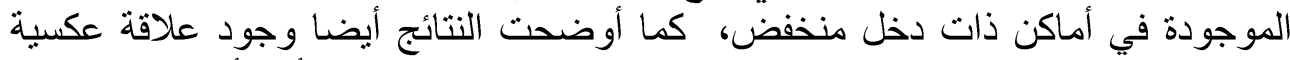

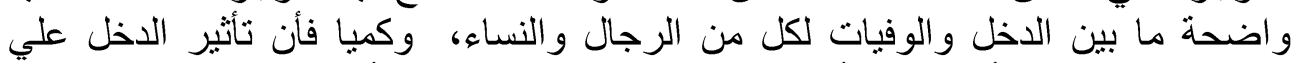

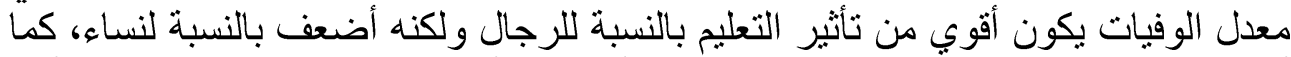

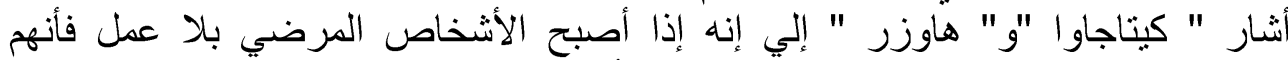

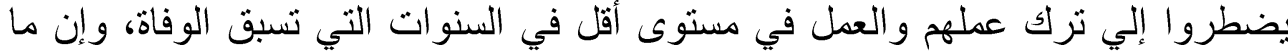

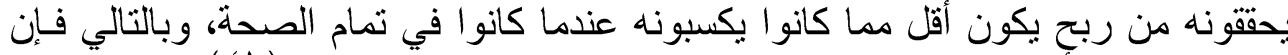

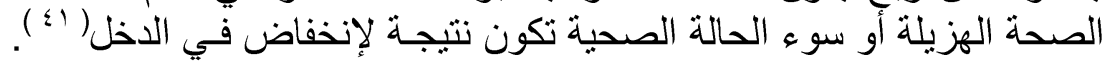

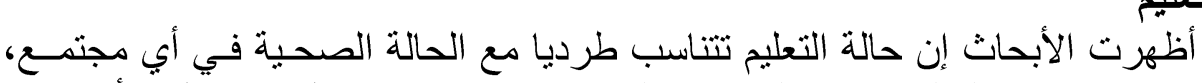

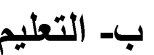

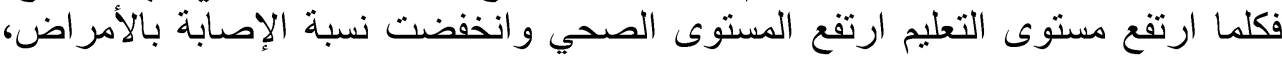

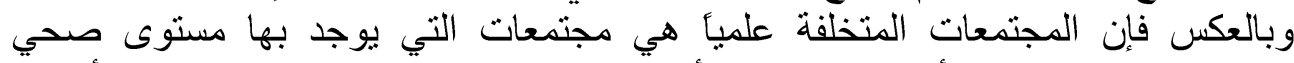

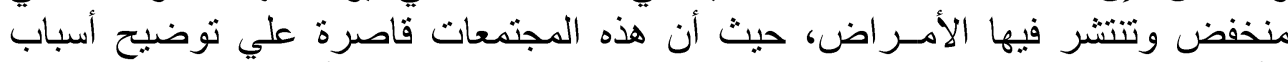

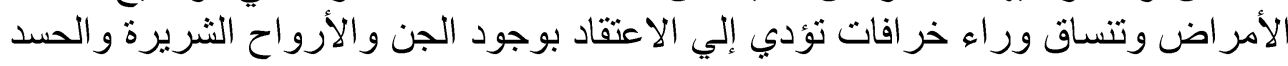




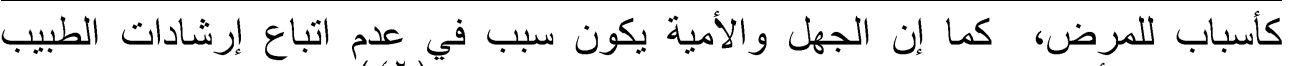

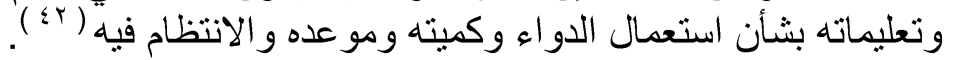

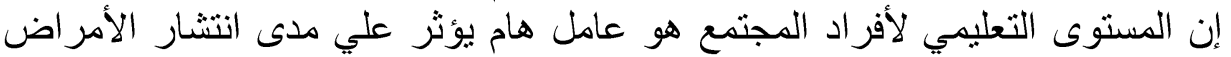

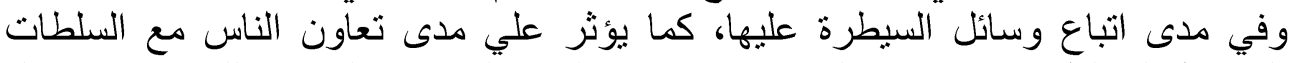

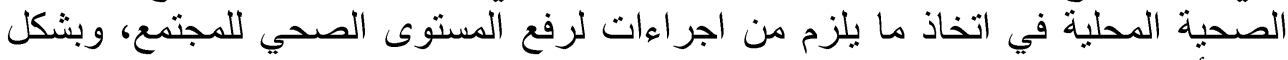

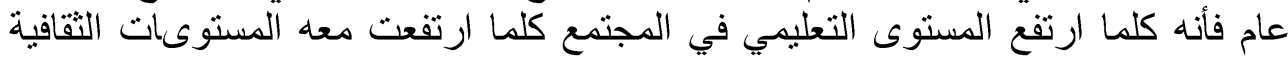

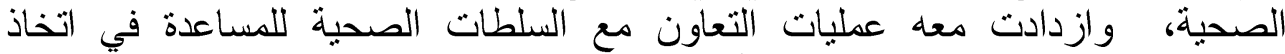

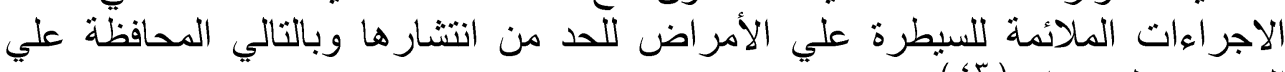

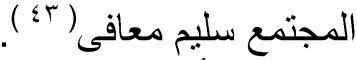
لقد أثـار العديد من الباحثين منهم " روس " إلي أن الناس الذين بتمتعون بتعليم عال

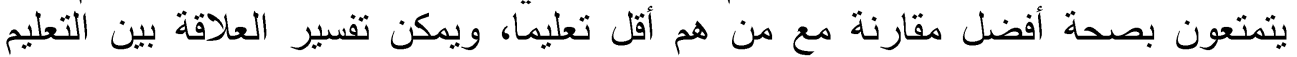

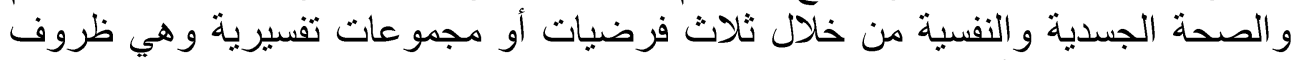

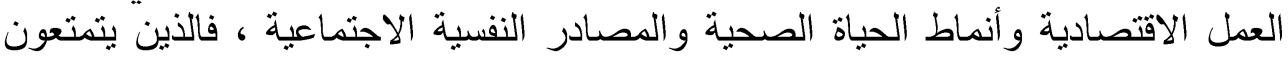

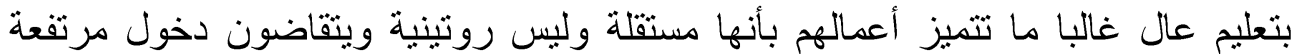

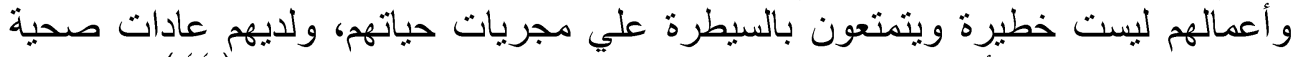

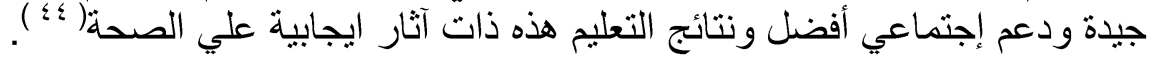

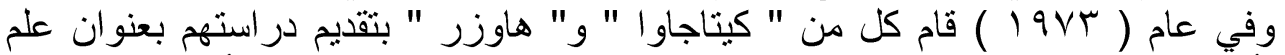
الأوبئة الاجتماعي والاقتصادي وفروق الوفيات في الولايات المتحدة الأمريكية، وقاموات التانيات

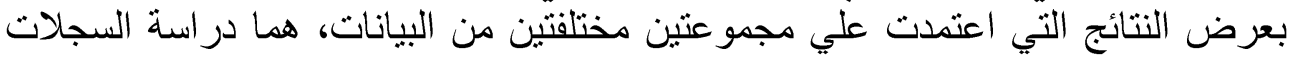

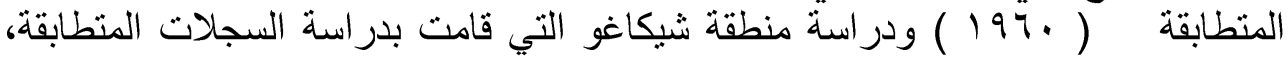

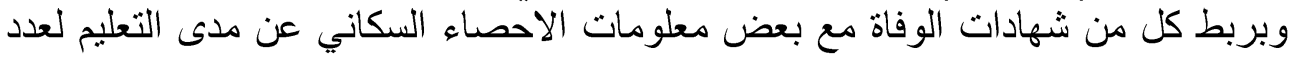

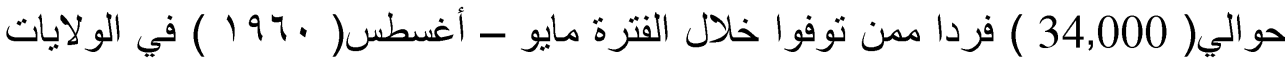

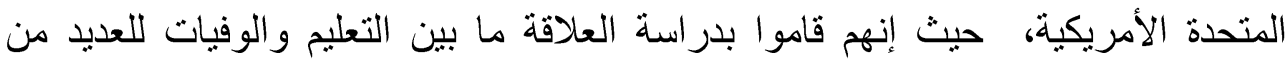

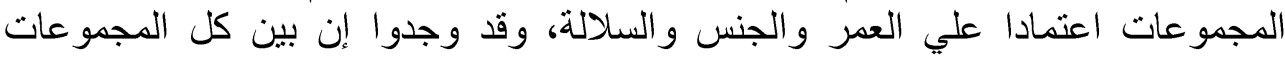

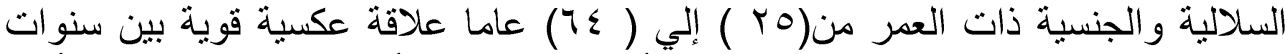

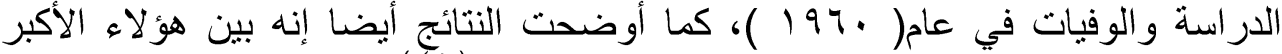

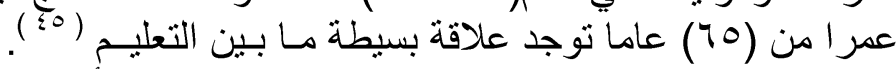

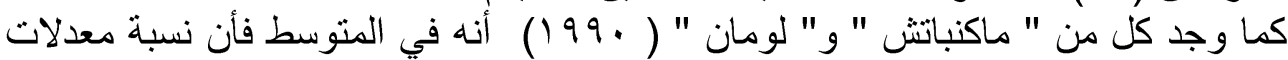

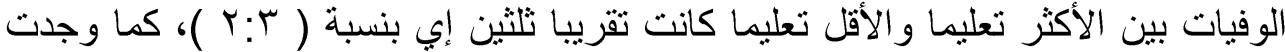

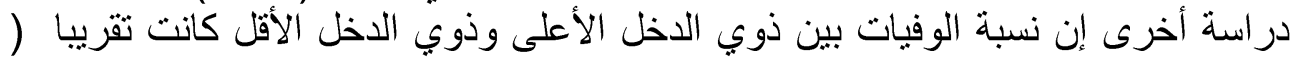

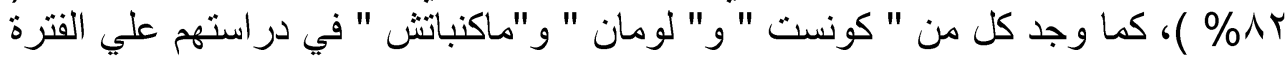

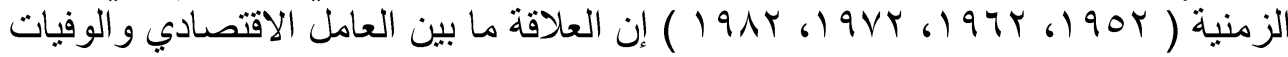

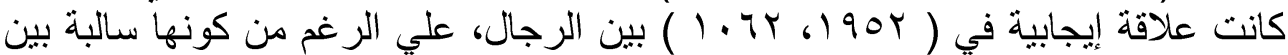

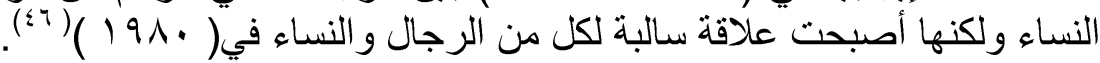

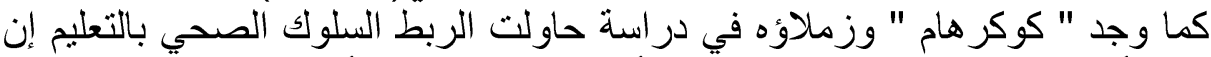

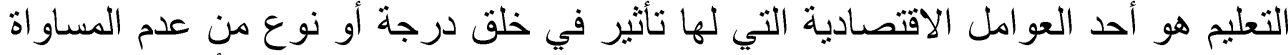

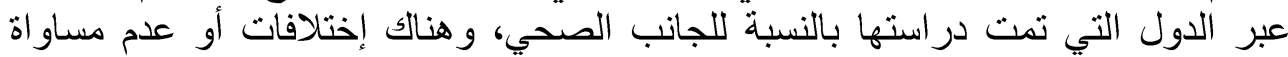

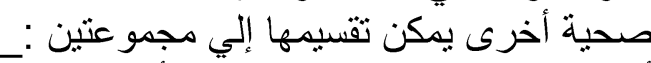

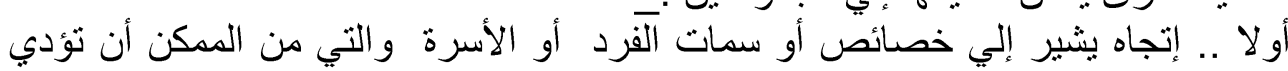

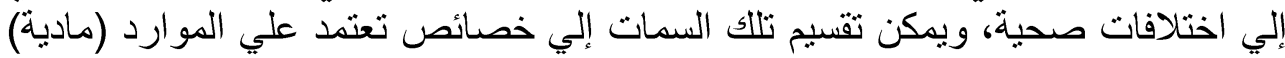


مثل الثروة وملكية المسكن، وملكية السيارة ، وخصائص لا تعتمد علي الموارد وهي خصائص سلوكية مثل العو امل النفسية والونة والور اثية و الثقافية .

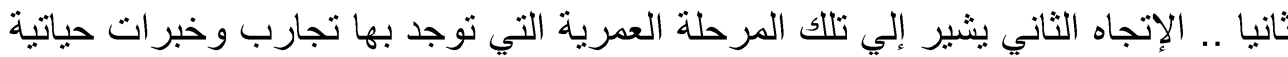

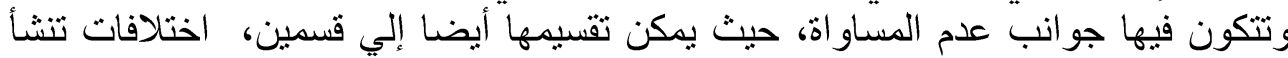

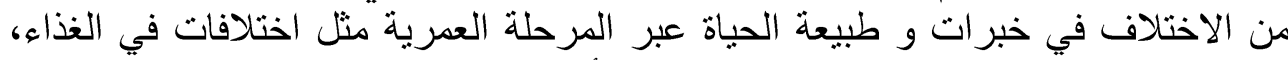

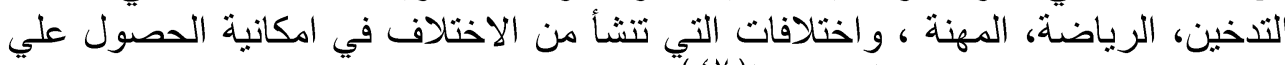

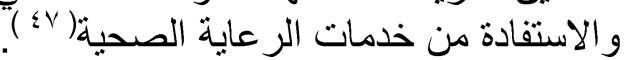

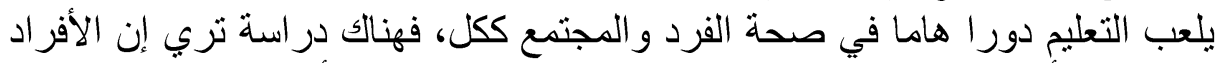

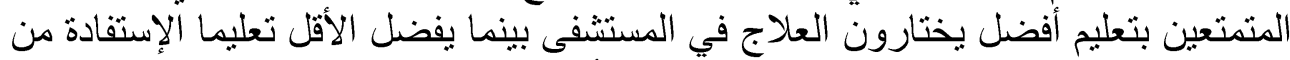

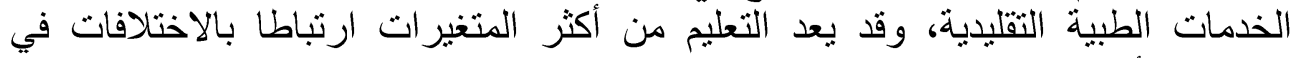

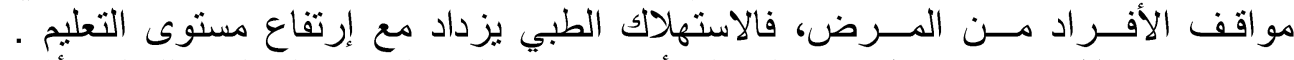

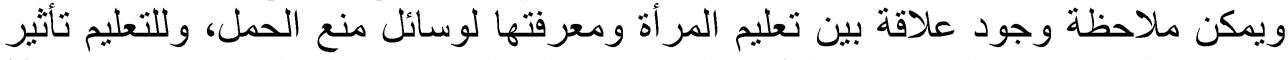

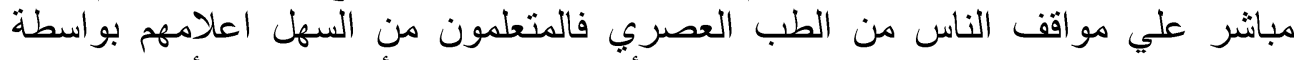

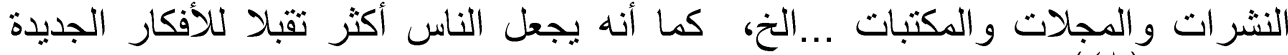

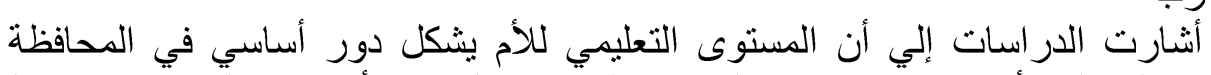

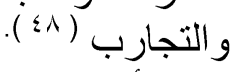

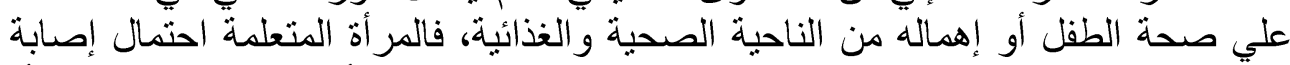

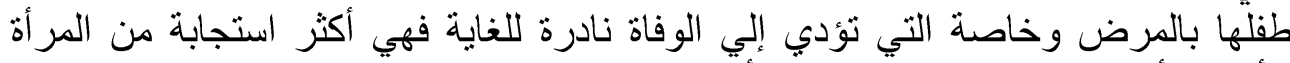

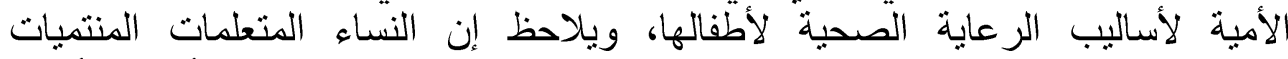

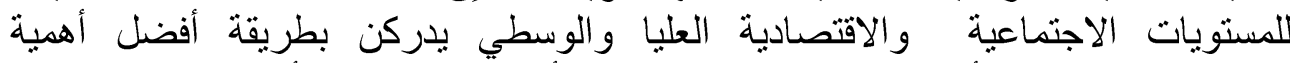

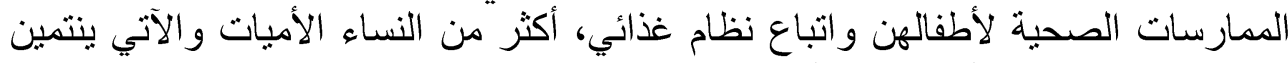

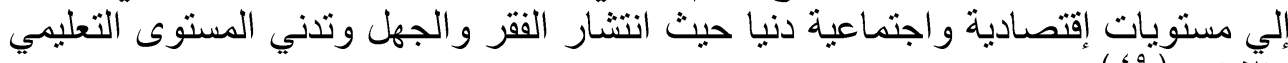
وعادة تتمتع الأسر التي نالت قدرأ كبيرًا من التعليم بصحة أفضل فالتعليم بالنسبة

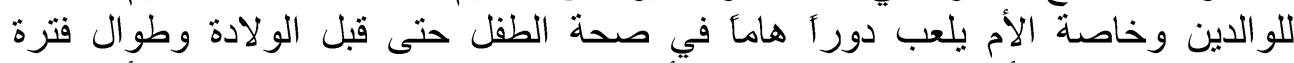

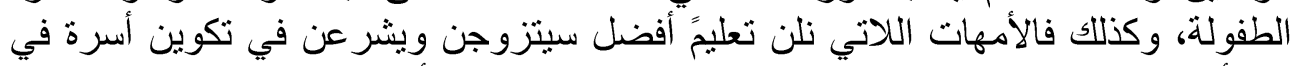

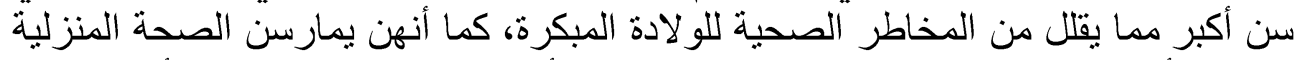

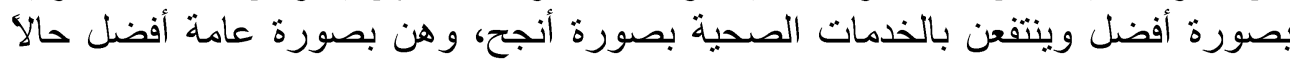

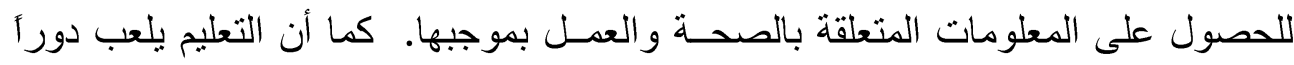

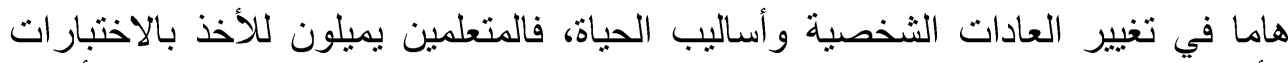

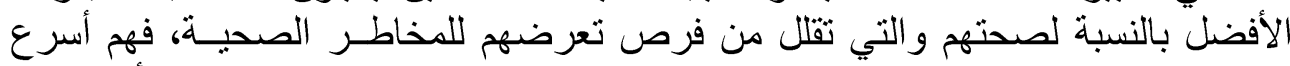

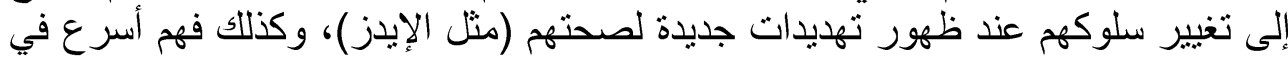

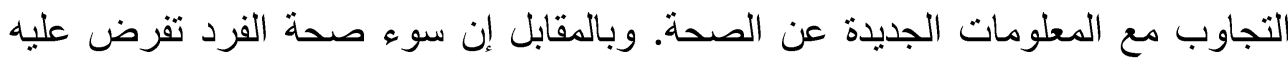

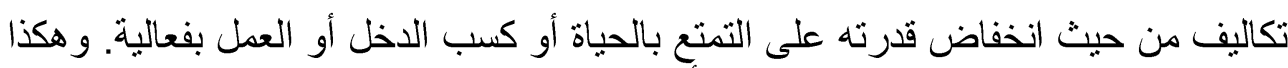

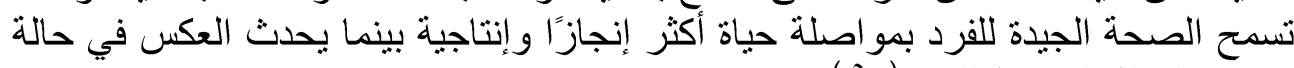

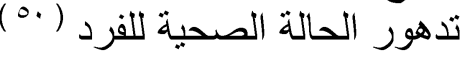

ج- المهنة

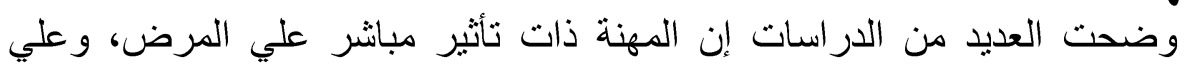

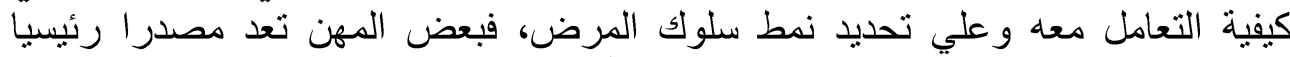

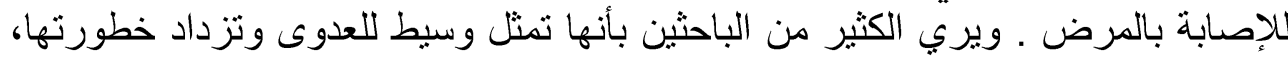




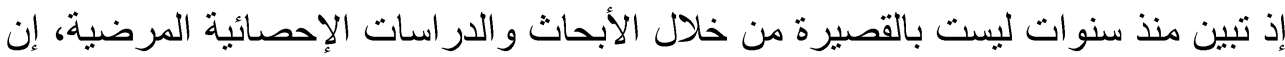

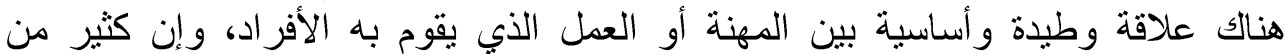

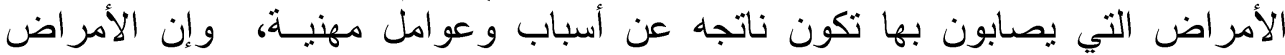

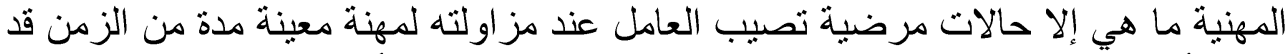

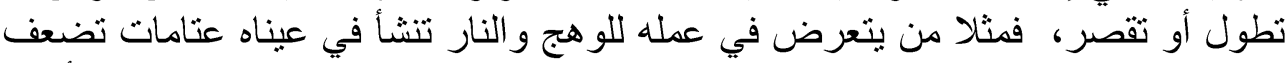
بصره ويعد ضعف البصر هذا مرضا مهنيا، ومن كان يتعرض فئ في في عمله لإنجره و وأتربه

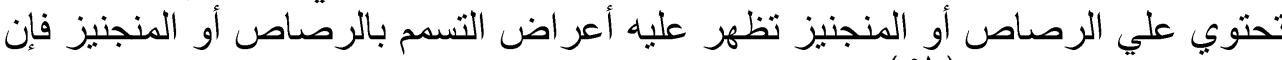

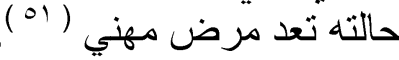

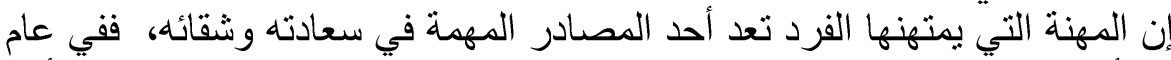

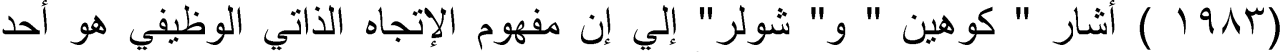

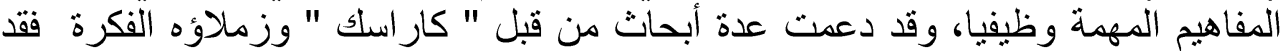

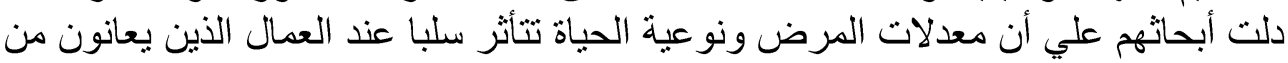

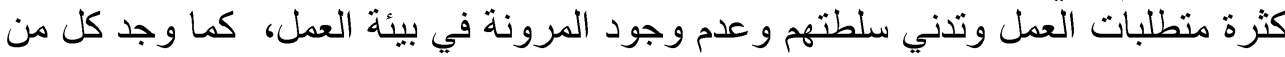
" جونسون "و" هول " إن الدعم الاجتماعي قوة تثوسط عمليات الطلب علي العمل وحرية

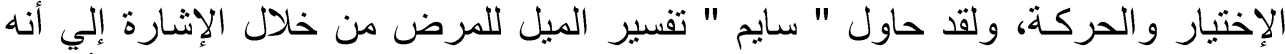

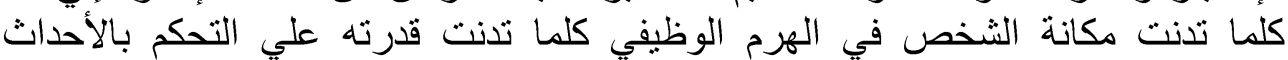

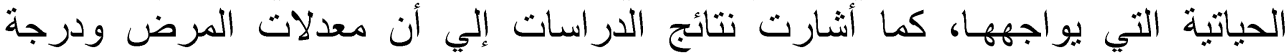
الوظيفة و الطبقة الاجتماعية تختلف بناء علي القدرة و الفرصة والتيات التدريب الذي يتلقاه الناس

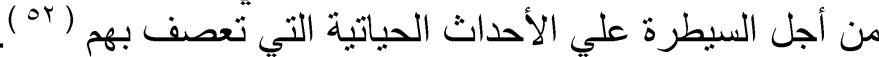

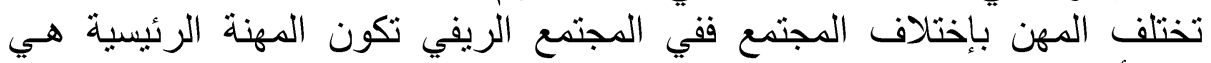

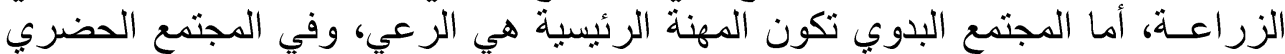

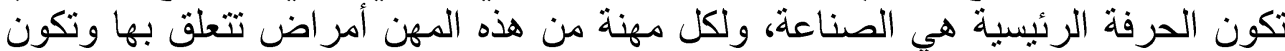

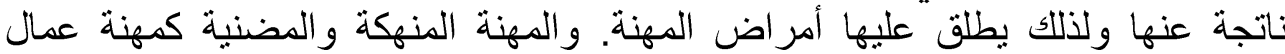

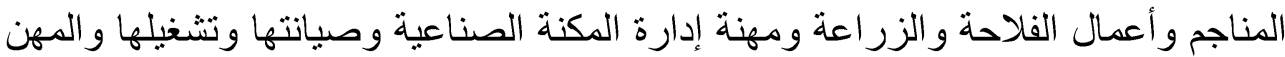

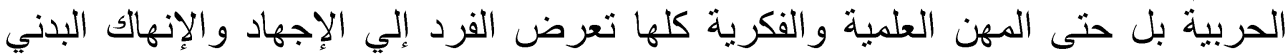

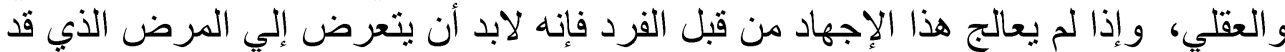

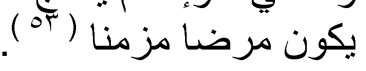
قد اقترح " سقرست " ( 1997 ( 197 ) طريقة جديدة للنظر الي ضغوط التون العمل حيث اقترح

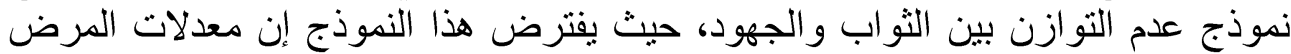

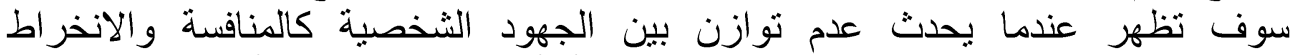

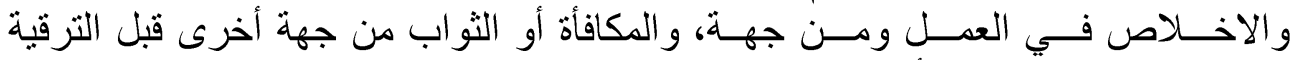

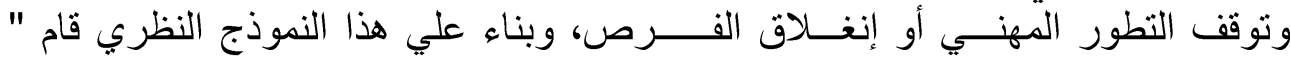

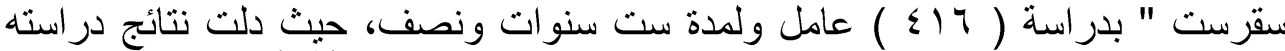

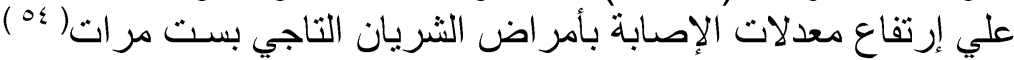

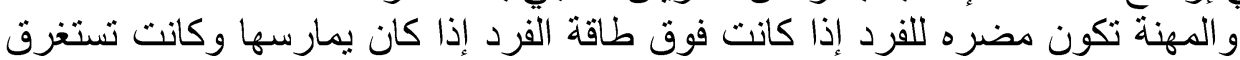

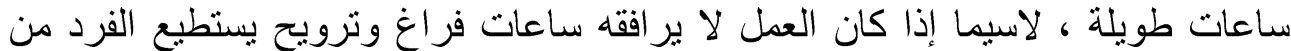
خلالها الحصول علي قسط من الراحة والإستجمام وتجديد طاقاته البدنية والعاتِ لإنلية المنهكة،

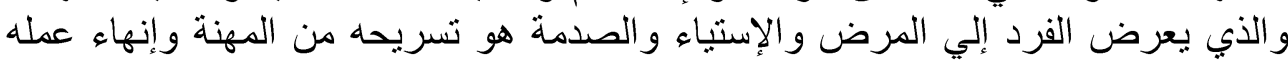

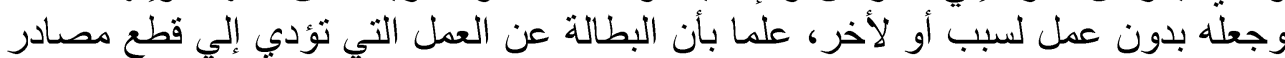

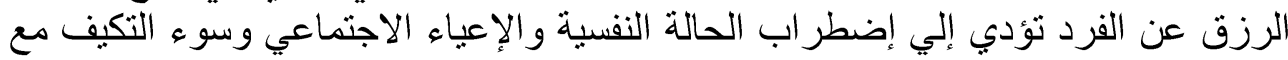


المحيط الذي يعيش فيه الفرد ويتفاعل معه، ومثل هذه الأعر اض التي بمر بها الفرد نتيجة

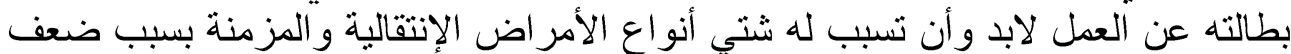

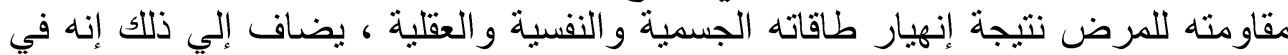

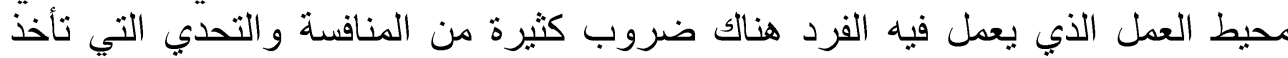

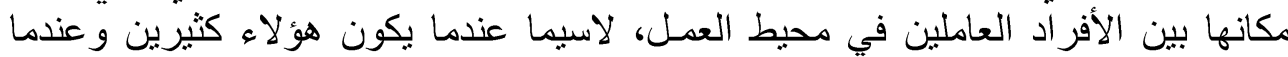

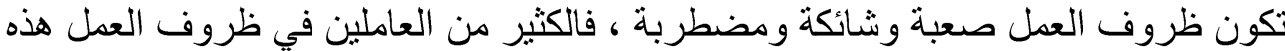

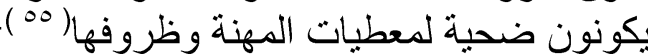
هنالك بعض الدارسات التي أوضحت تعرض الأوض الأجساد للأمراض وخاصة الأوفة الغدد

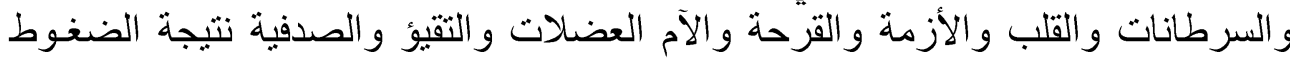

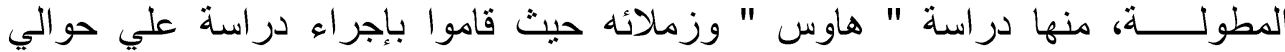

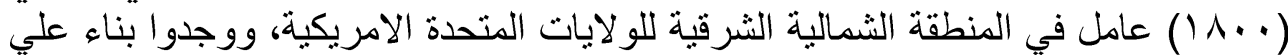
التقارير الذاتية " الاستبانات " للعمال أن الضغوط الضوفة الوظيفية المدركة من قبلهم مرتبطة

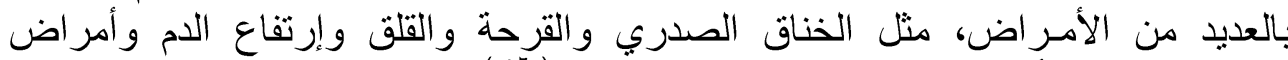

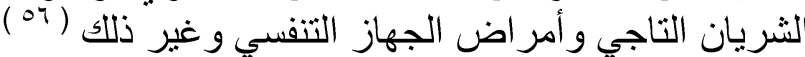
مما يؤدي إلي تفاقم بيئة العمل وإضطر ابها تميز التيز المهنة بالخطورة الناجمة عن فقدان

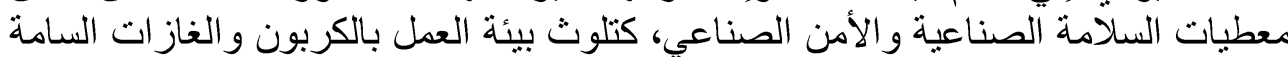
المنبعثة من المكائن الصناعية وتطاير التقاذفات والكتل النارية منها وربما وإنة إحتر اقها و إنفجارها مما يؤدي إلي إصابة العمال بإصابات جسيمه وخطيرة تؤدي إلي مرضهر

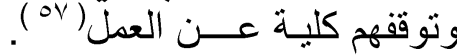

يتضح تعرض الأفراد في أثناء مزاولتهم لهنه لهنهم للإصابة بالمرض، من خلادل

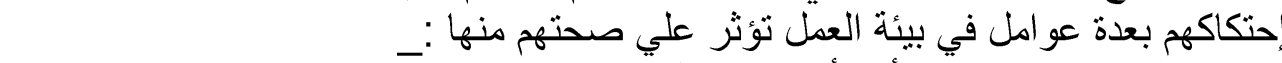

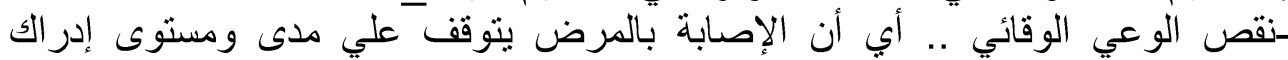

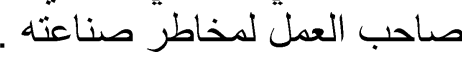
ـالعوامل الطبيعية .. كالحرارة والرطوبة والضة والضوضاء و الضغط الجوي والإشعاعات النووية. ـ الأتربة .. قد تكون عضوية مثل السكر و الدقيق و الخشب وز غب القطن و الصوف أو غير

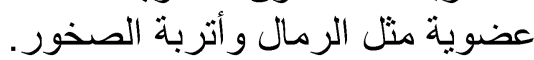
ـ الغازات و الأنجره والأدخنة التي تتصاعد الترد من الصناعات والتي بعضها سام وبعضها

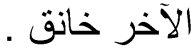
ـ ـ العو امل البيولوجية . . كالبكتيريا و الفطريات و الطفيليات . .

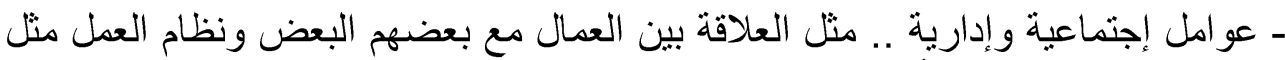

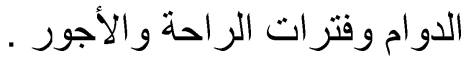
ـ عو امل شخصية ونفسية .. تتعلق بطريقة أداء العامل لعمله مثل وقوفه وحركته وجلوسه

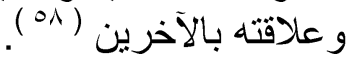

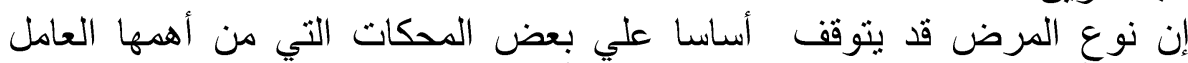

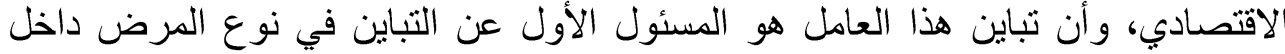

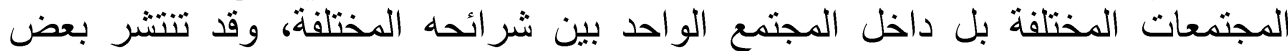

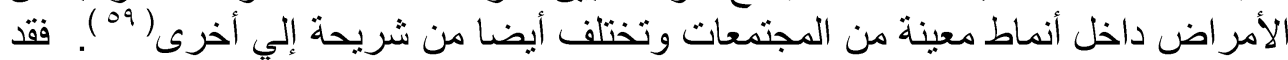

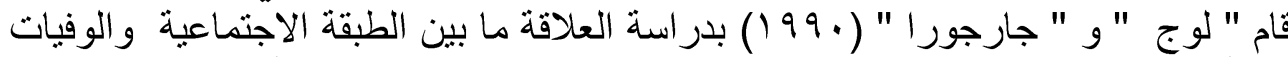

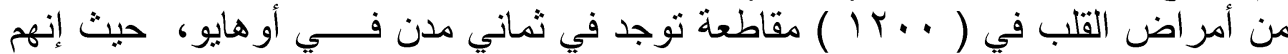

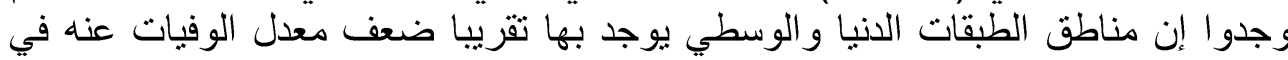




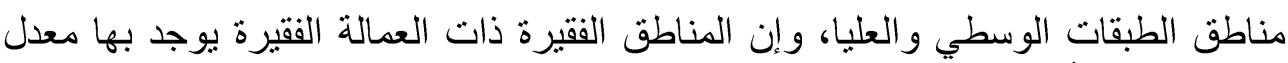

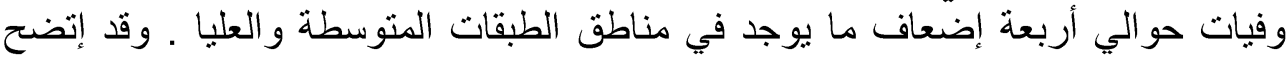

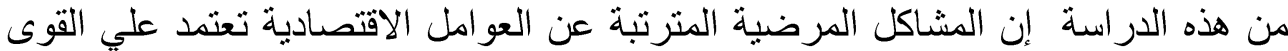

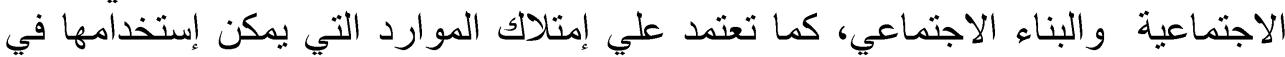

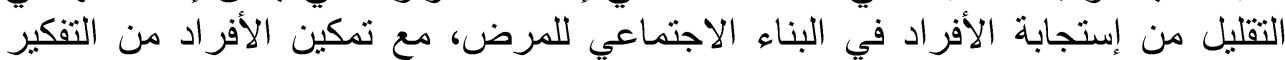

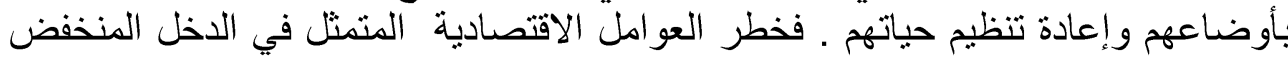

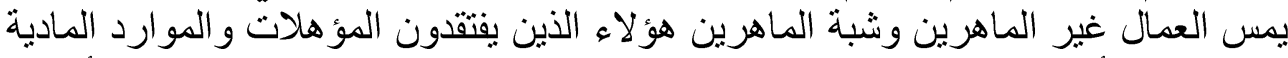

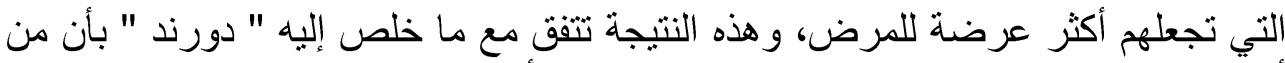

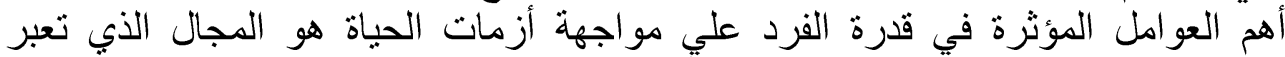

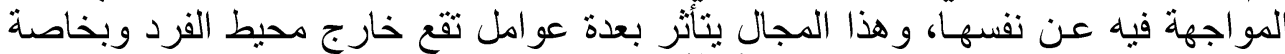

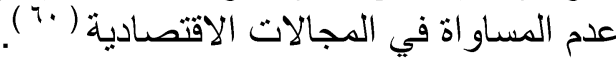

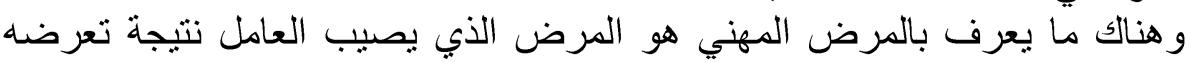

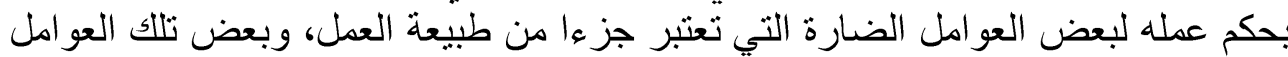

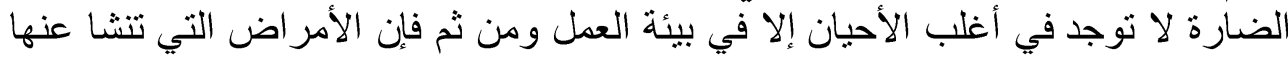

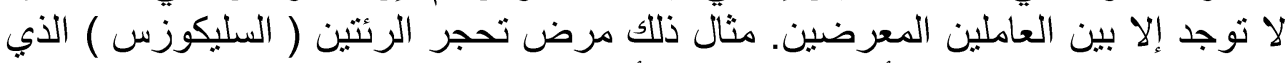

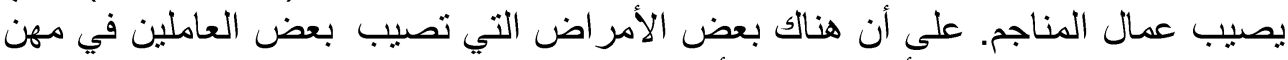

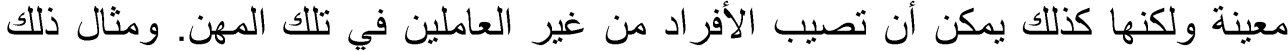

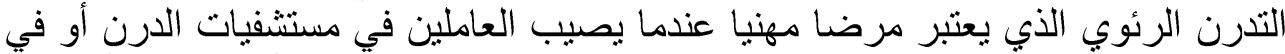

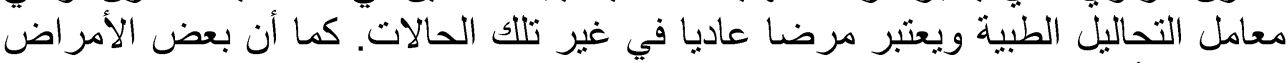

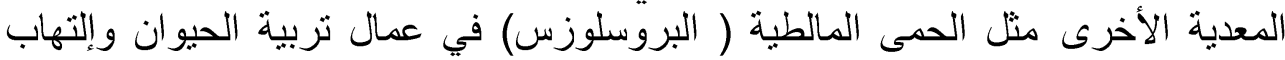

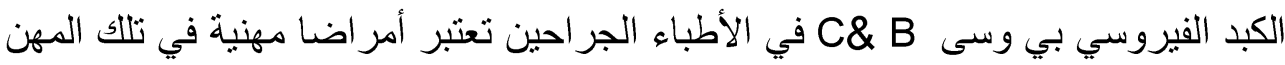

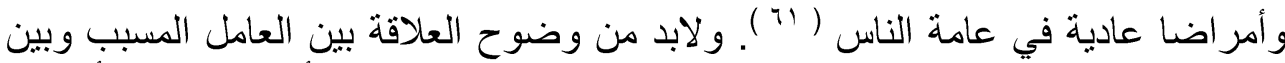

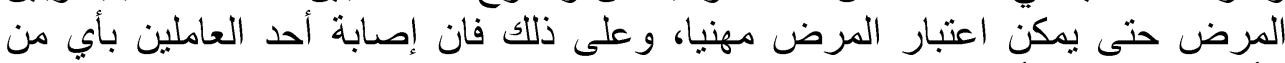

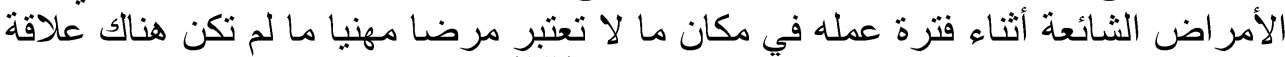

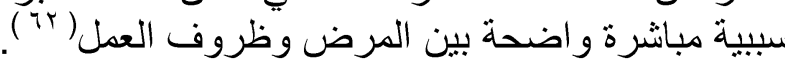

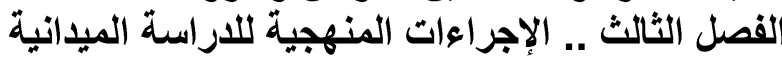

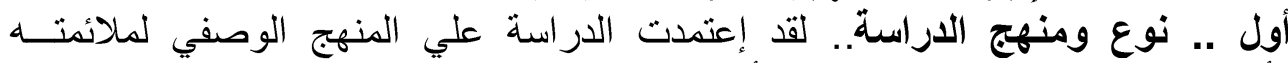

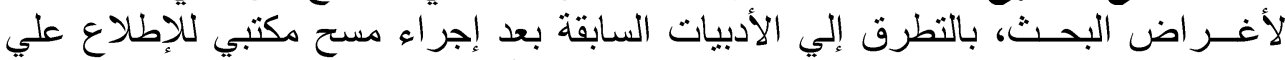

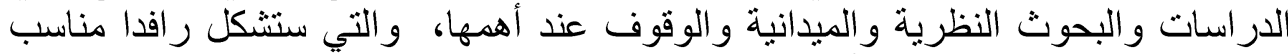

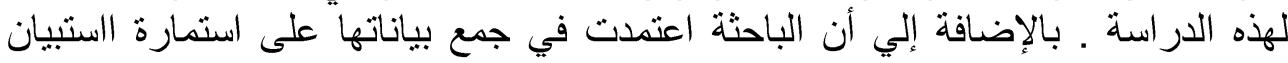

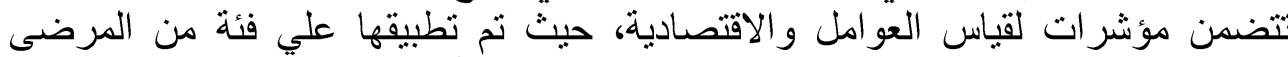

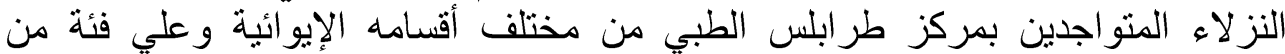

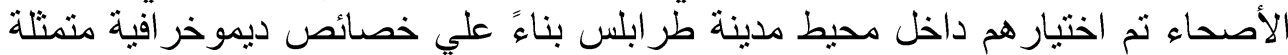

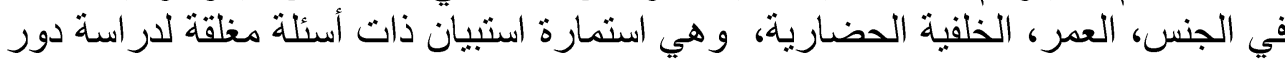

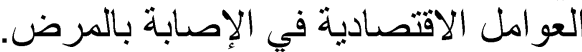

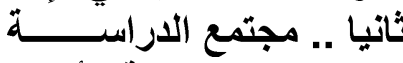

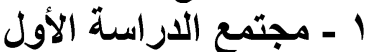

يتكون المجتمع الدر اسة الأول من مركز طر طر ابلس الطبي في العاصمة اللابيية طر ابلس،

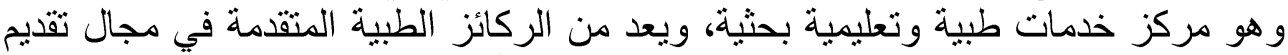

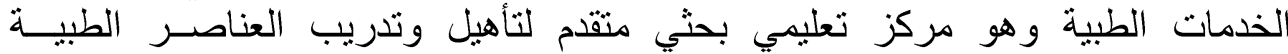




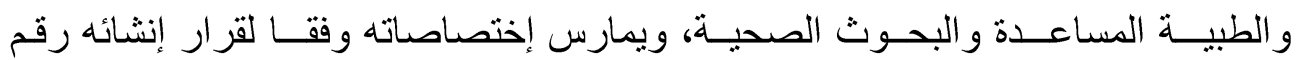

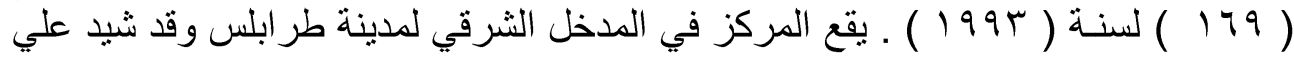

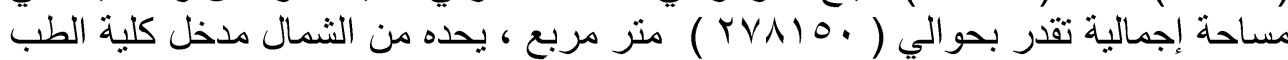

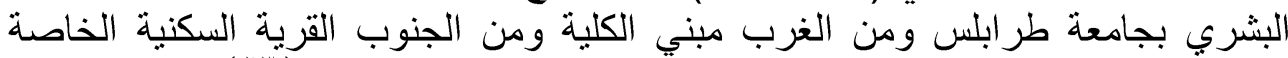

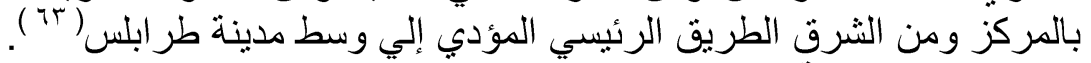

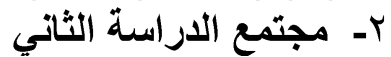

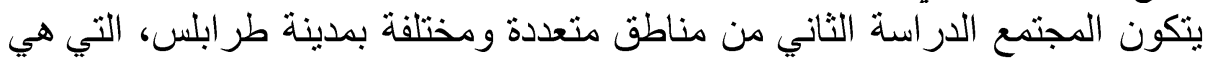
عاصمة ليبياوأكبر مدنها. تقع علي حوض البحر الأبيض المتوسط في الجزء الثران الثمالي

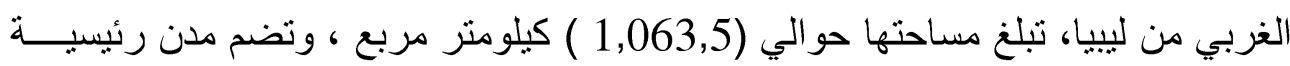

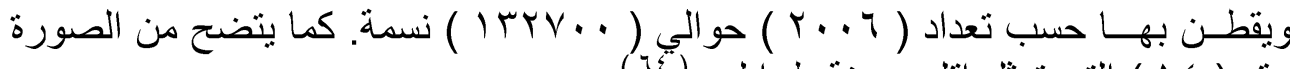

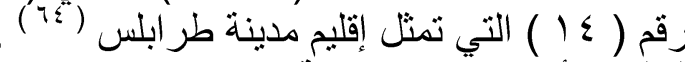
ثُالثا .. . أسس إختيار العينة

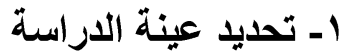

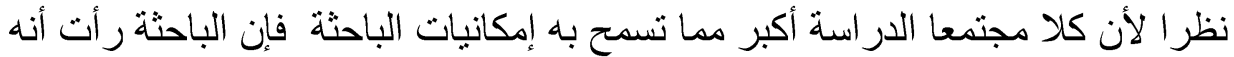

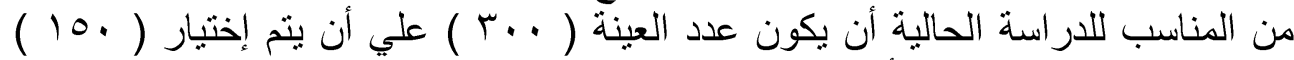
منهم من مجتمع الدراسة الأول مركز طر ابلس الطبي بإستخدام العينة العشوائية البسيطة

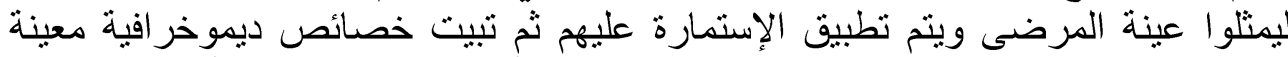

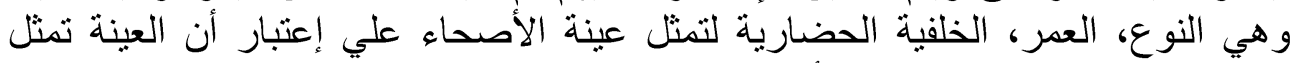

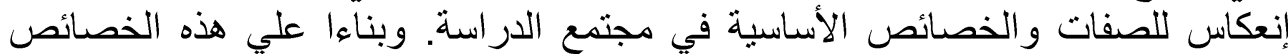
الديموخر افية بتم تطبيق الإستمارة بعد ذلك علي (10.1) في مجتمع الدراسة الثاني مدينة

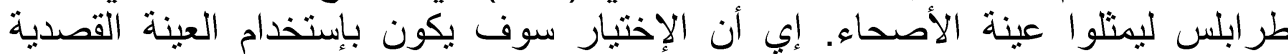

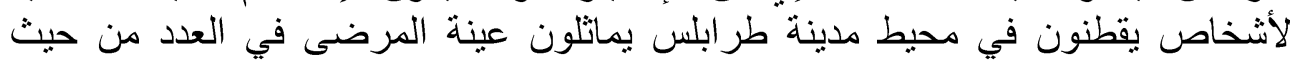
النوع، العمر، الخلفية الحضارية.

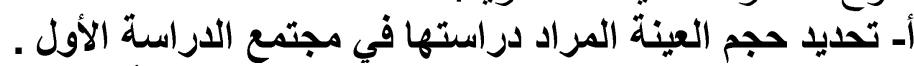

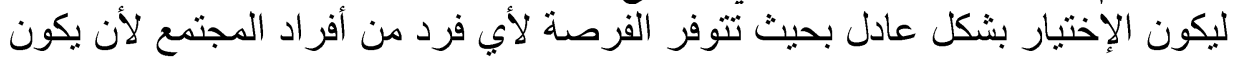

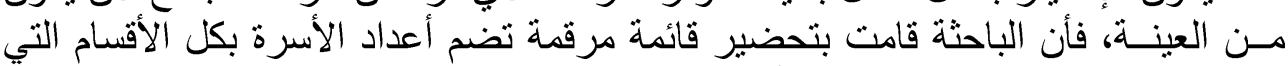

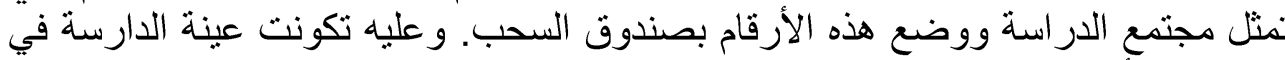

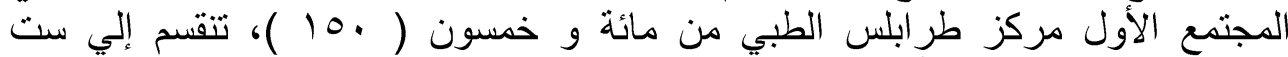

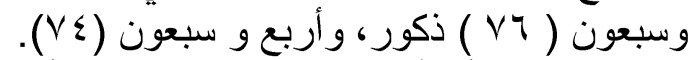

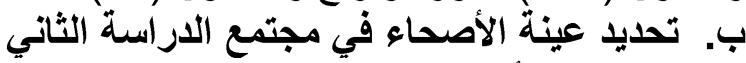

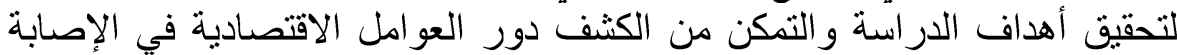

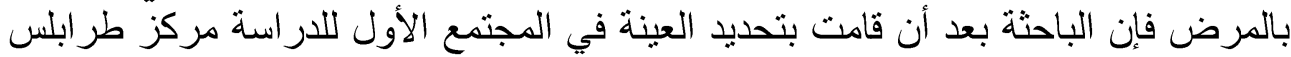

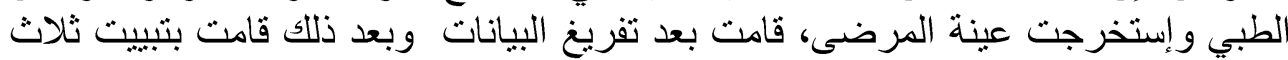

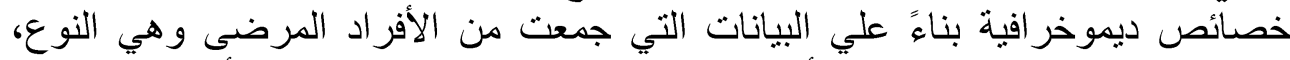

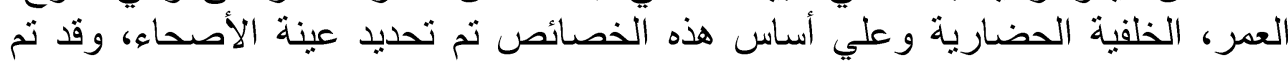

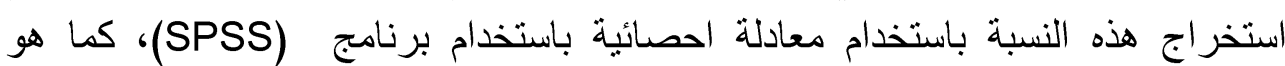

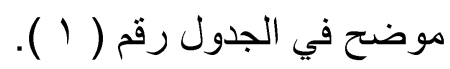




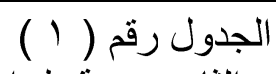

يوضح ثوزيع عينة الدر اسة بالمجتمع الثاني مدينة طر ابلس وفقا للخصائص الديموخر افية

\begin{tabular}{|c|c|c|c|c|c|}
\hline \multirow[b]{2}{*}{ المجموع } & \multicolumn{3}{|c|}{ العمر } & \multirow[b]{2}{*}{ النوع } & \multirow{2}{*}{ الحضلفية } \\
\hline & من فو من فما & من ·ـ ـ.0 & أقل من • ع & & \\
\hline$\varepsilon$. & 10 & 10 & 1. & \multirow{2}{*}{ ذكر } & \multirow{6}{*}{ حضري } \\
\hline$\% 1 \ldots$ & \%rV.o & $\% r v .0$ & \%Yo.. & & \\
\hline rA & 11 & $1 \pi$ & $\bar{V}$ & \multirow{2}{*}{ أنثي } & \\
\hline$\% 1 \ldots$ & $\%$ \%₹V.₹ & $\%$ \%५.Y & \%\^.乏 & & \\
\hline $\mathrm{VA}$ & Tr & rA & IV & \multirow{2}{*}{ المجموع } & \\
\hline$\% 1 \ldots$. & $\% \leqslant r . r$ & $\%$ \%०. 9 & $\%$ \%।.^ & & \\
\hline$r 7$ & ro & 0 & 7 & \multirow{2}{*}{ ذكر } & \multirow{6}{*}{ ريفي } \\
\hline$\% 1 \ldots$ & $\% 79.5$ & $\% 1 r .9$ & $\% 17 . \mathrm{V}$ & & \\
\hline$r 7$ & rT & 7 & $\varepsilon$ & \multirow{2}{*}{ أنثي } & \\
\hline$\% 1 \ldots$. & \%VY.Y & \%) \%.V & $\% 11.1$ & & \\
\hline$V Y$ & 01 & 11 & 1. & \multirow{2}{*}{ المجموع } & \\
\hline$\% 1 \ldots$. & $\% \vee \cdot . \wedge$ & $\% 10 . r$ & $\% 11.9$ & & \\
\hline
\end{tabular}

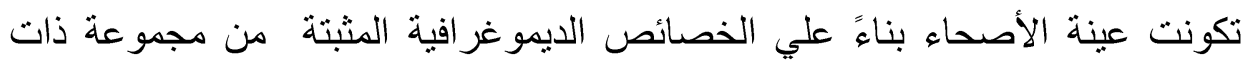

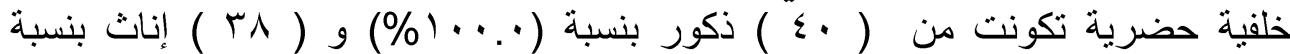

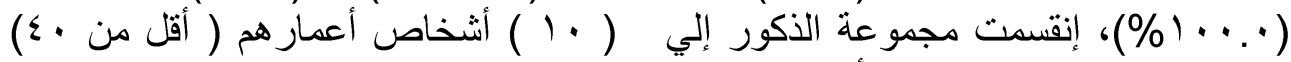

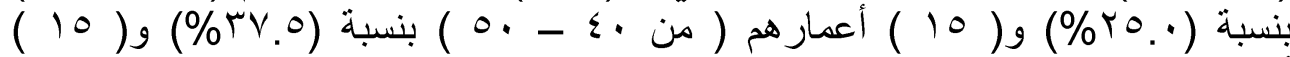

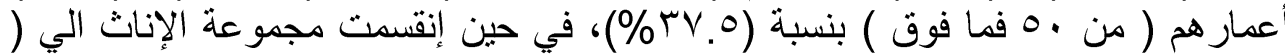

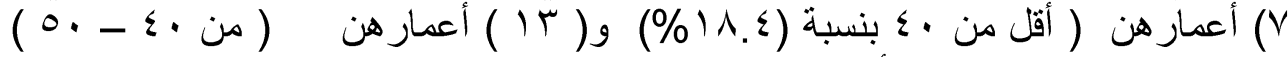

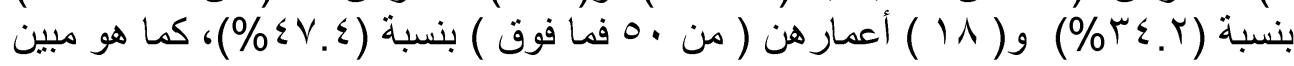

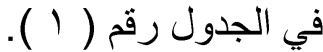
كما تكونت مجمو عة الأصحاء من مجموعة ذات خلفية ريفية تكونت من (Tب) ذكور

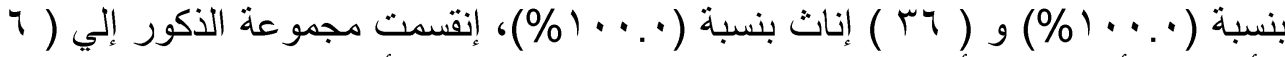

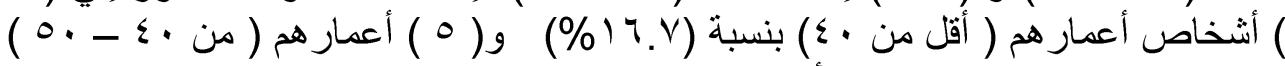

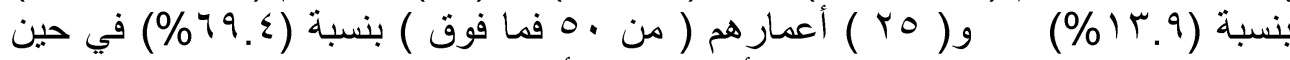

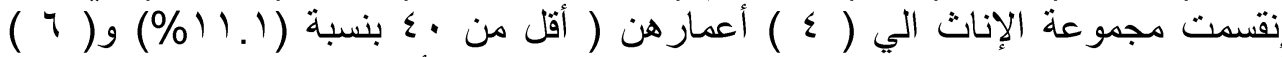

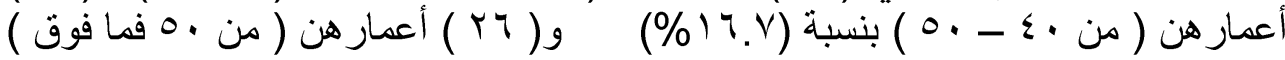

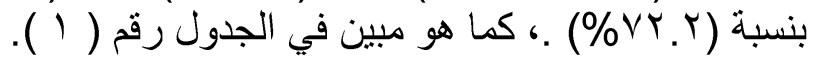
وبعد تحديد هذه النسبة قامت الباحثة باستخدام العينة القصدية لتطبية لتبيق استمارة

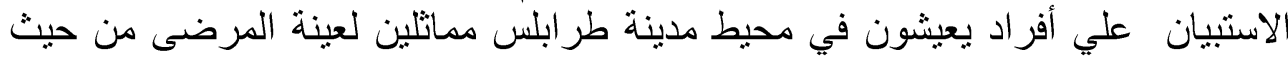

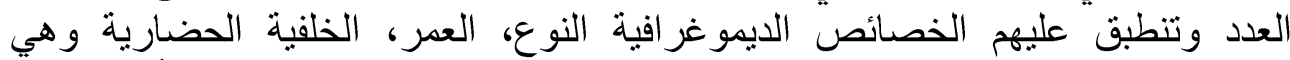

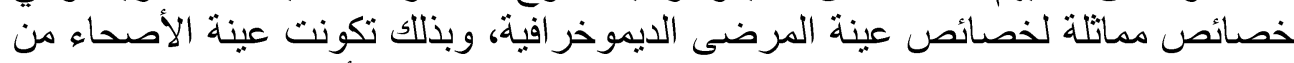

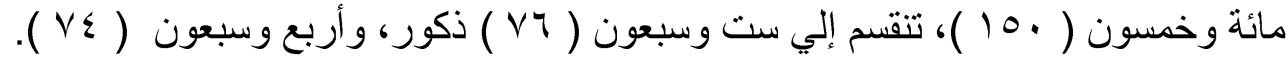


ثانيا .. عينة الاراسة

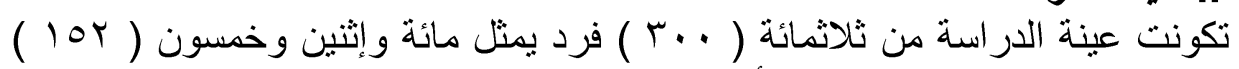

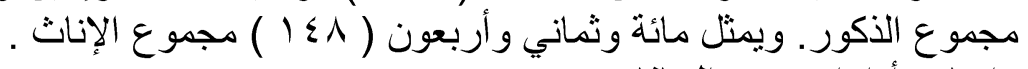

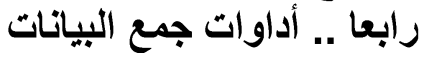
إستمارة الإستبيان .. تعد إستمارة الإسبيات إنبان من أدوات البحث العلمي التي أصبحت الأكثر

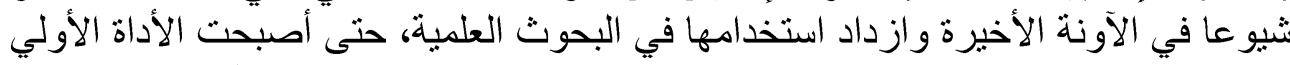

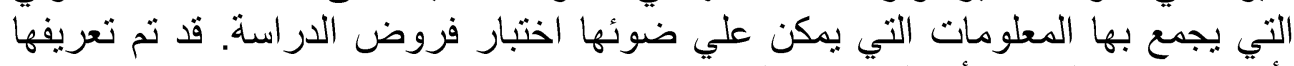

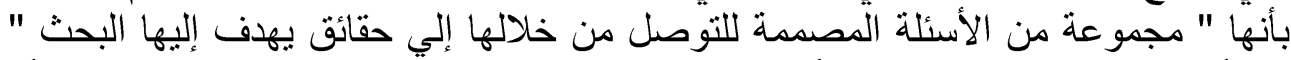

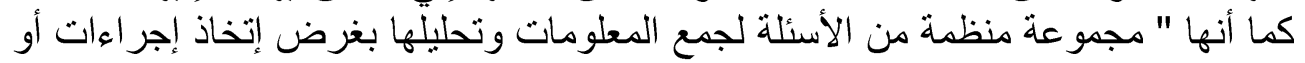

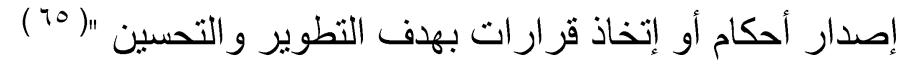
خطوات تصميم إستمارة الإستبيان

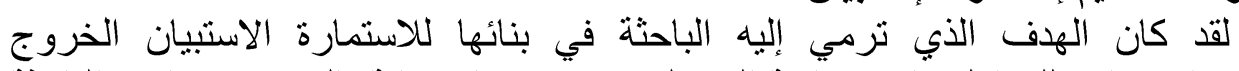

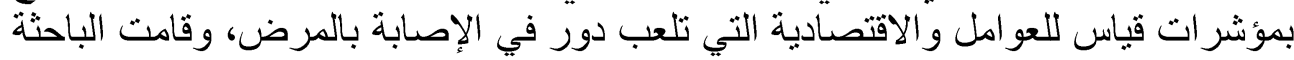

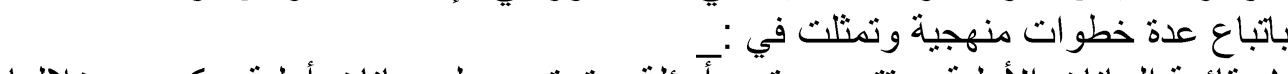

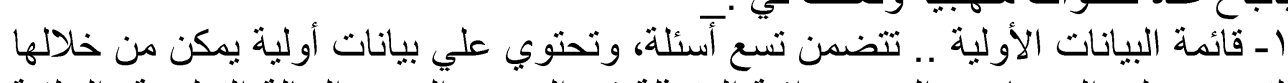

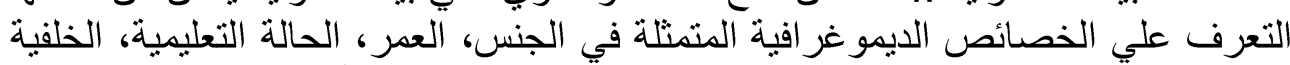

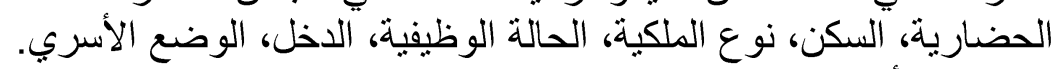

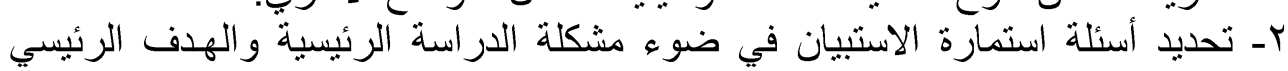

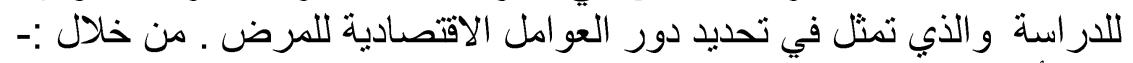
أ ـالاخل وال تل

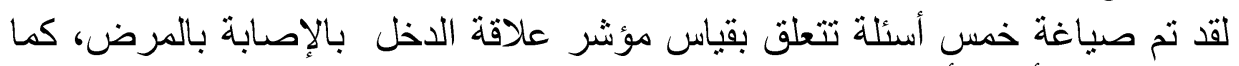

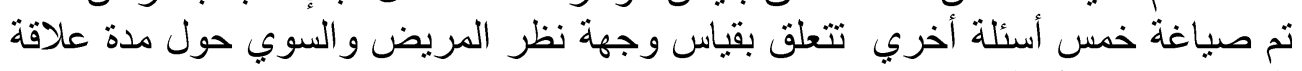

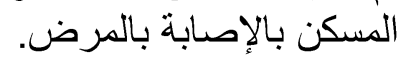
ب ب ـ التعليم

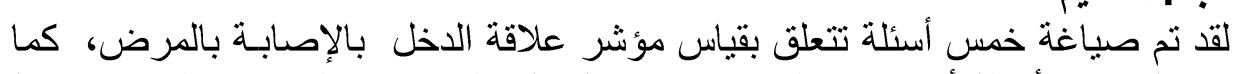

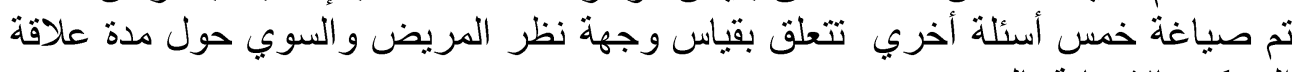
المسكن بالإصابة بالمرض أنئة أخري ج. المهنة

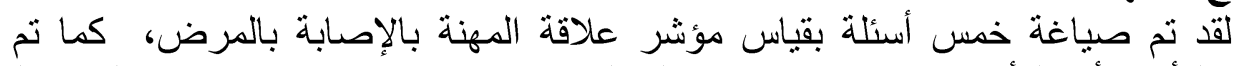

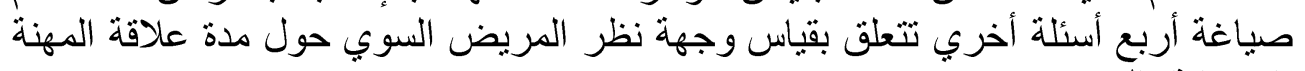

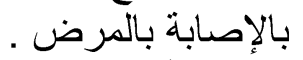

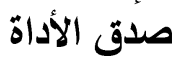

للتأكد من الصأداة الداخلي لإستمارة الإستبيان وتغطبتها لأهداف الدراسة وفرضياتها

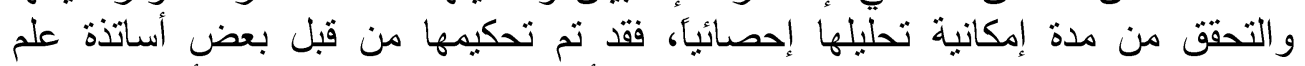

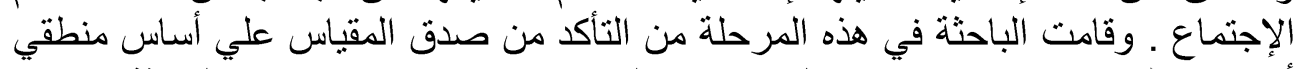

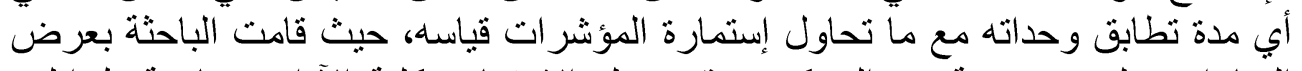

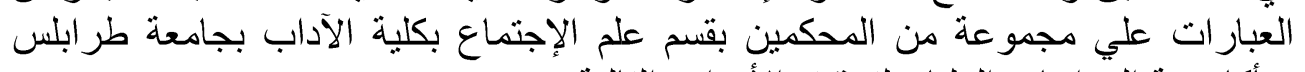

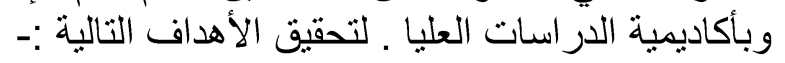

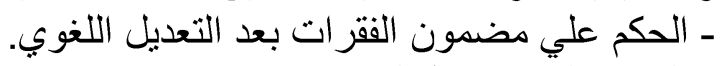
ـ الحكم علي صياغة الفقر ات و وضوحها بعدي . 


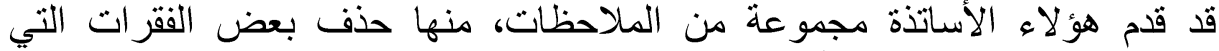

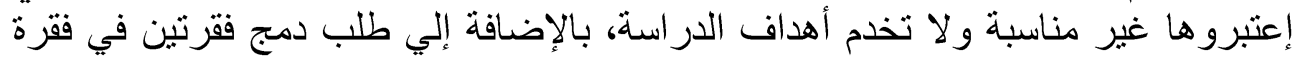

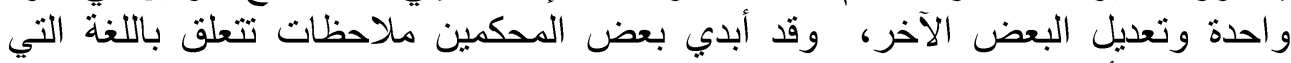

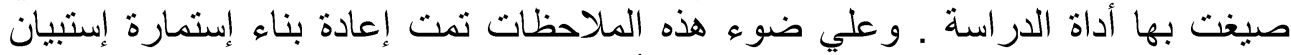

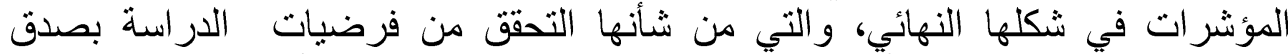

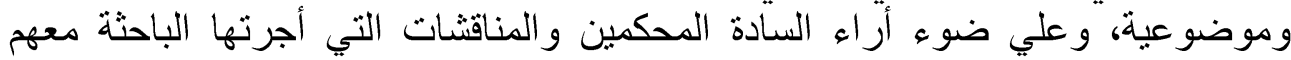

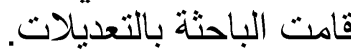

رأت الباحثة بعد إستعر اضها لطرق القياس أن تصوغ قياس إستمارة المؤشرات

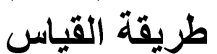

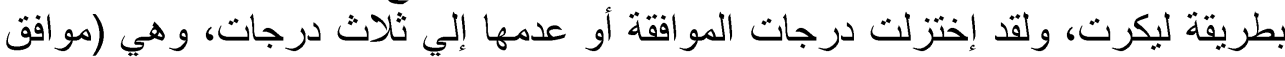

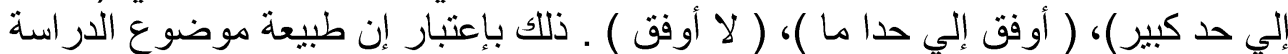

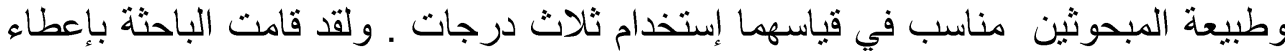

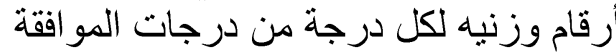

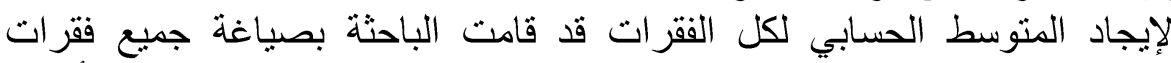

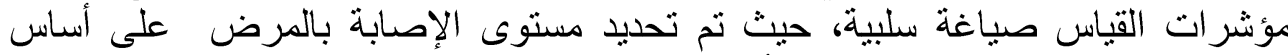

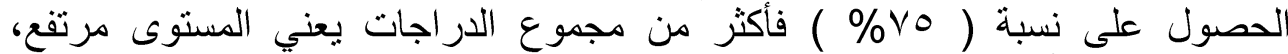

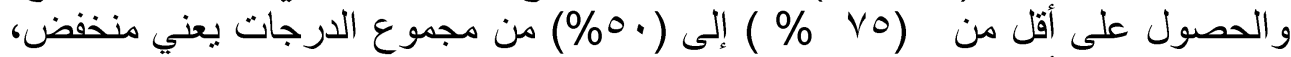

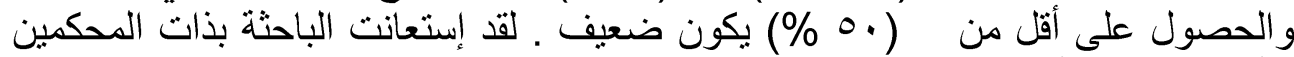
للأداة الدر اسة لتأكيد الإتجاه السلبي للعبار ات الهات

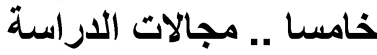

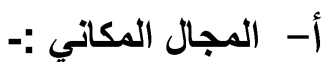

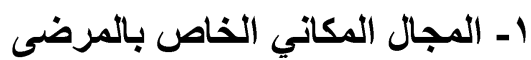
مركز طر ابلس الطبي في العاصمة الليبية طر ابلس يحتوي على ( . . 1 . ) طبيب

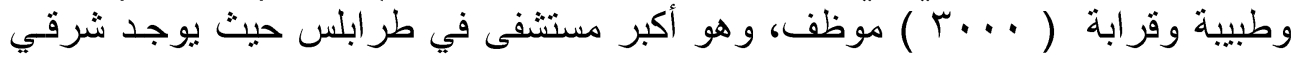

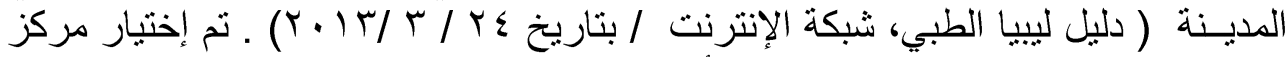

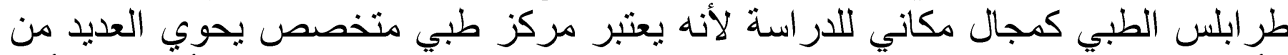

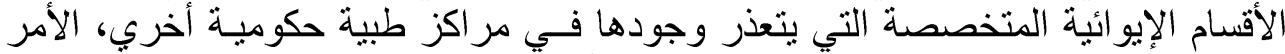

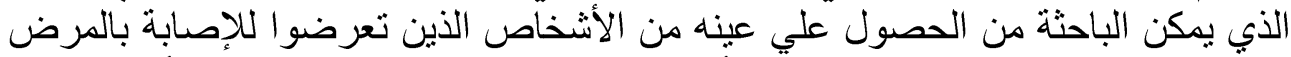

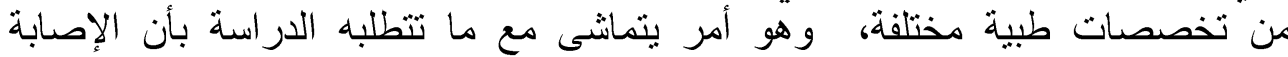
بالمرض بغض النظر عن نوع المرض هو في الغالب نتيجة للعوامل الاجتماعية

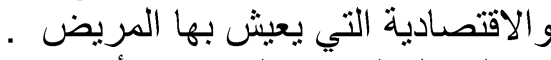

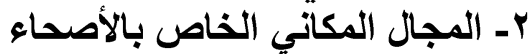

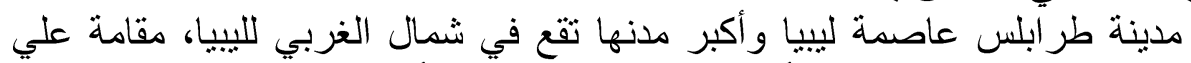

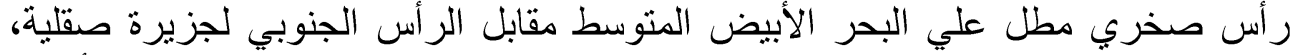

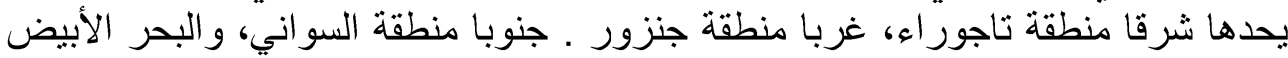

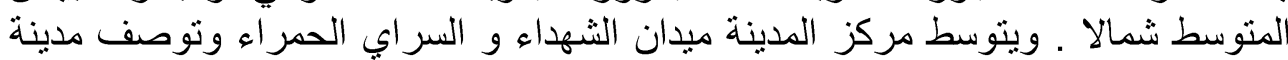

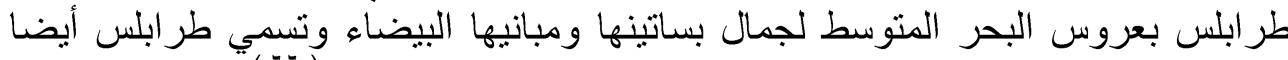

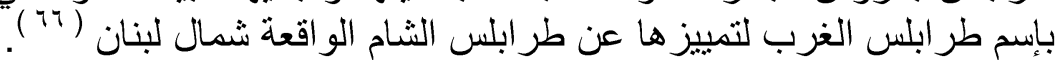




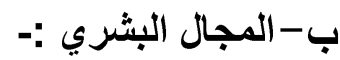

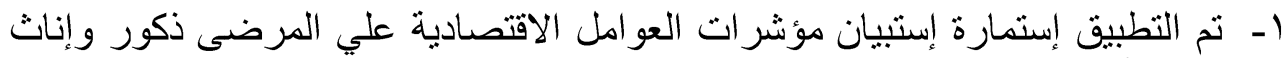

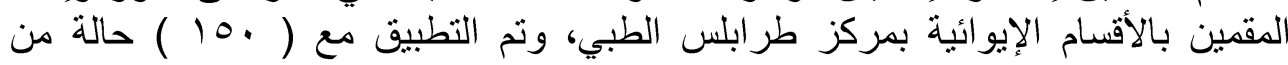

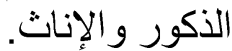

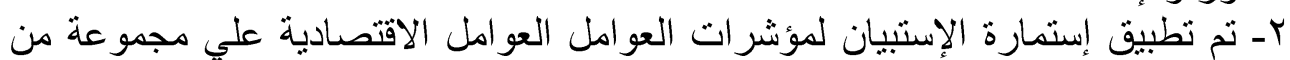

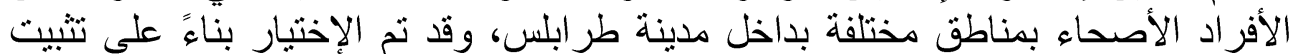

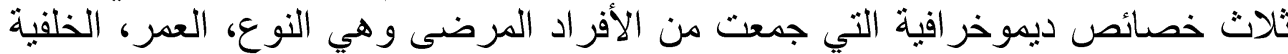

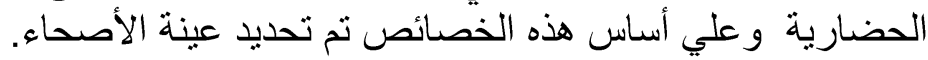

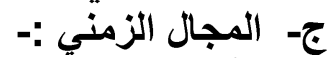

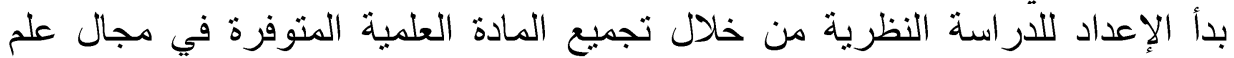

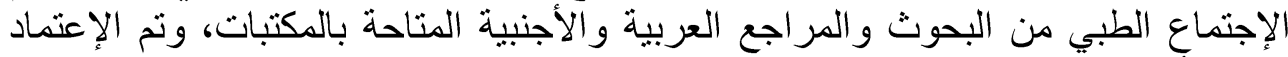

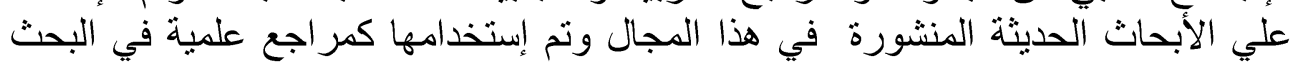

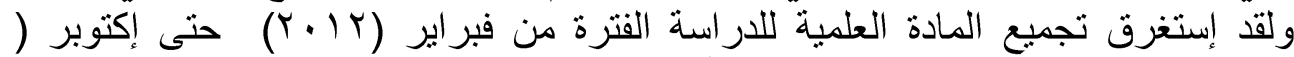

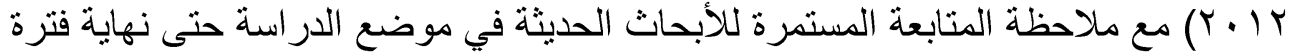

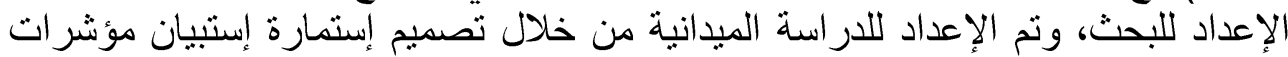

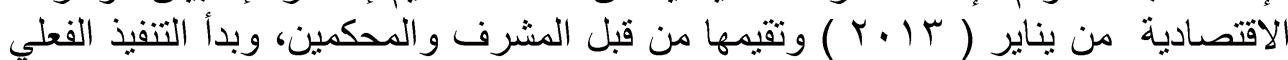

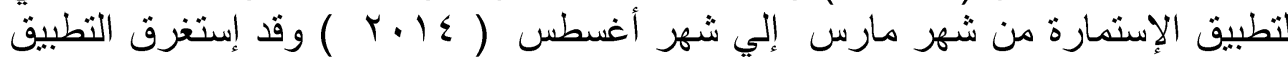
الميداني خمسة أثهر تقريبا وبدأت مرحلة التقريغ اليدوي للبيانات الخاصة بدانيل الثيل المقابلة

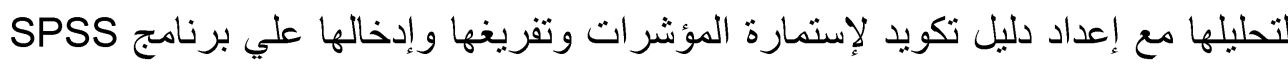

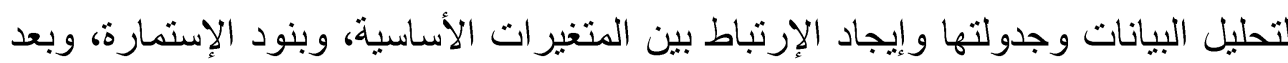

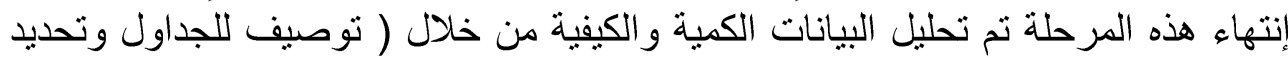

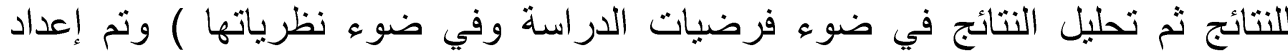

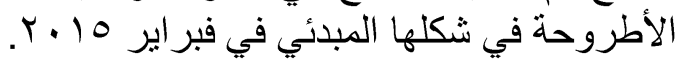
سادسا .. التحليل الإحصائي تم معالجة البيانات من خلال الحاسب الآلي بإستخدام برنامج ( SPSS ) الحزم

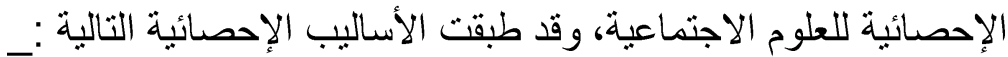

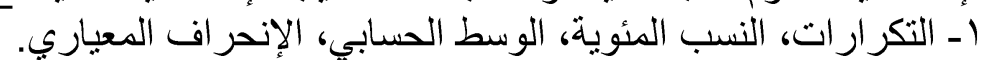

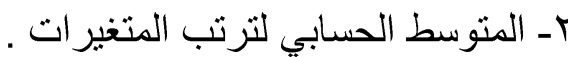

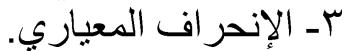

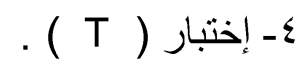

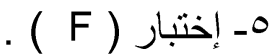
T- إختبار (كاب) (

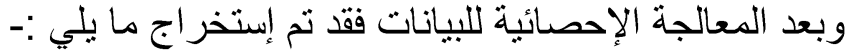

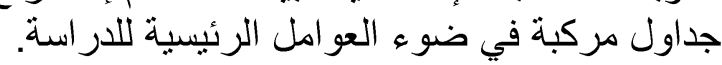
النسب المئوية للتوزيعات التكر ارية للار استة التئية - إستخدام التحليلات لمعرفة العلاقة بين متغير ات الدراسة ومستوي دلالاتها. 


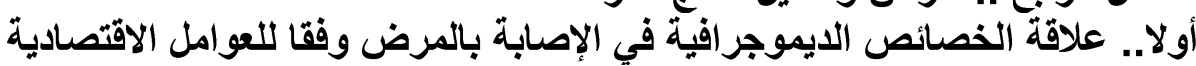
ا - لا توجد علاقة بين الجنس والإصابة بالمرض والإها بالها للعو امل الاقتصادية في مجموعتي

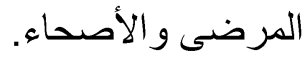
r- لا توجد علاقة بين العمر والإصابة بالمرض وفقا للعوامل الاقتصادية في مجموعة

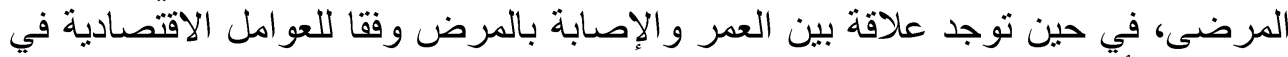
مجمو عة الأصحاء.

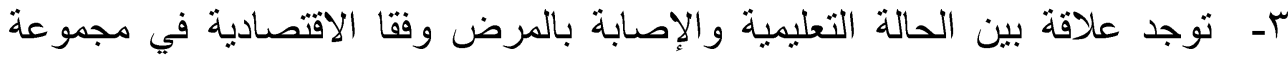

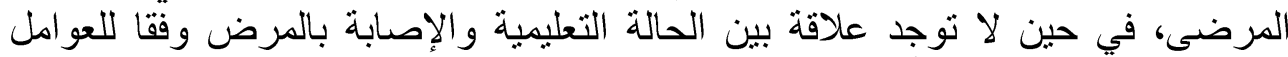
الاقتصادية في مجمو عة الأصحاء. عـ توجد علاقة بين الخلفية الحضارية والإنية الإبة بالمرض وفقا للعوامل الاقتصادية في مجمو عني المرضى و والأصناء.

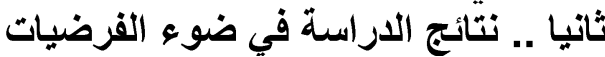

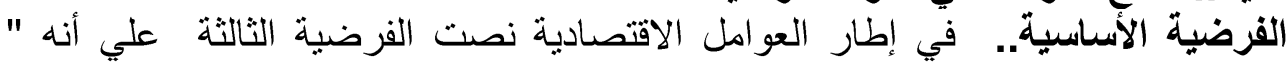

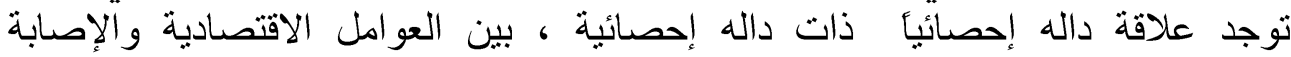

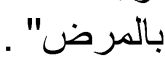
لتحقق من هذه الفرضية فقد صاغت الباحثة الفرضية التالية:-

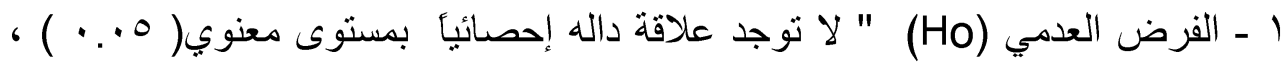

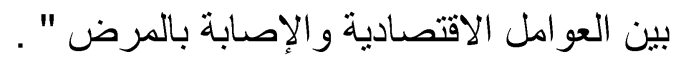

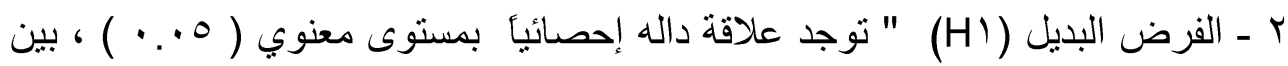

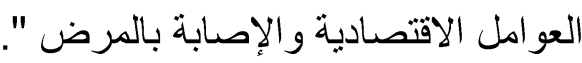
للتحقق من صحة الفرضية إحصائيا تبين أن قيمة إختبار ( t ) تساوي (24.136) بإحتمال دلالة (P=0.000) وبما أن إحتمال الدلالة (P) أصغر من مستوى المعنوية ( - : 0.05) لذلك

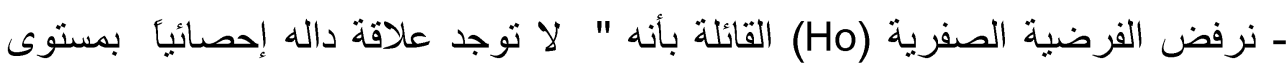

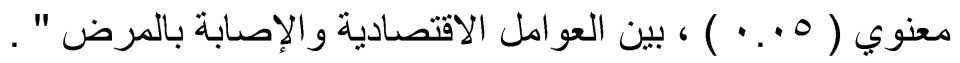

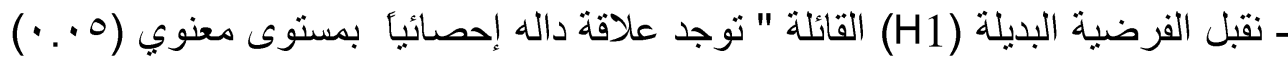

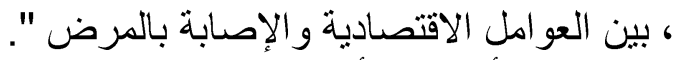
بمعنى أن هناك أثر معنوي دال إلحية الحصائياً للعوامل الاقتصادية على الإصابة بالمرض

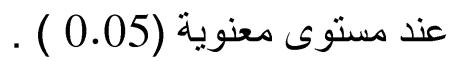

تثير البيانات بأن المنوسط الحسابي للعوامل الإنصادية بين المرضى قد بلغ

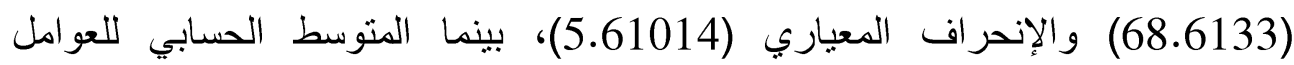

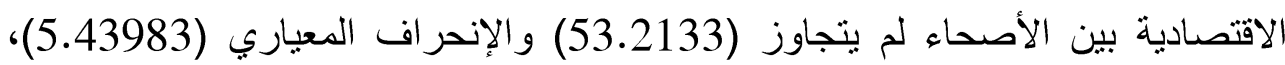

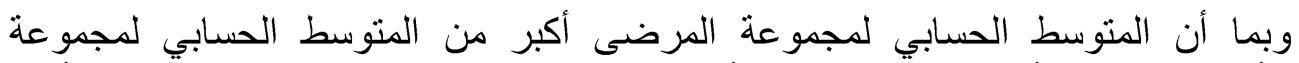
الأصحاء فبتالي فأن الفروق تثير إلي أن المرضى تحيط بهم عو امل إقتصادية سلبية أكثر 


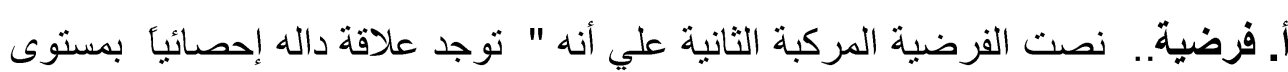

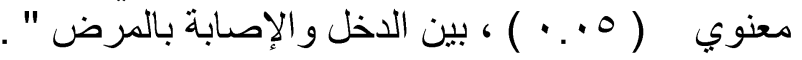
لتحقق من هذه الفرضية فقد صناغت البح الباحثة التالي:-

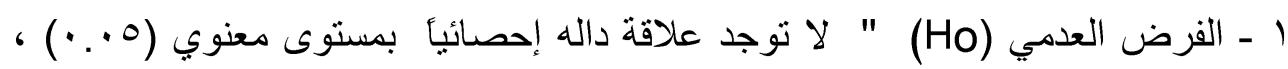

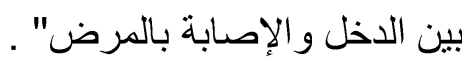

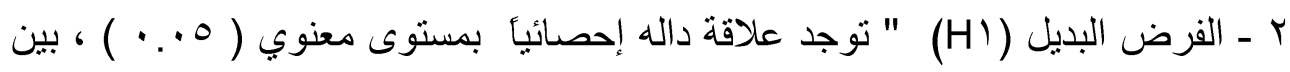

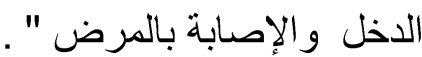
للتحقق من صحة الفرضية إحصائيا وتبين أن قيمة إختبار ( t ) تساوي (13.637) بإحتمال دلالة (P=0.000) وبما أن إحتمال الدلالة (P) أصغر من مستوى المعنوية ( -: 0.05

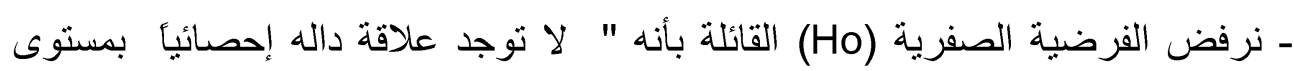

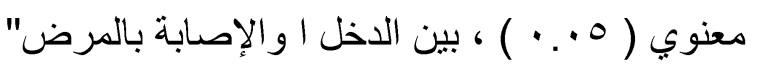

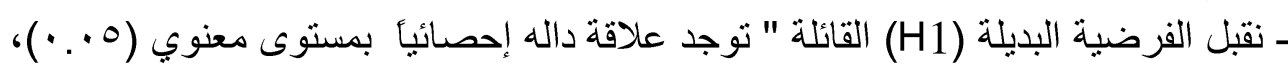

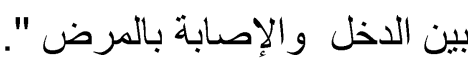
بمعنى أن هناك أثر معنوي دال إحصائياً لاخل في الإصابة بالمرض عند مستوى

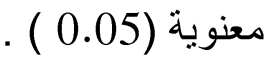

تثير البيانات بأن المتوسط الحسابي لدخل مجموعة المرضى قد بلغ الدئ (24.3267) و الإنحر اف المعياري (4.34192)، بينما المتوسط الحسابي لدخل مجمو عة لدان

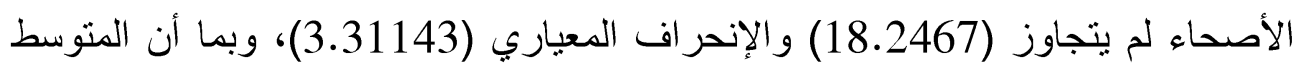

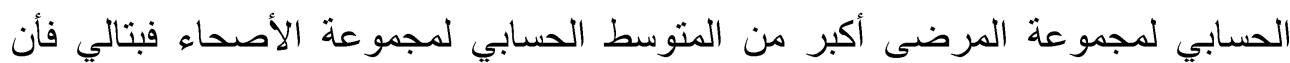

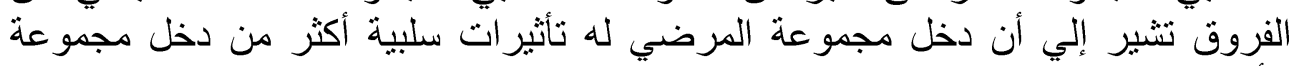

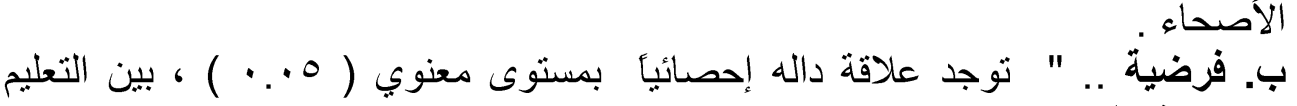

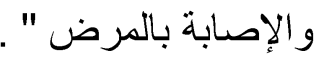
لتحقق من هذه الفرضية فقد صاغت الباحثة التالي:-

ـ الفرض العدمي (Ho) " لا توجد علاقة داله إحصائياً بمستوى معنوي ( ه . . . ) ، بين

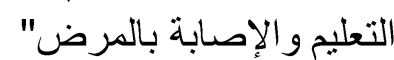

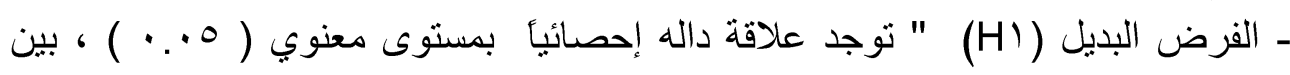

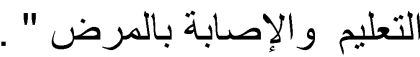

للتحقق من صحة الفرضية إحصائيا إستخدمت الباحثة إختبار( إختبار ) ل للعينتين

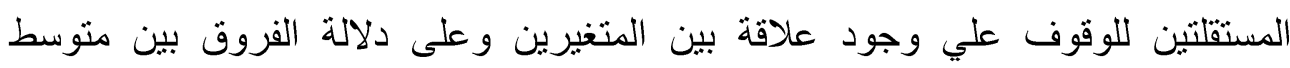

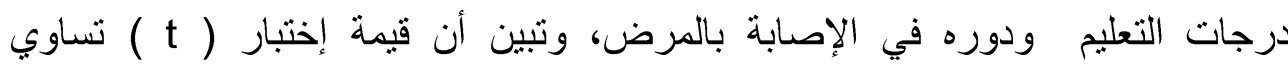
(12.029) بإحتمال دلالة (P=0.000) وبما أن إحتمال الدلالة (P) أصغر من مستوى الإصن المعنوية (0.05 ) لذلك :- 


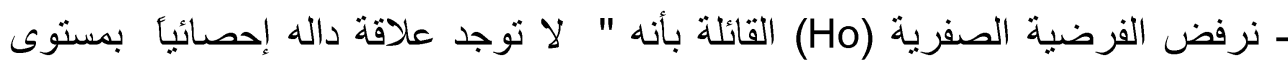

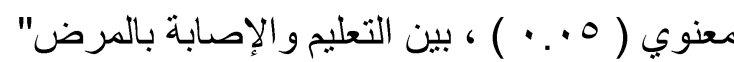

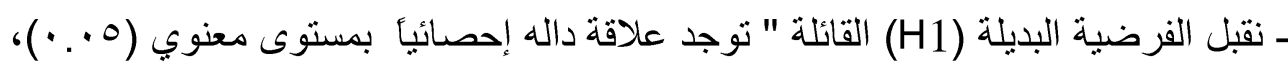

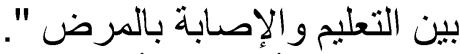
بمعنى أن هنالك أثر معنوي دال إحصائياً لتعليم في الإصابة بالمرض عند مستوى

تثير البيانات بأن المتوسط الحسابي لتعليم مجموعة المرضى قد بلغ

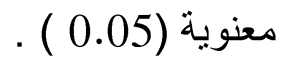

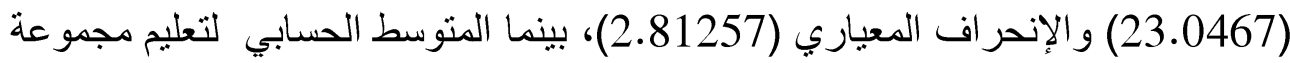
الأصحاء لم يتجاوز (19.0467) والإنحر اف المعياري (2.94545)، وبما أن المتوسط

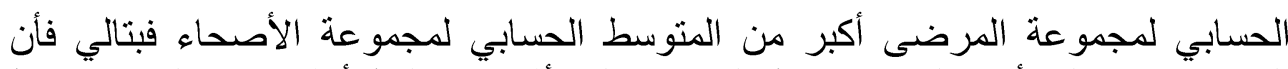

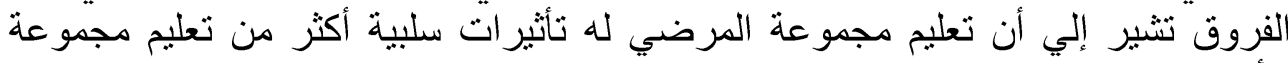

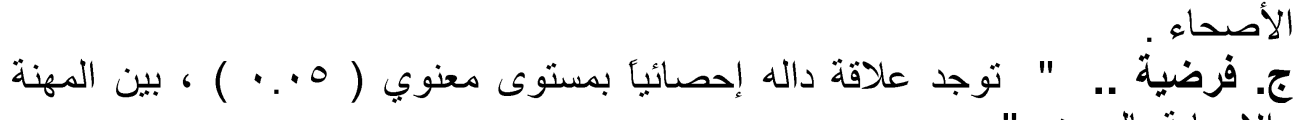

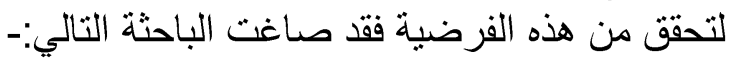

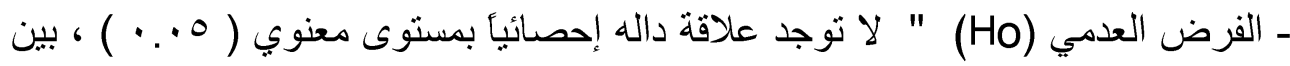

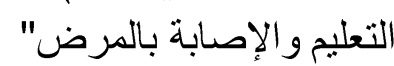

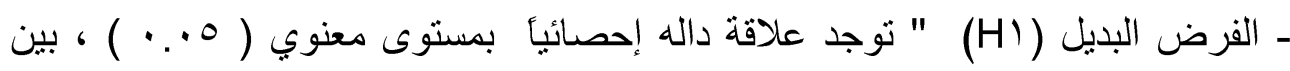

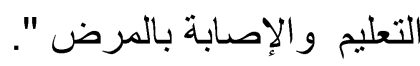
للتحقق من صحة الفرضية إحصائيا إستخدمت الباحثة إختبار( إختبار t ) للعينتين

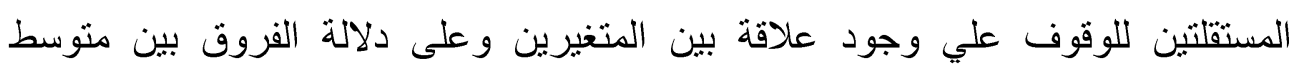

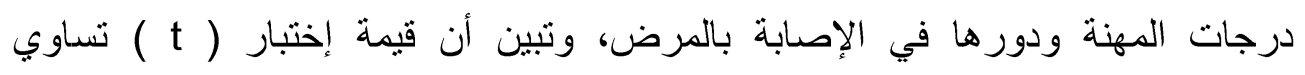

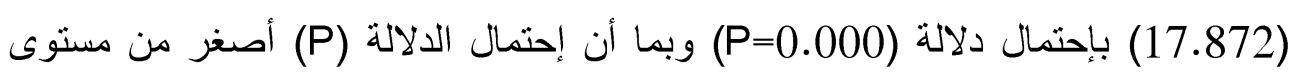
المعنوية (0.05 ) لذلك :- (1.85 - نرفض الفرضية الصفرية (Ho) القائلة بأنه " لا توجد علاقة داله إحصائبً بمستوى

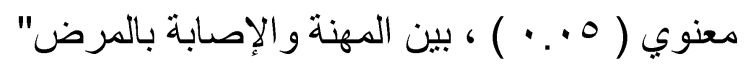

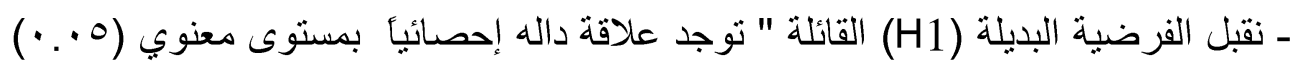

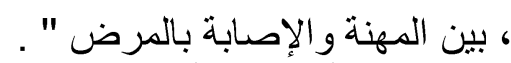
بمعنى أن هنالك أثر معنوي دال إحصائياً لمهنة في الإصابة بالمرض عند مستوى معنوية (0.05 ) منان تثير البيانات بأن المتوسط الحسابي لمهنة مجموعة المرضى قد بلغ (21.2400) و الإنحر اف المعياري (2.41272)، بينما المتوسط الحسابي لمهنة مجموعة الأصحاء لم بتجاوز (15.9200) والإنحراف المعياري (2.73314)، وبما أن المنوسط الحسابي 


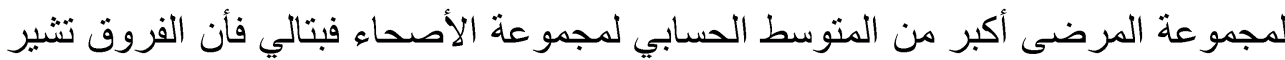

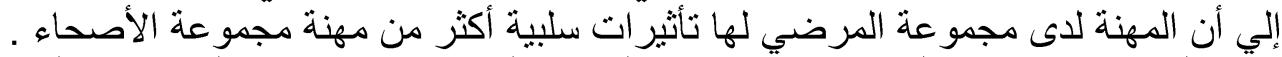

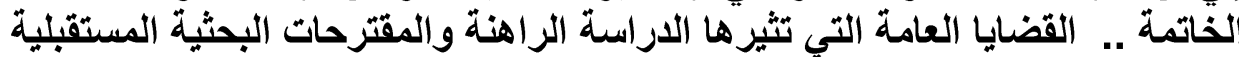

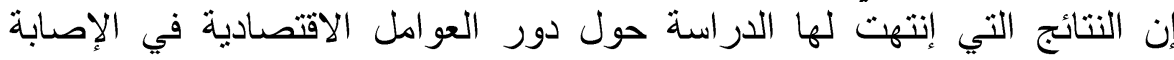

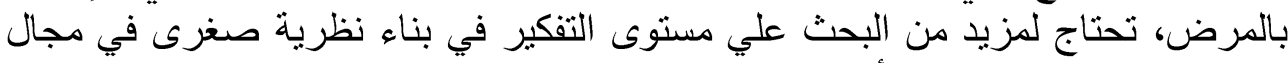

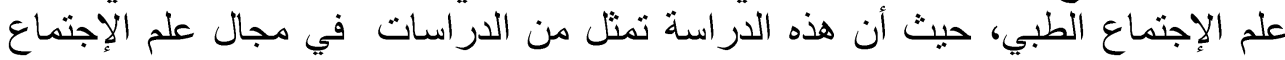

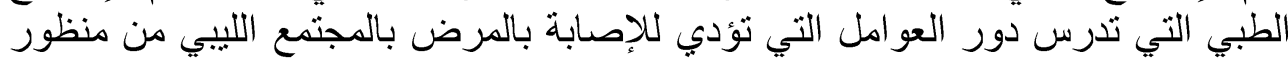

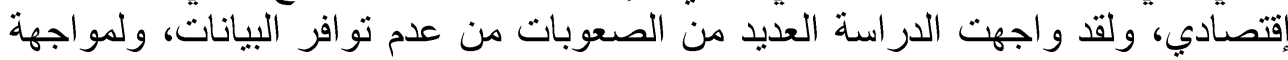

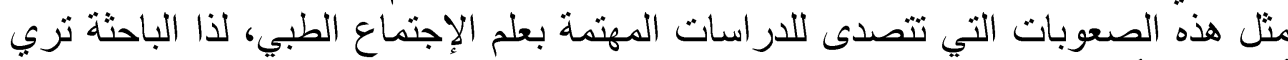

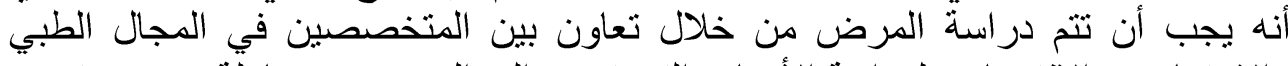

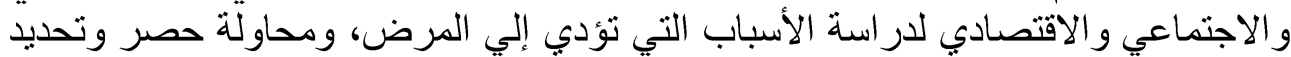

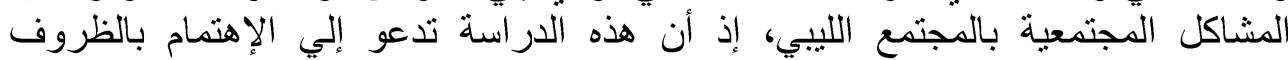

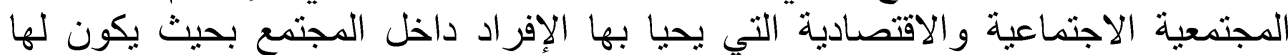

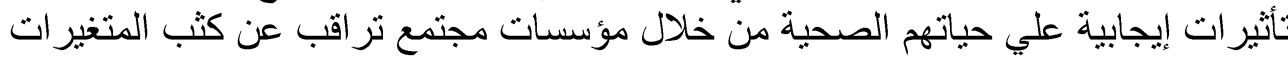

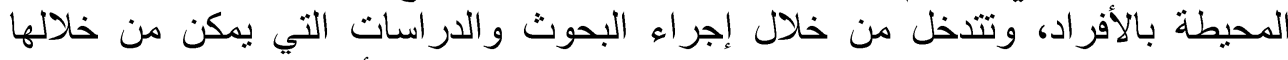

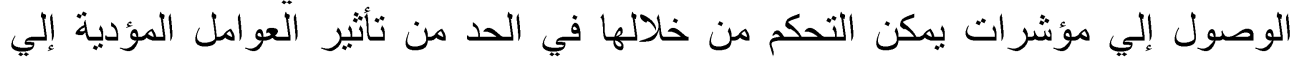

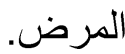




\begin{abstract}
The Role The Economic Factors In Disease، A Field Study Applied On A Sample Of Inmates In Tripoli Medical Center - Tripoli

By Ebtsam Melad

The study problem was studying the the economic factors. And the current study aimed to form a real structure for economic factors that may play an important role in disease, in order to use this knowledge as a social dimension for treatment \& asserting the importance of social aspects in treatment.Utilization the Descriptive method، and use Questionnaire forms to monitor the index conomic factors.. And use the stratified sample and intentionality
\end{abstract}

\title{
Study Results:-
}

- There is statistically significant relationship between economic factors and the pathogenesis of disease.

A. There is statistically significant relationship between income and the pathogenesis of disease.

B. There is statistically significant relationship between education and the pathogenesis of disease.

c. There is statistically significant relationship between profession and the pathogenesis of disease

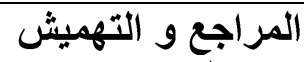

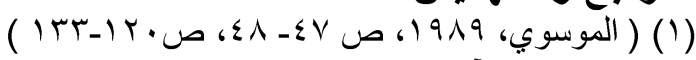

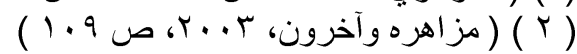

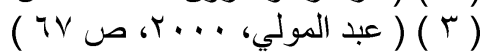

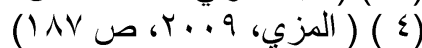

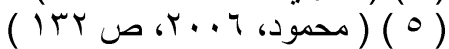

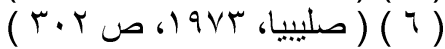

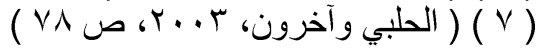

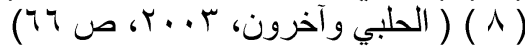

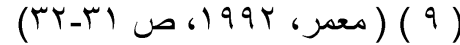

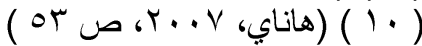

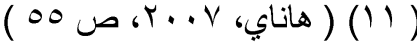

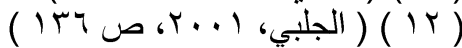

$$
\begin{aligned}
& \text { ، 1974،(Harvard and Barbara 16) (Ir) }
\end{aligned}
$$

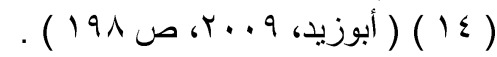

$$
\begin{aligned}
& \text { ، 1974،(Harvard and Barbara } 17 \text { ) (10) }
\end{aligned}
$$

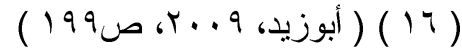

$$
\begin{aligned}
& \text { 1991, } 13 \text { )،( Abel ( IV) } \\
& \text { ، 1974،(Harvard and Barbara } 18 \text { ) ( } 1 \wedge)
\end{aligned}
$$

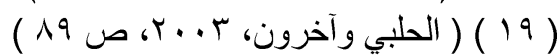

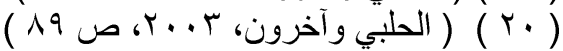

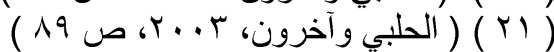

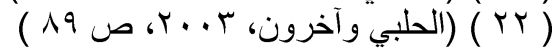




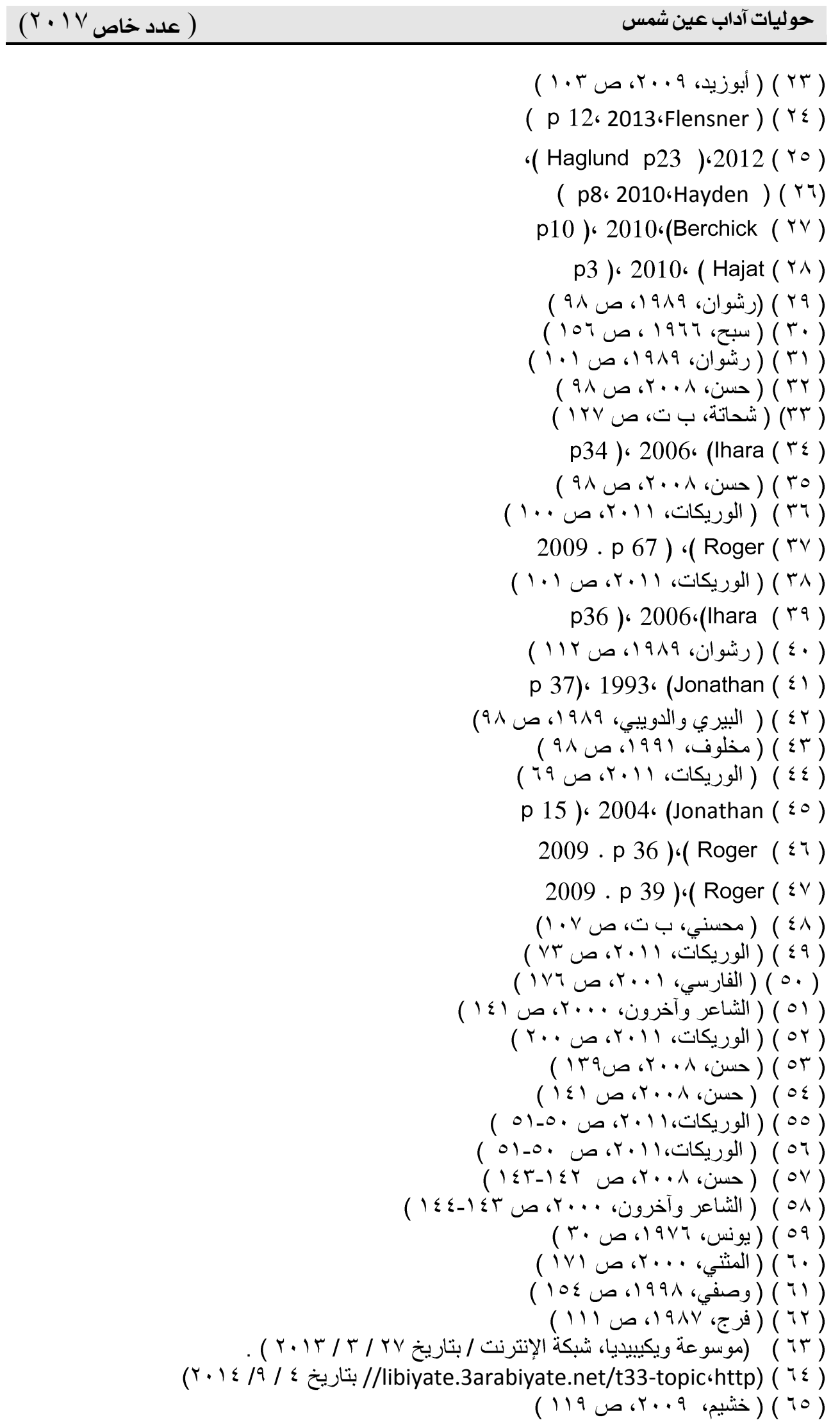




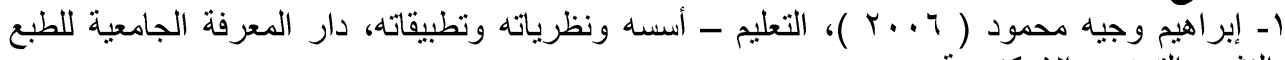

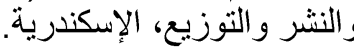

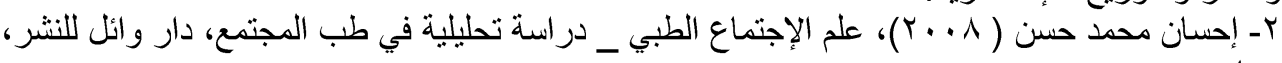

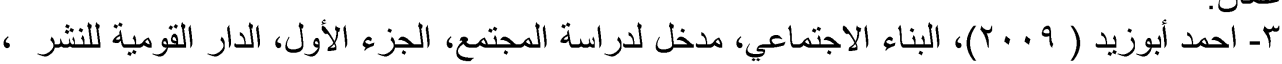
الإسكندرية أسمد أبوزية ع- إقبال إبر اهيم مخلوف ( الإنية (1991)، العمل الاجتماعي في مجال الرعاية الطبية ـ إتجاهات تطبيقية، دار

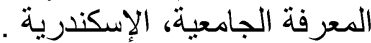
هـ الوحيشي البيري و عبدالسلام الدوبية (919 (1)، مقدمة في علم الإجتماع الطبي، مكتبة طر ابلس العالمية، طر ابلس. ד- انتصار بونس (• (91 ())، السلوك الإنساني، دار المعارف، الإسكندرية.

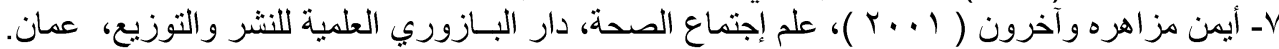

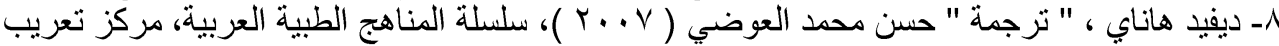

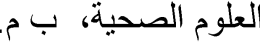

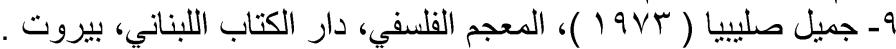

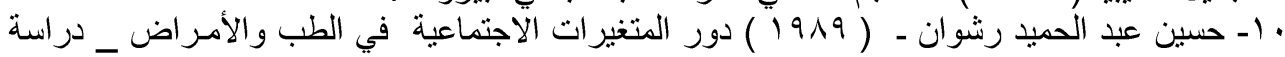
في علم الاجتماع الطبي، دار المعرفة الجامعية، الإسكندرية.

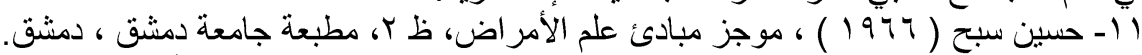

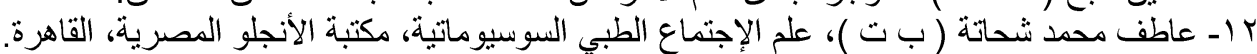

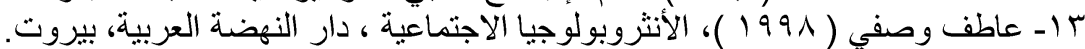

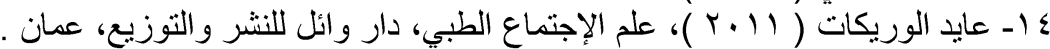

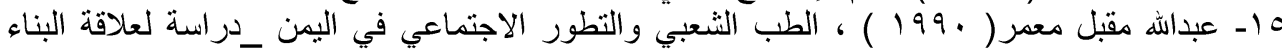

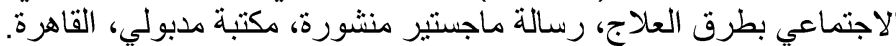

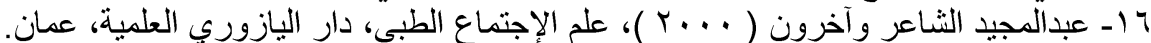

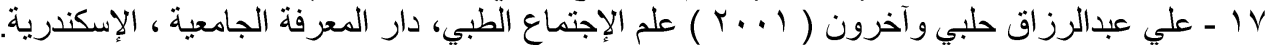

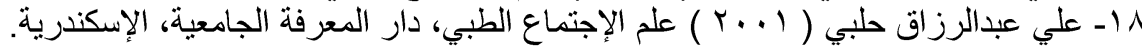

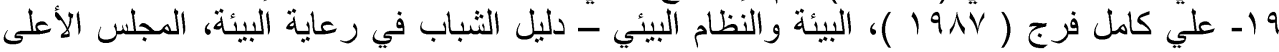

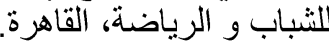

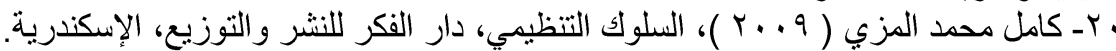

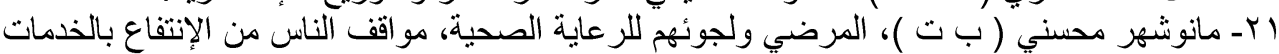

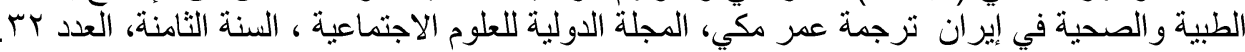

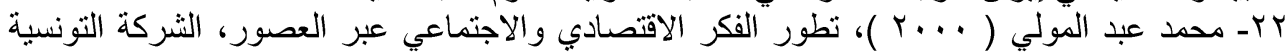

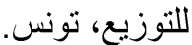

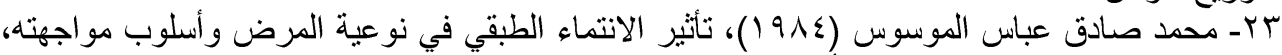

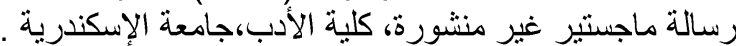

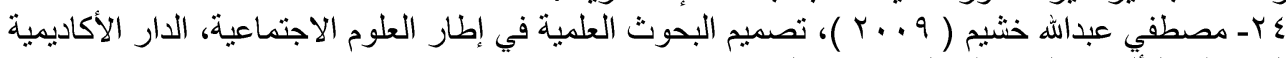

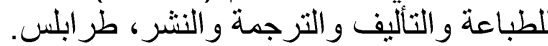

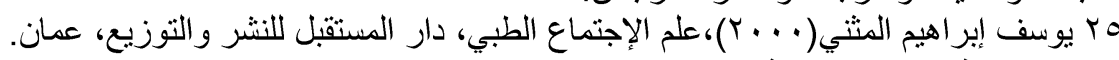

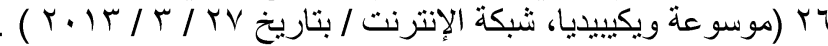
$r$ بتاريخ ع / http://libiyate.3arabiyate.net/t33-topic) YV

المراجع الاجنبية

28- Berchick، Edward R (2010) the effect of socioeconomic status on negative health consequences of involuntary job loss, Yale University.

Foucault Michel (2004)، Crisis of Medicine or Anti-Medicine،29- Foucault Studies. 
30- Flensner، Gullvi ( 2011)، work capacity and health - related quality of life among individuals with multiple rosis reduced

31- Harvard، wait zkin and Barbara، waterman ( 1974 ) the exploitation of illness in capitalist society،the bobs Merrill company،new York

32- Haglund، Emma ( 2012 ), Work productivity in a population based cohort of patients with spondylor thritis، center spensh alt Sweden

33- Hayden, Theresa Carolyn (2010), Kentucky interdisciplinary community screenings: Socioeconomic determinants as predictors of disparities in health outcomes in Kentucky، University of Louisville.

34- Jonathan S. Feinstein (1993)، The relationship between socioeconomic s John Knowles( 1977 )، The responsibility Daedal us winter106.

35- Hajat، Anjum (2010)، Do the wealthy have a health advantage? ? An investigation of wealth as a measure of socioeconomic status، The University of North Carolina at Chapel Hill.

36- Ihara، Emily S (2006)، Ethnicity matters: Socioeconomic position and health among Asian Americans، Brandeis University، the Heller School for Social Policy and Management.

37-Roger‘T ( 2009 )، Mortality Effects Community Socioeconomic Status‘ Vol 8، NO .1. 